Illinois State University

ISU ReD: Research and eData

Theses and Dissertations

$2-9-2020$

\title{
A Place To Grow: Examining Teachers' Interactions In An Online Thirdspace
}

Morgan Belcher

Illinois State University, morgieb19@hotmail.com

Follow this and additional works at: https://ir.library.illinoisstate.edu/etd

Part of the Teacher Education and Professional Development Commons

\section{Recommended Citation}

Belcher, Morgan, "A Place To Grow: Examining Teachers' Interactions In An Online Thirdspace" (2020). Theses and Dissertations. 1201.

https://ir.library.illinoisstate.edu/etd/1201

This Dissertation is brought to you for free and open access by ISU ReD: Research and eData. It has been accepted for inclusion in Theses and Dissertations by an authorized administrator of ISU ReD: Research and eData. For more information, please contact ISUReD@ilstu.edu. 


\section{A PLACE TO GROW: EXAMINING TEACHERS' INTERACTIONS IN AN ONLINE THIRDSPACE}

\section{MORGAN BELCHER}

\section{Pages}

In this qualitative study, I investigated teachers' participation in an online learning space. Nine participants including seven in-service teachers and two preservice teachers engaged in an online learning group via a secret group on Facebook. During the four months of participation, teachers collaborated through questions posed to the group, articles, infographics, videos shared from outside educational sources, book recommendations, and examples of classroom scenarios. The purpose of this study was to understand how an online collaborative thirdspace could provide novice and experienced teachers space to explore their beliefs and practices outside of their immediate educational contexts. This study is grounded in a social constructivist paradigm and employs action research within an online thirdspace. Pre- and post-study questionnaires, online posts, and post-study interviews were included in the data sources of this study. All data were first coded using an inductive approach including two cycles: descriptive and subcoding. Then online posts were coded deductively using the framework for understanding teaching and learning (Bransford, Darling-Hammond, et al., 2005) to understand what participants discussed in the online learning space. Findings identified that engagement in the online space led to participants shifting teaching practices. Findings also suggest the encouragement and cordial tone in the discussions within the online learning space may have interfered with deeper critical conversations. These implications suggest a need for the field to consider the discourse of 
conversations in school contexts and the possibilities of online professional learning contexts for educators outside of traditional experiences.

KEYWORDS: classroom teacher; mentor; preservice teacher; thirdspace; teacher agency; cordial conversations; 


\title{
A PLACE TO GROW: EXAMINING TEACHERS' INTERACTIONS IN AN ONLINE THIRDSPACE
}

MORGAN BELCHER

\author{
A Dissertation Submitted in Partial \\ Fulfillment of the Requirements \\ for the Degree of \\ DOCTOR OF EDUCATION \\ School of Teaching and Learning \\ ILLINOIS STATE UNIVERSITY
}


(C) 2020 Morgan Belcher 


\section{A PLACE TO GROW: EXAMINING TEACHERS' INTERACTIONS IN AN ONLINE THIRDSPACE}

MORGAN BELCHER

COMMITTEE MEMBERS:

Deborah MacPhee, Chair

Kyle Miller

Sherry Sanden 


\section{ACKNOWLEDGMENTS}

When I began my doctoral courses in the Fall of 2014, I could not have imagined how much the last five and half years would have impacted me. From the people I met both on and off campus and the reading and conversations that have pushed my thinking, I am very grateful to have gone on this journey, albeit long and arduous, it has been a great time of learning for me. I could not have become the educator I am today without so many people in my life. Looking back to the very beginning, thank you to the very first mentors I had in my PDS experiences. In this dissertation I tell the story of how I longed for more critical feedback, however the encouragement and confidence I felt from my initial mentors in education played a role in my desire to continue to push to see changes in myself and the field of education.

However, none of this would have been possible without the coaching, support, and friendship from my dissertation chair, Dr. Deborah MacPhee. From the day we met you have been encouraging me to grow through honest, thoughtful conversations as a doctoral candidate, researcher, and first grade teacher. When I felt times of discouragement throughout this process, you reminded me that it was normal, and I can do this. You also reminded me how important it is to take time away, have fun, and focus on self-care. Thank you for taking time out of your busy life to be my dissertation chair. Your feedback and support are very much appreciated in this writing and in the classroom. Thank you also for all that you do for the world of education and the children in schools, you continue to be an inspiration to me.

The other members of my committee, Dr. Kyle Miller and Dr. Sherry Sanden have also been important influences on me as a doctoral candidate and first grade teacher. I appreciate your feedback and conversations throughout this entire journey. You helped me think through tough 
questions and provided encouragement. Thank you for being part of my committee and helping me learn and grow as a researcher and teacher.

The participants in this study also deserve special recognition. Without your engagement in the online learning group, this study would not have been possible. I enjoyed our conversations together and am so grateful for you giving your time to participate and in some cases be interviewed. I am so glad we could learn together. I hope you continue to think critically and reflect on your teaching.

I will always remember the fellow students I met in my coursework along this journey as well. While there are many that have impacted me in one way or another, the conversations we had in class and over dinner will always be appreciated-Jill Donnel, Dr. Dana Karraker, and Sarah Bonner, thank you! Your passion for education and your strong desire to learn more encouraged me along the way. I also appreciated the conversations and willingness to answer my questions from Dr. Sarah Urbanc as we carpooled to ISU for both our master's and Doctoral classes. Thank you also for reading my work and providing feedback.

Finally, to my family and friends who have supported and encouraged me as well. You all checked in on me to see how my work was going but also made sure I was taking care of myself and remembering to enjoy a life outside of this dissertation. Sometimes it was hard to maintain a balance, but you all supported me through this. First off, I am thankful to my parents Gale Belcher and Kathy Belcher for their support throughout my entire educational career. From the days of watching Sesame Street, playing board games, and exploring outdoors you have been nurturing my love of learning since I was born. You have both shown me how important hard work, dedication, and reliability truly are. 
Thank you to my sister Amie Belcher for being an inspiration to me as a teacher as I watched you go through school experiences that were different from mine. You remind me to get to know every child and provide opportunities for every child no matter how they learn. I would also like to thank my fiancé Phil Angelico for his encouragement and helping me maintain my motivation on days when I would have rather cried and gave up. Some days you literally carried me to my desk and made me work when I thought I could not. I appreciate the times you stepped up around the house and kept me fed when I was too busy to cook.

I also cannot forget to mention my cat Purrcy, who sat by my side, on my lap, and sometimes on my keyboard while I was writing. She has always been so "helpful" and loving. As this journey comes to a conclusion, please know I appreciate every one of you and so many more I have met along the way.

M.B. 


\section{CONTENTS}

Page

ACKNOWLEDGMENTS

TABLES

FIGURES

CHAPTER I: BACKGROUND TO THE STUDY 1

Experiences in Education $\quad 2$

Beliefs and Practices $\quad 3$

$\begin{array}{ll}\text { Internship } & 3\end{array}$

Models of Literacy Teaching $\quad 4$

$\begin{array}{lr}\text { Collaborations with Others } & 6\end{array}$

$\begin{array}{ll}\text { Faculty Member } & 7\end{array}$

$\begin{array}{ll}\text { Hierarchies } & 10\end{array}$

$\begin{array}{ll}\text { Mentoring } & 10\end{array}$

$\begin{array}{ll}\text { Doctoral Studies } & 13\end{array}$

$\begin{array}{ll}\text { Statement of the Problem } & 15\end{array}$

$\begin{array}{ll}\text { Purpose of the Study } & 18\end{array}$

$\begin{array}{ll}\text { Research Questions } & 19\end{array}$

$\begin{array}{ll}\text { Significance of Study } & 21\end{array}$

Definition of Key Terms $\quad 22$

CHAPTER II: LITERATURE REVIEW 24

$\begin{array}{ll}\text { Theory vs. Practice Gap } & 26\end{array}$

$\begin{array}{ll}\text { Thirdspace } & 27\end{array}$ 
$\begin{array}{ll}\text { History of Thirdspace } & 28\end{array}$

Thirdspace with Mentors and University Supervisors 30

Thirdspace with Preservice Teachers $\quad 36$

$\begin{array}{ll}\text { Teacher Learning } & 38\end{array}$

Online Learning Spaces in Education $\quad 39$

Benefits of Online Learning Spaces $\quad 41$

Sharing Resources and Gathering New Ideas $\quad 41$

Improvement of Practices $\quad 42$

Collegial Support and Encouragement 43

$\begin{array}{ll}\text { Individual Needs } & 44\end{array}$

Challenges of Online Learning Spaces $\quad 45$

Time $\quad 45$

Lack of Critical Conversations $\quad 46$

$\begin{array}{ll}\text { Interactions with Others } & 47\end{array}$

$\begin{array}{ll}\text { Conclusion } & 48\end{array}$

CHAPTER III: METHODOLOGY 49

Research Paradigm-Constructivism $\quad 50$

$\begin{array}{ll}\text { Theoretical Framework } & 51\end{array}$

Framework for Understanding Teaching and Learning 51

Knowledge of Learners and Their Development $\quad 52$

Knowledge of Subject Matter and Curriculum $\quad 52$

Knowledge of Teaching $\quad 53$

$\begin{array}{ll}\text { Agency } & 54\end{array}$ 
Researcher Positionality 56

$\begin{array}{ll}\text { Research Design } & 58\end{array}$

$\begin{array}{ll}\text { Action Research } & 58\end{array}$

$\begin{array}{ll}\text { Research Setting } & 60\end{array}$

Professional Development in the District $\quad 61$

$\begin{array}{ll}\text { Participant Selection Criteria } & 62\end{array}$

$\begin{array}{ll}\text { Online Site } & 65\end{array}$

$\begin{array}{ll}\text { Data Collection Methods } & 66\end{array}$

$\begin{array}{ll}\text { Questionnaires } & 67\end{array}$

$\begin{array}{ll}\text { Observations } & 68\end{array}$

$\begin{array}{ll}\text { Interviews } & 69\end{array}$

$\begin{array}{ll}\text { Reflexive Journal } & 72\end{array}$

$\begin{array}{ll}\text { Data Analysis } & 72\end{array}$

$\begin{array}{ll}\text { Inductive Coding } & 75\end{array}$

$\begin{array}{ll}\text { Deductive Coding } & 77\end{array}$

$\begin{array}{ll}\text { Research Questions } & 78\end{array}$

$\begin{array}{ll}\text { Exploratory Display } & 79\end{array}$

$\begin{array}{ll}\text { Trustworthiness } & 79\end{array}$

$\begin{array}{lr}\text { Triangulation } & 80\end{array}$

$\begin{array}{lr}\text { Member Checking } & 80\end{array}$

$\begin{array}{ll}\text { Peer Debriefing } & 81\end{array}$

$\begin{array}{ll}\text { Thick Description } & 81\end{array}$

$\begin{array}{ll}\text { Reflexivity } & 82\end{array}$ 
$\begin{array}{ll}\text { Prolonged Engagement } & 82\end{array}$

$\begin{array}{ll}\text { Ethical Considerations } & 83\end{array}$

$\begin{array}{ll}\text { Summary } & 84\end{array}$

CHAPTER IV: FINDINGS

$\begin{array}{ll}\text { Participants } & 86\end{array}$

$\begin{array}{ll}\text { Anna } & 86\end{array}$

$\begin{array}{ll}\text { Elizabeth } & 88\end{array}$

$\begin{array}{ll}\text { Gretchen } & 89\end{array}$

$\begin{array}{ll}\text { Laurie } & 90\end{array}$

$\begin{array}{ll}\text { Lavendar } & 91\end{array}$

$\begin{array}{ll}\text { Lyn } & 93\end{array}$

$\begin{array}{ll}\text { MaryAnne } & 94\end{array}$

$\begin{array}{ll}\text { Nicole } & 94\end{array}$

Numerical Analysis: A Quantitative Look at the Online Space 95

$\begin{array}{ll}\text { Content of the Interactions } & 98\end{array}$

$\begin{array}{ll}\text { Topics of Posts } & 98\end{array}$

High Comments, High Participants, and Significant Posts 100

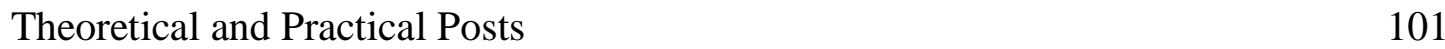

$\begin{array}{ll}\text { Framework Knowledges } & 101\end{array}$

$\begin{array}{ll}\text { Four by Four Posts } & 103\end{array}$

$\begin{array}{ll}\text { Interactions and Change in Thirdspace } & 107\end{array}$

$\begin{array}{ll}\text { Interactions Theme } & 107\end{array}$

$\begin{array}{ll}\text { Cordial Conversations and Discourse of Agreement } & 107\end{array}$ 
Resisting Moments of Critical Conversations

Change Themes

Shifting Practices

Participant Stories of Shifting Practices

Developing Agency

Four by Four Posts

Participant Reflections on Interactions

Summary

CHAPTER V: DISCUSSION

130

Introduction

Thirdspace

Numerical Analysis: A Quantitative Look at the Online Space

Interactions and Change in Thirdspace

Cordial Conversations and Discourse of Agreement

Context of Collaboration

Talk Moves

A View of a Mentor

Resisting Moments of Critical Conversations

Role of the Researcher Promoting Critical Discussions

Critical Conversations and Other Facebook Pages

Shifting Practices

Developing Agency

Unanswered Questions and Missed Opportunities 
Graphic Display of Online Interactions

Implications for Practice

Implications for Research

Limitations

Conclusions 


\section{TABLES}

Table

Page

1. Participant Demographics $\quad 64$

2. Participant Interviews $\quad 71$

3. Codes Indicating Topics of Posts 99

4. Number of Posts of Framework Knowledges 102

5. Posts with all Three Framework Knowledges 103 


\section{FIGURES}

Figure $\quad$ Page

1. Participant Recruitment Slide $\quad 63$

2. Facebook Post Visual $\quad 74$

3. NVivo Crosstab Query Results $\quad 77$

4. Online Space Postings Overview 97

5. Top Five Codes in Four by Four Posts 104

6. Post-Study Questionnaire Results 116

7. NVivo Crosstab Query Results: Posts with High Comments and High Participation 118

8. Graphic Display of Online Interactions 156 


\section{CHAPTER I: BACKGROUND TO THE STUDY}

My desire to become an educator began at a young age when I played school with my sister. We would always fight over who would be the teacher each time we played. My own schooling experiences only furthered my love of learning: I loved school and I admired all my teachers at that time, just as young children often do. In my elementary years, school was easy for me. In high school, I had to work hard and study often, but I was still a good student. I completed my assignments, I earned good grades, and continued to admire many of my teachers. At the same time, I began to recognize that not all teaching practices were effective in supporting my learning. In college, coursework became more challenging, as I was asked to think critically and comprehend deeply. This was something new for me as most of my schooling experiences centered around a banking model (Freire, 1970), in which I was expected to regurgitate information on a test. Since this had been a common part of my experiences as a student, upon entering college, I did not recognize the potential of other possibilities.

As an elementary education major in college, I realized there is more to teaching than what I enacted playing school with my sister, what I interpreted as a student, or even what I learned during my undergraduate teacher education which began in 2002. I chose to participate in the Professional Development School (PDS) program during my final year at Illinois State University (ISU). I was excited for the opportunity to work closely with a mentor teacher in a district where technology was prevalent. I had heard many great testimonials from other PDS teacher candidates, I could not have imagined being prepared to teach in another student teaching placement. However, it was also during this time that I began to notice some conflicts between my own teaching and what I learned about during my undergraduate coursework. My perspective on teaching and what it meant to be a teacher continued to evolve as I began working in my 
classroom in the same school where I was a student teacher. Tensions that I perceived in my teaching became even more evident as I began the Reading Master's program in 2008 at ISU and also mentored student teachers in the PDS program. My awareness of the effectiveness of the practices I was employing at that time was heightened even more as I began doctoral courses in 2014 and taught undergraduate courses at ISU beginning in 2017. The courses and conversations happening throughout these times allowed me to see various points of views and differing perspectives.

These experiences have fueled my desire to advocate for opportunities for both preservice teachers and in-service teachers that move beyond the common institutionalized practices of teacher preparation and professional development (Graham, 2006; Wang \& Odell, 2007; Zeichner, 2010). I am uniquely situated to conduct research on professional learning with online spaces because I have stepped into multiple roles within the realm of teacher education and have had various experiences that have informed my practices.

\section{Experiences in Education}

In this chapter, I will describe my experiences as a classroom teacher, intern, mentor, doctoral candidate, and university faculty. I will also reflect on two overarching themes that have informed the study I conducted: how my beliefs about teaching and learning informed my teaching practice and how my experience in a traditional student teaching/mentoring dyad influenced my teaching practices and my thinking about teacher education. Below I will discuss how these experiences and themes have influenced who I am as an educator today, and how I have conceptualized this research project that addressed my questions about preservice teacher education and teacher development in online spaces. 


\section{Beliefs and Practices}

The examples I share below highlight how over a span of 12 years I grappled with disconnects I noticed between my beliefs about teaching. These were based on my own experiences in school, my learning at the university, the practices I enacted during my student teaching, and the practices I enacted in my own classroom. Cochran-Smyth and Lytle (1999) acknowledged this as a form of professional development where one is "recognizing discrepancies between beliefs and practices and rethinking practices based on self-reflective analysis" (p. 271).

\section{Internship}

My year-long internship at a Professional Development School (PDS), during my senior year in college, provided me with an experience in a school setting that differed in some ways from a traditional student teaching setting. This particular PDS hosted senior year fall coursework within a school at the district instead of at the university, which is common in a traditional setting. Two university supervisors led the cohort of 30 interns that year. However, the overall model of the program still followed a traditional student teacher/mentoring dyad. Mentors and interns were paired by university supervisors with input from school principals. Due to the differences in the calendar years between universities and elementary schools, I was able to see almost an entire school year; beginning with back to school preparation, to parent teacher conferences, and some end of the year wrap up. I felt completely welcomed by all school staff and attended school and district meetings with my mentor. I left the program feeling confident about my ability to be an effective classroom teacher. As I began teaching, I felt tensions and conflicts between what I learned and believed about teaching and the expectations of my school 
and peer teachers, even though I was often praised by my mentor, administrator, parents, and colleagues telling me I did a good job and described this as a natural capability for teaching.

Some examples of these tensions included implementing constructivist approaches to instruction (Dewey, 1904) in a context that seemed overwhelmingly behaviorist, to using assessments to inform instruction (Afflerbach, 2011; Stiggins, 1995) as opposed to completing assessments because I was told to, and teaching reading and writing in a workshop approach (Calkins, 1994; Goodman, 1996) in an environment where reading seemed to be taught in a behaviorist manner and word accuracy was valued. In addition, I struggled with creating a classroom community that moved beyond using behaviorist approaches to control (Skinner, 1954) and instead allow for student input and respect among one another (Freire, 1970; hooks, 2009) in a social learning environment (Vygotsky, 1978).

Models of Literacy Teaching. As an intern and new teacher, I struggled with implementing literacy practices that were different from my coursework. At that time, I simply mimicked the procedures in place at the school without questioning why the literacy practices did not align with my coursework. I was implementing practices such as round robin reading, placing students into reading groups solely based on reading levels, DEAR (Drop Everything and Read), and writing time which consisted of copying letters and words. I had learned about whole language (Goodman, 1996) and workshop approaches (Calkins, 1994) in my coursework but I did not feel that those practices were acceptable, and I did as I was expected to do. Thinking back, I planned fun and cute activities for the children, but I was not thinking critically about how this was impacting their growth and development. Unfortunately, I was just teaching lessons and not teaching students. Much research has been done on the socialization of teachers in schools. Previous research from Lacey (1977) aligns with the experiences I faced as a novice 
teacher. Internalized adjustment and strategic compliance are two strategies he identified as common among teachers as they grapple with socializing within a school context. I saw myself as wavering between these two realms: doing what I was expected to do as I thought it was for the best (internalized adjustment) and doing as I was told but having some private hesitations (strategic compliance).

Furthermore, I had a difficult time implementing a workshop-based literacy framework (Calkins, 1994) which more closely aligned with my undergraduate coursework. I was planning for instruction and talking with other teachers, reaching out trying to gather ideas. It was during this time that I began to think critically about these disconnects as I tried to implement guided reading groups. At that time a team of teachers and literacy instructors, not the classroom teacher, obtained a reading level on each child via a running record, then the students were divided between all grade level teachers and reading teachers based on their reading level for 45 minutes of daily literacy instruction. I worked with a small group of students consisting of students from my classroom and another teacher's classroom. I always felt lost and confused about what I should do during this time. I knew I was supposed to use leveled books and do word work and writing, but I did not understand why or how. I was unsure what to do to support children in their reading development. Again, I was doing what had always been done at this school but feeling some disconnect between my beliefs about reading and practices that were happening at the school. What I was doing as a teacher was similar to what Freire (1970) called a "banking approach" to education. While I could not have named this at the time, I could feel tension in my teaching as I noticed I was going through the motions of teaching what was being called reading. I know I learned about reading instruction as an undergraduate, but I did not understand fully how to conceptualize this when working in a classroom with students. Yet, I 
continued to be told by administrators and colleagues I was doing a good job teaching. While there were many people willing to engage in conversations with me and provide emotional support, I did not feel there were colleagues I could talk in-depth with about these tensions and receive the feedback I needed for growth, as I wanted to move beyond just receiving praise and support.

\section{Collaborations with Others}

As I was working through the tensions I felt, I continuously talked to other teachers and mentors. I visited a few first-grade classrooms and talked with other teachers, but I felt misunderstood in what I needed as a teacher. I began to think more about workshop approaches and miscue analysis (Goodman, 1969)/running records (Clay, 1985; Fountas \& Pinnell, 2008) I learned about as an undergraduate. I wanted to try this in my classroom, and I began talking with another first-grade teacher and she too was interested in workshop. It was refreshing to connect with another educator who was feeling similar tensions. This aligns with Lacey's (1977) notion of strategic redefinition where I attempted to change the social norms of this school and introduce new elements. I quickly learned that I enjoyed talking with colleagues as I worked to strengthen my practices, but still felt I was not doing all I wanted to. At the same time, I was beginning to develop professional agency. Fairbanks et al. (2010) defined this as, awareness of one's beliefs and theories about teaching and learning, a vision to guide practice, a sense of belonging to and a stake in the professional community, and ways of imagining and enacting identities consistent with the visions and beliefs they have constructed from knowledge and experience. (p. 167)

Doing this alongside another educator who was noticing tensions with the practices that were happening made this journey more enjoyable and attainable. Cochran Smith and Lytle (1999) 
consider this collaborative effort a time where, "participants struggle along with others to construct meaningful local knowledge and where inquiry is regarded as part of larger efforts to transform teaching, learning, and schooling” (p. 278). I had to create a space for myself where I could navigate these tensions I was experiencing, as this was not made available for me at the onset of my career. This collaborative connection and learning I experienced has helped me conceptualize a thirdspace for teacher candidates and practicing teachers to connect with one another in an online environment where traditional mentoring approaches and learning experiences for practicing teachers are reconceptualized as a space of inquiry and learning for all. Flessner (2014) summarizes my understanding of the term thirdspace: "a place of reflection, renewal, and change in which two supposedly oppositional worlds are re-imagined to identify tensions, conflicts, exaggerations of distance, commonalities across domains, sources of insight, and inspiration for action" (p. 6).

\section{Faculty Member}

Extending my desire to conceptualize a different space for teacher candidates and classroom teachers has been my work as a faculty member at ISU, teaching a section of an undergraduate Language Arts course. During the semester before student teaching, preservice teacher candidates are immersed in clinical experiences in K-2 classrooms. While they value their time in classrooms, similar to my experience as an undergraduate student teacher, what they shared about their mentors' practices regarding literacy learning and classroom communities, was not always aligned with what they read about and discussed in their coursework. This aligns with another common tenant of a traditional model of preservice teacher education, the assumption that student teachers will be able to seamlessly transition from university coursework to successful experiences in the classroom (Levine, 1992). These teacher candidates stated they 
recognized differences in some cases, but have not yet developed agency to challenge or question the traditional models of education. In other words, they were hesitant to talk to their mentors about these differences.

The scenarios I describe are similar to the tensions I experienced as an intern and new teacher where beliefs about teaching are different from what is being enacted in classrooms. For example, preservice teachers have shared stories about observing writer's workshops where students were not allowed to choose their own writing topics and where a heavy emphasis was placed on spelling and grammar and less on content and process. In another example, preservice teachers were grappling with ways to help students choose just right books for independent reading, which was what they were typically learning in their coursework, yet their classroom mentors were requiring students to pick books from specific levels. Despite these noticeable disconnects, teacher candidates often felt they were in high quality classrooms and hoped to mimic some of what they were learning from their mentors. The thirdspace that I envisioned was designed as a space where teacher candidates could collaborate to develop a sense of professional agency and discuss the disconnects or tensions they were noticing. DarlingHammond et al. (2005) notes a mentor teacher is often the most significant influence over how a teacher candidate will design his or her own classroom and philosophies in the future. Student teachers are often only seeing one model of teaching and they can leave clinicals with preconceived notions about what they should be doing in education even if what they are seeing differs from what they have learned at the university, similar to my experience as an undergraduate.

Feiman-Nemser and Buchmann (1985) suggested teacher candidates often base their own teaching on how they learned in schools. I have heard teacher candidates discuss how they would 
like to operate their own classrooms based on their experiences as students that may not align with current trends in education or what they have learned in their undergraduate coursework. On the other hand, some teacher candidates have shared some wounding school experiences that they had as children and recognize they do not want to do this in their own classrooms. WoodKofono and Meyer (2017) described these experiences as "injuries to the feelings of learners during experiences in school or in situations involving learning or related to school" (p. 95). These examples highlight how students are using their own schooling experiences (Lortie, 1975), whether good or bad, to influence their own practices in the classroom.

The examples I shared above highlight how one's beliefs do not always align with their practices. I experienced this as an educator and have observed this with teacher candidates as well. While it is no surprise that teacher candidates are influenced by their own schooling experiences and their interactions in a mentor's classroom (Darling-Hammond \& Bransford, 2005; Feiman-Nemser \& Buchmann, 1985) this study was designed so that another perspective or collaborative space could benefit teacher candidates' development as they transition from university coursework to a classroom alongside practicing teachers who desire to collaborate as they work in their own classrooms. While interrogating my own experiences, I have found it difficult to step out of the institutionalized practices that are typically enacted in teacher education, as I have been experiencing them since I was a young child. I will now describe some examples of how traditional models of student teaching, where the novice learns from the expert (Graham, 2006; Wang \& Odell, 2007), influenced me as an educator and continue to be common tenants of teacher education. 


\section{Hierarchies}

In a traditional model of student teaching, novice teachers are placed in classrooms with more experienced educators and it is assumed that the teacher candidate will learn from the expert (Graham, 2006; Wang \& Odell, 2007). Cochran-Smith and Lytle (1999) name this "knowledge in practice" and suggested, "learning depends on the assumption that the knowledge teachers need to teach well is embedded in the exemplary practice of experienced teachers" ( $p$. 263). Thus, hierarchies of knowledge are common in student teaching as a teacher candidate may be expected to learn from a mentor and a mentor may be expected to transmit knowledge to the novice (MacPhee \& Belcher, 2019). My experiences as an intern, classroom teacher, and doctoral researcher highlight how hierarchies influenced me as an educator.

As an intern and novice teacher, I was given positive feedback from my classroom mentor, university supervisor, and administrator, therefore, I assumed what I was doing was what was best for children. Spending a year in a school was beneficial, but looking back now, I recognize that I could have had a very different experience which included critical feedback to enhance the content of my teaching or focus my attention on student learning. Although I could not exactly identify it at the time, I felt some kind of disequilibrium in my teaching. The feedback I was given typically fit within the traditional model of student teaching where the expert mentor gives feedback to the novice student teacher (Graham, 2006; Wang \& Odell, 2007) and I felt I was expected to emulate what was already happening. Perhaps I was perceiving this expectation because of the traditional encounters surrounding my involvement in education.

\section{Mentoring}

As I persisted in working to strengthen my approaches to teaching, and after three years of teaching, I began to mentor interns in the PDS program in my district. I found this to be 
challenging, and I was often unsure how to give feedback to support interns' educational development. There were times when I mentored interns, that I questioned: What am I doing? Am I really qualified to work with preservice teachers? Throughout this time, I desired to become a more effective mentor. I attended all mentor professional development courses offered by my district, but still felt something was missing. I learned a great deal about classroom management and building relationships with interns, but I was still unsure how to provide feedback regarding content and pedagogy to encourage critical reflection with interns. Therefore, I found providing critical feedback to interns to be a challenge. I wanted to be supportive and honest, but I did not know how to implement this balance of providing encouragement and critical feedback within the context of the institutionalized teacher education practices firmly in place.

This may have been difficult for me because I was rarely given critical feedback in my own PDS experience. In my discussions with teacher candidates, I privileged feedback on classroom management and gave superficial feedback that likely did not deepen the intern's knowledge, or my own, and most importantly, the students. I understood the student teaching experience was critical in a preservice teacher's development, yet I struggled with how to provide the best space for learning. The discourse that I remember from my early days as a mentor centered on the expert-novice dichotomy where I was the expert and should model best practices, so the preservice teacher can learn from me (Wang \& Odell, 2007). This aligned with traditional institutional parameters that are common among school-university relationships and teacher candidates and what Graham (2006) identified as maestros: "[those who] focused on the surface and readily observable aspects of teaching" (p. 1126) and encouraged student teachers to observe and copy. 
For me it was not enough for preservice teachers to observe and copy in a first-grade classroom, we needed to engage in conversations that were in-depth and pushed each other's thinking, moving beyond the traditional dyad model (Graham, 2006; Rodgers \& Keil, 2007; Valencia et al., 2009; Wang \& Odell, 2007). What I had hoped to do as a mentor aligns with what Graham (2006) called a "mentor." From this view, a mentor is interested in engaging in dialogue with a preservice teacher, having critical conversations that transform practices, and finding areas of strength and weakness while working together to build practices. As Graham (2006) stated, "transforming content knowledge from college courses into 'pedagogical content knowledge' requires time and effort. They [mentors] underscored the need for both classroom experience and critical reflection on those experiences in the process of learning to teach" ( $\mathrm{p}$. 1127). However, when I would attempt to create these experiences with teacher candidates, I was often met with push back and teacher candidates wondering why I was being so critical. In some instances, candidates wanted to adhere to the traditional mentoring/novice roles even though I attempted to break down these hierarchies. They observed their peers engaging in traditional roles with their mentors and wondered why their encounters were different. There was a constant pull back to the institutionalized discourse, the expert/novice dichotomy, where interns wanted to receive the feedback from me and then implement the directions or feedback they were given.

My experiences as a mentor along with my doctoral research, that I describe below, helped me conceptualize a thirdspace for in-service and preservice teachers to work together to move beyond a traditional approach to mentoring and student teaching that is common in teacher education and instead allow for collaborations and critical discussions. 


\section{Doctoral Studies}

After eight years of teaching first grade and mentoring, I began my doctoral work and continued to focus on understanding teacher education and mentoring preservice teachers as a co-researcher with Dr. MacPhee. In our research project (MacPhee \& Belcher, 2019) we observed and analyzed participants' (preservice teachers, classroom teachers, and university supervisors) language during debriefing conversations following lessons taught by a classroom teacher or preservice teacher candidate. After post-lesson debriefing conversations were transcribed and analyzed, we found six themes related to how participants used language in this professional context. These included participants using language to praise and encourage one another, critique and suggest, explain and describe practices, recognize and acknowledge practices, make connections to personal experiences or coursework, and ask questions. We also saw a hierarchal structure of conversations emerge. Supervisors provided feedback to teachers, teachers provided feedback to interns, or intern-to-intern feedback was provided in a top down fashion. The highest number of comments centered on praise and encouragement, and there was a hesitation to provide critical feedback or suggestions. In addition, critical comments were made but were not always elaborated upon. This, again, seemed similar to the feedback I was given as an intern and later giving as a mentor to the interns I worked with. Furthermore, this aligns with the traditional and institutionalized practices often seen in university and school partnerships where teacher candidates are placed (Rodgers \& Keil, 2007; Wang \& Odell, 2007; Zeichner, 2010).

Working on this research project and thinking back on my own intern and mentor experiences in the PDS program, helped me see how beneficial a collaborative space for teachers and interns could be. In addition, listening to these collaborative conversations helped me see 
how valuable reflective conversations could be. While there was room for growth in these conversations, I noticed that teachers and interns were given a space to provide positive comments and critical feedback to one another. I also heard how connections were made between coursework and classroom experiences. These conversations began to support educators through reflection, co-planning, co-teaching, modeling, and feedback (Darling-Hammond \& Bransford, 2005).

However, the conversations still took on a tone of traditional institutional practices where most critical feedback and questions were discussed in top down fashion from mentor to intern (Wang \& Odell, 2007). For example, interns would ask classroom teachers questions about their practices: "How do you find like the mentor text that you use? Is it just kind of like a trial and error thing that you've kind of like over the years gotten to that point?" Or, another example, “How do you figure your writing partners? Do you pick them?" In addition, critical feedback was provided from intern-to-intern and teacher-to-intern. Yet, there was a hesitation to provide this type of feedback and participants used buffer words (e.g., um, yeah, kind of) to soften the potential impact of the suggestions:

I did, yeah, I mean, I thought that it was, um, it felt a little rushed but I, I was in your head and I knew, I saw you looking at the clock, and I knew exactly where you were at. But yes, I would allow that, just, a whole lot more, kind of, wait time. Praise and encouragement were the most common type of feedback given during these debriefing conversations. Phrases such as "Nice job" and "I really liked your lesson." were prevalent but did not really give specific enough feedback to push participants thinking about teaching and learning (MacPhee \& Belcher, 2019). 
Although, as researchers, we were trying to create a space where this did not happen, it was not easy to push back against these traditional approaches that Zeichner (2010) referred to as "the historically dominant 'application of theory' model of preservice teacher education in the United States" (pp. 90-91). Engaging in this type of research and data analysis only furthered my desire to develop ways to provide additional spaces for learning with preservice teachers and teachers to explore possibilities outside of this traditional approach.

All of these personal encounters throughout my journey as a professional educator have fueled my passion for providing high quality collaborative experiences and classrooms for preservice teacher candidates. As a mentor myself, I recognized the need for professional development on mentoring, and as a university faculty member, I heard firsthand how teacher candidates are encountering diverse classroom experiences. In addition, I valued my own yearlong internship but could also see a need for different preparation for preservice teachers, as I, too, had to grapple with a disconnect between university coursework, my beliefs, and classroom practices. I will now expand upon how my personal encounters in education are reflected in the broader world of teaching and helped me conceptualize and implement an online thirdspace for educators.

\section{Statement of the Problem}

As teaching has shifted with a heavy emphasis on testing and diverse student populations increase (Webber \& Miller, 2016), it is important to take a closer look at preservice teacher preparation models and teacher development. Within the last decade, the National Council for Accreditation of Teacher Education (NCATE) Blue Ribbon Panel on Clinical Preparation and Partnerships (2010) made a call for teacher education programs to be reexamined to place a stronger emphasis on the amount of time teacher candidates spend in classrooms (Zeichner \& 
Bier, 2015). While no one is arguing there should not be more time in classrooms, I agree with Rust (2010) simply spending time in a classroom does not guarantee that quality experiences will be taking place.

The perceived variance between theory and practice has been well documented in educational research (Allsopp et al., 2006; Linda Darling-Hammond, 2014; Feiman-Nemser \& Buchmann, 1985; Knowles \& Cole, 1996). It is commonly suggested that theory at the university and practice at the schools are often two separate spaces. It is typically alleged that universities are too theoretical, and schools are often assumed to be too practical, or anti-theoretical, resulting in a perceived gap between the two (Grossman et al., 2009). Literature continues to purport university coursework can be disconnected from classroom experiences and both parties are often unsure as to what the other is doing. Teachers may lack understanding about what is happening at the university and university supervisors may be unaware of what is happening in mentor classrooms (Grossman et al., 2009; Hammerness \& Klette, 2015; Zeichner, 2010). In addition, student teachers often feel they are competent teachers because they themselves have been students and are quite familiar with education (Feiman-Nemser \& Buchmann, 1985; Lortie, 1975). This familiarity also enables preservice teachers to use approaches they experienced in their own education (Bransford, Derry, et al., 2005). Due to this perpetual discourse of division between university and classroom settings, the benefits of a thirdspace were explored for inservice and preservice teacher collaborations (Flessner, 2014; Soja, 1996). I will expand more upon this perceived gap in chapter two.

Undergraduate teacher education majors typically finish their schooling within a classroom, where they gradually take on more responsibility until they have full control of the classroom during their student teaching placement. Field experiences in classrooms afford 
preservice teachers the opportunity to observe and enact their learning thus far with students and a mentor teacher (Darling-Hammond et al., 2005). Hollins (2015) suggested, "clinical preparation refers to opportunities to apply conceptual and theoretical knowledge to practice in a real classroom setting under the guidance of an experienced and knowledgeable mentor" (p. 15). While these experiences can be beneficial, Graham (2006) noted, "field experiences have been criticized for being fragmented, lacking curricular definition, and appearing disconnected from other components of teacher preparation programs" (p. 1118). However, it is well known that the time a candidate spends in classrooms is often touted as being the most beneficial in their preservice teaching opportunities (Feiman-Nemser \& Buchmann, 1985; Valencia et al., 2009). Excellent field experiences are not a new idea as Dewey (1938) stated, "it is not enough to insist upon the necessity of experience, nor even of activity in experience. Everything depends upon the quality of the experience which is had" (p. 27).

Dewey's statement not only resonates with teacher candidates but with practicing teachers as well; we all need quality learning experiences. Eisner (2015) purported, "professional growth should be promoted during the 25 years that a teacher works in a school- not just during the year and a half that he or she spends in a teacher education program" (p. 27). Professional development or professional learning in education has taken on many appearances such as one day workshops, communities of practice, Professional Learning Communities (PLC) and recently online learning spaces. As Guskey (2002) suggested, professional learning can take the form of: "study groups, action research, collaborative planning, curriculum development, structured observations, peer coaching, mentoring, and so on. But regardless of its form, professional development should be a purposeful endeavor" (p. 46). Research concurred that a one size fits all approach, common in schools, is not always the best fit, as teachers are all unique 
learners with various strengths and areas for growth (Bernhardt, 2015; Carpenter \& Harvey, 2019). Bernhardt (2015) even went as far as saying that professional development has "become an unfavorable practice" (p. 2) and unfortunately has a negative connotation in schools.

When pressures surmount and challenges arise, social support and interactions among teachers are named as being important in a teacher's career and success (Hur \& Brush, 2009). To expand upon this, House (1981) identified four types of social support: emotional support (selfesteem, listening, trust); appraisal support (affirmation, feedback, social comparison); informational support (advice, suggestions, information); and instrumental support (monetary, time, volunteer or labor). Teachers often have to find this support on their own, as I sought out social support in my own educational endeavors. Just recently, more attention has been given to teachers receiving social support in online environments. Killeavy and Moloney (2010) argued that "technology can facilitate written and verbal dialogue and connections to other communities" (p. 1071) thus increasing one's social support beyond the walls of their own schools.

All of these concerns, within field experiences, teacher professional learning, and social support among educators suggest a need for alternative considerations within the world of teacher education. These studies juxtaposed with my own personal experiences as an intern, mentor, faculty, and doctoral researcher, led to my development of a collaborative thirdspace, a space for preservice and in-service teachers to converse and critically reflect with one another within an asynchronous online environment.

\section{Purpose of the Study}

The purpose of this study was to understand how an online collaborative thirdspace could provide preservice and in-service teachers space to explore their beliefs and practices outside of 
their immediate educational contexts. More specifically, I was curious about how preservice and practicing teachers could support one another through online collaborations. This thirdspace learning community embraced the approach of deconstructing traditional mentoring hierarchies (Wang \& Odell, 2007; Zeichner, 2010) and explored how interactions within an online thirdspace addressed the perceived university/school gap, as well as provided an additional space for learning and support for teachers. Recent literature on learning communities in teacher education have similar goals to "promote professional dialogue and inquiry together with colleagues...so that learning outcomes are maximized for all learners" (Korhonen et al., 2017, p. 154). Through this study, I sought to understand if an online thirdspace could support preservice teachers as they moved from coursework at the university to work in a classroom setting, as well as support in-service teachers as they worked in their classrooms alongside students. In addition, I sought to understand how teachers perceived the use of an online learning community. I intended for the space to promote teacher agency, reflect on teacher identities, and critically examine teaching practices. While this was the proposed purpose of this study, the small number of preservice teacher participants and their lack of sustained engagement in the online space, created a different thirdspace than was initially intended and prompted questions regarding why there was low participation among preservice teachers These changes and variances from the initial proposal will be discussed in the methodology, findings, and discussion chapters. The research questions below guided me as I moved through this study in the design, analysis, and findings.

\section{Research Questions}

As discussed above, I believe there is a need to provide additional contexts for preservice teachers as they engage in their student teaching experience, and various contexts for teachers to 
engage in critical professional learning. Common traditional approaches to mentoring such as mentor as the expert and student teacher as the novice (Wang \& Odell, 2007; Zeichner, 2010) and a concern from a recent literature review that suggested mentors are often unprepared for their role (Hoffman et al., 2015) furthered my desire to develop an online thirdspace. Both support the idea of looking at additional contexts for student teachers and classroom teachers to collaborate. Moreover, student teachers have appreciated an additional space to discuss concerns and celebrations with peers and non-evaluative mentors (Nafziger, 2006), and previous studies employing an online environment have shown some success in providing spaces for communities of practice (Assaf, 2005). The following research questions guided my study as I sought to understand the potential of an online thirdspace where preservice and in-service teachers could engage in critical reflections and discussions.

1. In what ways can an online collaborative thirdspace support in-service and preservice teachers' learning? How do teachers navigate connections/disconnections across coursework and classroom practices? How do teachers critically reflect on their own classroom practices?

2. What interactions occur among in-service and preservice teachers when they engage in a thirdspace? How do participants construct understanding related to knowledge of teaching, knowledge of learners, and knowledge of subject matter and curriculum in a thirdspace? What roles do participants assume within the online space?

3. How do teachers describe their experiences with an online thirdspace? How do participants reflect on their own learning and professional agency?

The questions that I crafted for this study potentially add to the field of education because previous literature has suggested a need to study small closed social networking sites (Kelly \& 
Antonio, 2016; Killeavy \& Moloney, 2010; Macià \& García, 2016; Turvey \& Hayler, 2017) and thirdspace theory has suggested a need to study a place where connections and disconnections between two spaces can be explored for reflection and renewal (Flessner, 2014). Also using the framework for understanding teaching and learning (Bransford, Darling-Hammond, et al., 2005) as a guiding question has helped me examine how participants are or are not making connections between theory and practice and understand what is happening in online spaces among educators. In chapter two, I will address how online spaces are common for teachers to use but it is not yet understood how these spaces are influencing teachers' decisions.

\section{Significance of Study}

Despite the many studies on teacher education, there is still a need to explore more comprehensive spaces for preservice teachers to further their journey within a teacher education program as well as how spaces for in-service teachers to engage in critical reflection and conversations can be enacted as a form of professional learning. This study informs education, as I explored a collaborative thirdspace where in-service teachers and preservice teachers engaged in an online learning environment. Student teaching is an integral part of a preservice teacher's journey into the profession of education (Darling-Hammond, 2006; Zeichner, 2010). The mentors who work with these teacher candidates have a tremendous job to collaborate and work with future teachers. As I know from my own experiences, it is complex work understanding how to be an effective mentor for a preservice teacher. However, educational research is paying more and more attention to this area of teacher education as field experiences are occurring more frequently in teacher preparation programs (Hoffman et al., 2015; Zeichner, 2010). There is a concern that mentor teachers are not adequately prepared to work with preservice teachers and in-school experiences can differ from the methods and theories learned during undergraduate 
coursework (Hoffman et al., 2015). In addition, spaces that move beyond the traditional novice/expert dichotomy and allow for more collaboration among peers, as well as reflection and inquiry within a group, are being explored (Cochran-Smith \& Lytle, 1999; Korhonen et al., 2017; Quesenberry et al., 2018). Therefore, an additional space to offer preservice teachers another perspective as they transition from university student, to student teacher, to teaching in their own classroom, was explored.

This study is significant in that it used an online environment as a space for educators to critically communicate, reflect, support, and collaborate with one another. Online learning spaces have begun to appear in education. Previous studies of online learning spaces have shared both benefits and challenges. These will be explored in chapter two. Within this study, I implemented an asynchronous collaborative space online to provide a thirdspace (Flessner, 2014; Soja, 1996) for preservice and in-service teacher collaborations. Within this dissertation I have described my personal experiences in education, the literature informing my study, my theoretical framework, how data was collected and analyzed, the findings, how the study varied from the initial proposal, as well as a discussion of the findings and implications for the future in both practice and research.

\section{Definition of Key Terms}

In-service teacher: a certified practicing teacher working in a K-6 classroom. This person may also be referred to as a practicing teacher or classroom teacher

Mentor: a school-based classroom teacher who provides support for teacher candidates while student teaching.

Online community: a social media platform via the internet where participants can engage in discussions about teaching. 
Teacher candidate/preservice teacher: a student within a university teacher education

preparation program. This person may also be referred to as a student teacher or intern as they engage in student teaching in classroom settings.

Thirdspace: a space where two seemingly contrasting worlds can come together. For the purpose of my study, the definition of thirdspace provided by Flessner (2014) summarizes my understanding of the term: "a place of reflection, renewal, and change in which two supposedly oppositional worlds are re-imagined to identify tensions, conflicts, exaggerations of distance, commonalities across domains, sources of insight, and inspiration for action" (p. 6).

Teacher agency: recognizing times of critical reflection and opportunities of learning in one's own practices. The following definition from Toom et al. (2017) most closely aligns with the design of the study:

professional agency is manifested in having the understanding and will to collaborate, build a community, develop through shared professional work for the best of student learning, solve problems and challenges together via discussions, utilize feedback received from the peers, support others as well as the ability to be supported. (p. 127) 


\section{CHAPTER II: LITERATURE REVIEW}

My experiences in education as a classroom teacher and preservice teacher that I described in chapter one demonstrate a typical occurrence in education: teachers engaging in practices that are common to the school culture in which they are immersed (Lacey, 1977; Russo \& Beyerbach, 2001; Zeichner, 2010). Although I felt tensions with how I was teaching children, I also found it to be easy to slip into a world where I did as I was expected. When I finally began to critically examine and question how and why the school was embracing certain practices, I was sometimes met with pushback. Russo and Beyerbach (2001) echoed this sentiment in teacher education, "We must challenge the teacher role of supporting 'business as usual' approach" (p. 87).

Field experiences in a preservice teacher education program are a valuable part of a teacher candidate's journey within the profession of education (Bransford, Darling-Hammond, et al., 2005). Teacher candidates often spend time throughout their undergraduate courses observing and working in classrooms. Typically, towards the end of an undergraduate program, teacher candidates begin a student teaching placement in a classroom with a mentor teacher. Traditional and hybrid models of field experiences are two overarching models that preservice teachers might engage in. However, the expectations of preservice teachers can be overwhelming, and these candidates may be in settings where they are not always seeing the best models of teaching. How do preservice teachers negotiate this struggle between practice and theories of education? Who can they turn to as they negotiate this terrain? Classroom mentors and university supervisors provide a source of refuge for student teachers as they engage in bridging their theories to practice. However, recent studies suggest that not all mentors are prepared for the roles they take on (Hoffman et al., 2015). 
Furthermore, classroom teachers have named social support (House, 1981) as a critical importance in their success and happiness in the workplace. It is not uncommon for teachers to seek out colleagues to converse with. Almost 40 years ago, Larson (1980) wrote about "intensification" in the workplace, where people feel overwhelmed and lack a space to relax or even feel like they have time to eat lunch. Moreover, intensification leads people to feel there is “no time at all to keep up with one's field, to retool one's skills" (Larson, 1980, p. 166). Feelings of being overwhelmed and a perceived lack of time are still very common in educational contexts. Hargreaves (1994) found this still to be a concern among educators 14 years after Larson. Even today teachers continue to face more and more challenges and expectations within their roles, often without additional support or time, and teachers need collegial support (McNinch, 2015). Personally, I feel this almost daily and hear similar sentiments from colleagues. But what types of support are teachers receiving? Districts often offer professional development and fellow teachers lend a sympathetic ear, but are deep critical conversations actually happening? Is there a place for classroom teachers to turn to discuss theories of education and practical applications?

This study was grounded in thirdspace theory within an online learning community with in-service teachers and preservice teachers to engage in collaboration, support, and critical reflection and discussions. This literature review will begin with a closer look at the perceived gap of theory and practice in education and thirdspace theory. Furthermore, I will review literature on preservice teacher field experiences and mentoring within teacher education, professional learning and social support for classroom teachers, and online learning spaces implemented in education. 


\section{Theory vs. Practice Gap}

Educational research has purported a gap between theoretical understandings at the university and practical applications in classroom settings (Allsopp et al., 2006; DarlingHammond, 2014; Feiman-Nemser \& Buchmann, 1985; Knowles \& Cole, 1996). A common discourse in education purports universities are too theoretical and schools are too practical, resulting in a perceived gap between the two (Grossman et al., 2009). The Holmes Group (1990) acknowledged this concern as well, "This absence of strong practical connections between the knowledge and skills taught in the classroom of the education school and their application in practice represents a central, glaring weakness in most university-based professional learning for educators" (pp. 80-81). It is suggested that university coursework is often disconnected from classroom experiences and both parties are often unsure what the others are doing.

Professional development schools (PDS) were enacted to help address these gaps within the field of education. Abdal-Haqq (1998a) cited four purposes of a PDS that differentiate this opportunity from other student teaching experiences: test and improve structures to enhance student achievement, prepare teacher candidates, provide ongoing support and professional development for practicing teachers in schools and universities, and allow for inquiry that supports student and teacher growth. However strong this vision for collaboration and renewal, not all PDS partnerships are operating at full potential. Despite collaborative leadership and mentor meetings, professional development for all stakeholders is not always present, making many PDS cooperations an in-name only site (Abdal-Haqq, 1998b; Teitel, 2001) and not consistently upholding a PDS model. A PDS should not just be a place for new teachers to grow and develop, but instead should be a school of continuous renewal among teachers, professors, administrators, and teacher candidates (Darling-Hammond, 2014). 
Furthermore, classroom teachers may be unaware of what is happening at the university and university supervisors may not be in touch with what is happening in mentors' classrooms (Grossman et al., 2009; Klette \& Hammerness, 2016; Zeichner, 2010). However, determining if there really is a gap of theory and practice between universities and schools can be challenging as the two are intertwined. I agree with Flessner's (2012) suggestion, “a divide between research and practice is often used as a scapegoat to maintain distance between these two worlds" (p. 160). These discourses can perpetuate this perceived "gap" and interfere with the experiences for both mentors and teacher candidates (Cuenca et al., 2011). Therefore, while a common discourse suggests there is a gap between universities and classrooms settings, this may not always be the case, yet there is more work needed in supporting student teachers and classroom teachers. Turvey and Hayler (2017) agree and suggested,

The processing, critical examination and synthesis of such knowledge, experience and belief, is vital if they [preservice teachers] are to make meaning, and gain insights about their own role as teachers, including the assumptions and beliefs that they bring to this process. (p. 44)

This is why I wanted to study how an online thirdspace could be beneficial for the field of education as this statement does not only apply to preservice teachers, but in-service teachers as well. Below I will share the history of thirdspace theory and previous educational studies that have implemented thirdspace theory.

\section{Thirdspace}

Above I shared how not all student teaching placements provide the same opportunities for all teacher candidates and how traditional hierarchies and one's understanding of their beliefs about teaching and what they enact while teaching, impact in-service and preservice teachers. 
Recently much attention has been given to thirdspace as a route to bridge the perceived theory and practice divide in order to provide spaces for both teacher candidates and teacher educators or mentors to learn. Zeichner (2010) brings attention to thirdspace as a hybrid approach to education where all stakeholders can come together for growth and renewal. Forgasz (2016) concurred, "As its metaphorical associations imply, it [thirdspace] offers a powerful alternative to the problematic binaries that plague teacher education discourse: in particular, theory/practice and university/school" (p. 101). Flessner (2014) agreed, noting that a thirdspace can provide an opportunity for the two spaces, universities and schools, to converge, "I define a third space as a place of reflection, renewal, and change in which two supposedly oppositional worlds are reimagined to identify tensions, conflicts, exaggerations of distance, commonalities across domains, sources of insight, and inspiration for action" (p. 6).

Thirdspace is not a new theory; however, it is getting more attention in education recently. Three significant thirdspace theorists: Bhabha, Soja, and Guitierrez all consider this theory in multiple ways. However, "Common across all three conceptualisations of the thirdspace is the political act of disrupting both united and binary ways of seeing through the introduction of a 'third' possibility" (Forgasz et al., 2018, p. 35). Within this theoretical framework, there are first spaces and second spaces, and these two spaces do not always need to be seen as separate binaries but instead through disruption of traditional dichotomies, a new thirdspace can be envisioned (Flessner, 2014). In order to better understand how these theorists have influenced recent work in education, a brief history will follow.

\section{History of Thirdspace}

Philosopher Homi Bhabha (1994) brought forth an idea of thirdspace when understanding indigenous cultures and marginalized populations. Within the culture or population, the first 
space is the knowledge and identity within a culture. While the second space is the knowledge and identities imposed upon the culture. One within the culture may choose to remain within the first space or assimilate into the second space. However, Bhabha (1994) suggested that a new hybrid identity can emerge when a thirdspace is realized between these two dichotomies, "two contradictory and independent attitudes inhabit the same place" (p. 132). While Bhabha wrote about these spaces when discussing marginalized populations, in an interview with Mitchell (1995), he noted a desire to apply these discourses to modern applications. Hence, the appeal of the application of thirdspace to research in education especially where two dichotomies existthe perceived gap between theory and practice I discussed above. Forgasz et al. (2018) concurred,

Bhabha's conceptualisation of the third space offers a useful way in which to theorise the tensions in identity and knowledge construction that can arise for preservice teachers, teacher educators and school-based personnel as they negotiate their roles and identities within professional experience partnerships. (p. 36)

Furthermore, Bhabha's (1994) definition of a thirdspace can be applied to developing teacher agency as part of teacher agency adheres to pushing back against common institutionalized practices (Fairbanks et al., 2010).

Additionally, geographer Edward Soja (1996) wrote about thirdspace as an intersection of a first, a "real" place, and second space, the "imagined" place (p. 6), which leads to a thirdspace that is a combination of both first and second spaces. He described a "thirding as othering" notion which is not simply adding one space to another, but instead considers, "disordering, deconstruction, and tentative reconstitution of their totalization producing an alternative that is both similar and strikingly different" (p. 61). In education Soja's (1996) thirdspace can be used 
as a lens for the disruption of hierarchies between universities and schools that are often prevalent as preservice teachers navigate their experiences in schools after or alongside university coursework.

Gutierrez et al. (1995) used the term thirdspace to describe the intersection of teacher knowledge and student knowledge. Within this research, discourses among students and discourses among teachers, which were called "scripts," did not always align, causing communication struggles. However, when knowledge and power was negotiated among students and teachers, a thirdspace emerged, thus "their interaction between their scripts creates a thirdspace for unscripted improvisation where the traditional binary nature of the student and teacher script is disrupted" (Gutierrez et al. 1995, p. 453). These scripts are not just seen in classrooms with students and teachers but are also prevalent in interactions among preservice teachers and mentors or university supervisors who oversee their field experiences.

Often it is assumed that mentors should be guiding the learning of student teachers, potentially creating hierarchies among these relationships (Graham, 2006). But thirdspace could provide a lens where learning is happening for all, breaking down these binaries. These pioneers of thirdspace have provided a guide for application of this theory into educational practices. In the following sections, I will share research related to thirdspace theory.

\section{Thirdspace with Mentors and University Supervisors}

A comprehensive literature review by Hoffman et al. (2015) suggested being a classroom teacher mentor or university faculty mentor is a great responsibility and those who take on the role are often underprepared for the diverse demands. However, there are many educators in these roles who are interested in improving their abilities as a mentor. Several recent studies have 
used thirdspace theory to understand how these mentors are changing their perspectives about mentoring and engaging in critical self-reflection to improve their practices.

In order to understand the dynamic roles university supervisors' engage in when working with mentor teachers between school and university settings, Williams (2014) conducted a qualitative study and acknowledged three themes: shifting identities, changing perspectives, and negotiating relationships. Within the shifting identities theme, teacher educators felt their experience as a classroom teacher gave them credibility among the mentor teachers. Others felt they could offer empathy and ask suggestions from mentor teachers.

Williams' (2014) findings within this theme supported that, "the distinction between teacher and teacher educator is a false one and they [teacher educators] are... rejecting binaries of practitioner and academic" (p. 322). The second theme, changing perspectives, noted occurrences of student teachers reverting to their mentors' practices even when this contradicted their university coursework. However, a three-way dialogue between mentor, university faculty, and student teacher could be an avenue to disrupt this cycle. The final theme from this study, negotiating relationships, noted the importance of communication as establishing a professional relationship among parties. When university faculty saw practices happening in schools that they did not agree with, they noted it was difficult to navigate these tensions, as they did not want to challenge one party or be unprofessional and agreements were made "just to be polite and avoid conflict" (Williams, 2014 p. 324). From this study using thirdspace theory, Williams suggested "collaboration in the thirdspace provides an opportunity for all participants to work together to gain new knowledge and understandings about teaching and learning and to develop boundary practices that enhance the learning" (p. 325), not just for preservice teachers but practicing teachers as well. 
In another qualitative study, McDonough (2014) completed a self-study on her three roles: as a teacher, teacher educator, and university mentor. She created a space for weekly team meetings of preservice teachers and communicated via an online setting. She found her hybrid roles to be "messy," as she navigated whom she should advocate for. However, she found the weekly online meetings to be a great space for preservice teachers to learn from one another because they provided a space for communication beyond the sparse visits within a traditional model of university supervision. I envisioned a space for peer interactions in the online learning environment in this study for teachers just as McDonough investigated.

A concern emerging from this study highlights the struggles that can occur in field experiences. McDonough (2014) noted,

Some interactions comprised supervising teachers telling me that they had 'told them what to do' and that pre-service teachers were not taking on this feedback. In these interactions, the power imbalances became clear as some supervising teachers expected a replication of pedagogical practices, preventing pre-service teachers from experimenting with practice. (p. 277)

These tensions caused McDonough to advocate for student teachers in order to provide an environment where preservice teachers have the opportunity for risk taking and growth allowing them to develop an understanding of teaching as opposed to just giving them the answers. Hence, developing teacher agency. The online environment of their weekly discussions provided a space for dialogue and reflection among preservice teachers. Moreover, "the exchange of ideas and the buzz of conversation in these moments confirmed for me the value of creating a thirdspace where pre-service teachers and school teachers could work collaboratively" (McDonough, 2014, p. 219). It may not be easy to adjust or rethink clinical practices, but this study highlights the 
need for doing so in order to maximize the learning for preservice teachers and teacher educators, both classroom and university based. McDonough's study concurs with NCATE's (2010) call for reform in clinical practices, where all parties can benefit from the relationship, mentioned in chapter one.

Also drawing upon thirdspace theory, Cuenca et al. (2011) sought to create a bridge between the perceived gap between university work and classroom work by creating breakout sessions with university supervisors and student teachers. These authors recognized that student teaching is an important facet of learning to be a teacher however, the role of the supervisor is quite varied and often underutilized. In order to establish better relationships with student teachers, weekly breakout sessions from five university supervisors were recorded and later analyzed.

After coding, three themes emerged from the data: "(1) accessing new kinds of conversations; (2) providing a more refined focus for observation visits; and (3) cultivating deeper relationships" (Cuenca et al., 2011, p. 1072). The conversations during the breakout sessions allowed student teachers to not only communicate with one another, but also with multiple supervisors, who felt the traditional hierarchical roles were diminished in this type of conversation. As Cuenca et al. (2011) noted, "We [university supervisors] were able to talk with them instead of talk to them" (p. 1073). In addition, university supervisors were able to use what they heard during the breakout sessions to plan for observations with student teachers. Therefore, supervisors could approach the observation with greater awareness of pedagogy, which according to the researchers, is lacking in many student teaching experiences. One additional benefit of the breakout session was the development of deeper relationships among participantsstudent to student and supervisor to student. 
While Cuenca et al. (2011) noted that their breakout sessions were beneficial for this program, they did offer specific suggestions for future research in this area. First, a structured approach to thirdspace theory and bridging these two spaces, schools and universities, could increase the benefits of breakout sessions. In addition, how this work actually benefits and impacts the student teaching experience should be explored as well. In my study, I developed a space to understand how an online learning community could support preservice teachers through peer interactions and conversations with in-service teachers.

In addition to the studies I explored above, additional research using self-study methodology has been employed to understand how a thirdspace was utilized by teacher educators. Taylor et al. (2014) sought to understand how they, as teacher educators, along with 14 mentor teachers could come together in a thirdspace in order to understand how this influenced their work as teacher educators. They stated one purpose of their study was related to the ongoing discussions about how a mentor teacher plays a substantial role in a student teacher's development, yet the roles of a mentor are not clearly defined and vary among programs across the nation. In order to answer their questions about their work in a thirdspace, Taylor et al. compiled weekly written narratives, field notes from meetings, and transcriptions of mentor interviews for their data sources. Overall, the authors noted that education should be ongoing for all stakeholders-mentors, university faculty, and preservice teachers and done so in a community. They argued that, "Teacher education must exist across multiple spaces. The challenge of teacher education is simply too large to continue to reside solely in the university, isolated from the realities of schools" (Taylor et al., 2014, p. 16). Furthermore, a thirdspace provided a platform for this model of hybrid education. 
Forgasz (2016) collected qualitative data from both mentors and preservice teachers in a unique school-university partnership. However, they only reported on the findings from mentor teachers within this article. The goals of this partnership included breaking away from the traditional one mentor-one student teacher dyad to a community of mentors working with a community of preservice teachers, allowing for professional learning opportunities for mentors, and designing a curriculum for preservice teachers in an observation-focused course. Preservice teachers were placed at one school site to allow for the collaborative community to develop among mentors and preservice teachers. From the coding and analysis, Forgasz described how mentors were appreciative of the community because they did not feel pressure to have all the right answers for their preservice teachers and the mentors saw deeper reflection among preservice teachers during their collaborative conversations. Mentors also suggested they developed better relationships with their colleagues. On the other hand, there were some tensions when mentors heard about practices happening in other classrooms that they did not agree with, and some mentors did find it hard to relinquish control for the sake of the community.

According to Forgasz (2016), the thirdspace community did allow student teachers to simultaneously enact their identities as both teachers and students, getting at the suggested divide between coursework and practical applications. Another benefit from this study noted that structured observation protocols helped lift the quality of conversations among participants. While this model may be different, Forgasz concurred this study helped address the perceived theory-to-practice divide and broke boundaries of the traditional approach to mentoring one to one into a community-based model.

Relationships within a thirdspace seem to play a significant role in the development of the participants. Both Beck (2016) and Martin et al. (2011) engaged in a self-study utilizing a 
thirdspace to understand the complexities of hybrid educators working in university and school settings. They recognized hybrid educators were engaged in complex work and realized that different participants had various understandings of the academic and practitioner worlds. From these studies, the authors asserted the use of thirdspace could result in more consistency and transformative practices in teacher education programs.

\section{Thirdspace with Preservice Teachers}

From the studies I mention above, most authors asserted that future studies should work to understand how preservice teachers are impacted by the work within a thirdspace. The following will describe research that has analyzed the perceptions of preservice teachers and how the researchers sought to close the perceived gap between universities and schools. Within all these studies, participants spoke positively of the opportunity to collaborate with various colleagues including peers, mentors, classroom teachers, and university supervisors.

Embracing the collaborative nature of Zeichner's (2010) thirdspace, a study with teacher candidates, who were supported by mentor teachers within a school-university partnership, reported they appreciated the space to build relationships and converse with multiple people (Quesenberry et al., 2018). Adding on to this, teacher candidates in this study also stated they did follow their mentor teacher's lead in some areas but also felt they could bring in ideas from their coursework and share new ideas with their mentor teachers, noting that both parties were involved in the learning process. Furthermore, teacher candidates appreciated a space to see inaction, what they had been learning about in their coursework. Quesenberry et al. explained, "When field-based experiences include well-run, developmentally appropriate classrooms that reinforce and support the theories and practices that candidates learned in their university coursework, there are numerous benefits for TC growth" (p. 289). 
Greca's (2016) study encouraged teacher candidates to investigate inquiry learning within a "discursive" thirdspace during their time in classrooms in Spain. The researcher noted a perceived variance between theory and practice and created this space as Greca insisted ...teaching education programs should be intentionally designed to make the practicum a teaching experience that successfully integrates new theory with implicit conceptions. These programs should be spaces in which pre-service teachers can analyze and reflect upon what they see, believe, and actually do, in the light of the theoretical knowledge acquired. (p. 793)

The results from this study indicated preservice teachers felt empowered by the thirdspace but still struggled with fully integrating theory and practice. Therefore, additional support for preservice teachers, such as more time to develop knowledge in practice or even professional development, should be considered.

McIntyre and Hobson's (2016) study sought to develop a thirdspace where preservice teachers in England could interact with an external mentor, as they suggested this area of research is lacking. The authors asserted there can be a hesitancy for preservice teachers to honestly open up to their mentors and ask for clarification or support when they need it. This may be due to a fear of being judged or a concern that their mentor is also often an evaluator. Communication between the two parties mostly took place via text messaging, Facebook, email, and some phone calls. Three overarching findings were described from this study: negotiating the school cultures, developing their pedagogy within their subject matter (science), and overcoming isolation or building relationships in a community of practice. They suggested the thirdspace was the convergence of the beginning teachers' personal beliefs and experiences with that of the formal school culture. The implications from this study suggested preservice teachers 
should be approached with an understanding that they are still learning and growing, and future studies should consider spaces where they can engage in critical reflection and conversations with an external mentor, not an evaluative mentor.

These three studies all demonstrate how innovative practices in teacher candidates' field experiences can produce experiences that move beyond the traditional dichotomies that often play out in these circumstances. However, there is still more research to be done in this area.

\section{Teacher Learning}

As the world continues to evolve globally and reports such as Every Student Succeeds Act (ESSA) (U.S. Department of Education, 2017) are pushed forward, one must consider, how are teachers learning and what is happening to support them. Cochran-Smith and Lytle (1999) wrote about the "new teacher learning" coming forth in educational research at the time. They suggested all learners, including classroom teachers, bring prior knowledge to their new learning and are influenced by that particular social setting. Furthermore, "it is now broadly understood that teacher learning takes place over time rather than in isolated moments in time and that active learning requires opportunities to link previous knowledge with new understandings" (CochranSmith \& Lytle, 1999, p. 258). They suggested moving beyond knowledge being transmitted to teachers and instead allow for educators to construct knowledge of their practices through various experiences. Yet, nearly twenty years later, many educators are presented with one-day workshops or staff development meetings that continue to perpetuate a bad taste for professional development among educators (Bernhardt, 2015). Pervin and Campbell (2015) expand on this and suggested, "effective and lifelong teacher development depends on teachers taking ownership of their learning and having the capacity to develop and renew themselves" (p. 49). While the field of teacher learning and development is quite vast, a need for a small amount of 
background information was necessary to the development of this study. In order to narrow this down for the significance of this study, I will now focus on teacher learning within online settings.

\section{Online Learning Spaces in Education}

Numerous forms of professional development or professional leaning have been a part of educational contexts for many years. However, professional development can often be associated with a negative connotations, especially when initiatives are seen as a top down approach being pushed on teachers (Bernhardt, 2015; Carpenter \& Harvey, 2019). In the early 1990's more faceto-face teacher groups and learning communities were beginning to form and networking among teachers were considered valuable experiences (Lantz-Andersson et al., 2018). More recently, with advances in technology and social media spaces becoming a part of most people's everyday lives, online learning communities with a focus on teachers and education are becoming more prevalent (Kelly \& Antonio, 2016; Lantz-Andersson et al., 2018; Turvey \& Hayler, 2017). Prestridge (2019) suggested professional development relates to more formal top-down approaches where participants are given minimal choice in what they learn. On the other hand, professional learning may be better understood as self-directed learning that teachers are doing on their own time and to suit their own interests. This may be happening online or in other spaces. If an online learning space is to be considered a space for professional learning, it is imperative that studies are done to understand how teachers are using online spaces and how it is affecting their work in education. A comprehensive literature review of formal and informal online spaces was completed by Lantz-Anderson et al. (2018). This comprehensive review along with other research in this field helped me conceptualize and craft questions for my dissertation as well as the design of online learning space. 
Although top down professional development initiatives seem to not take into consideration the individual needs of teachers (Carpenter \& Harvey, 2019), self-directed learning through book studies and online communities among educators allow for "more collective shifts in understanding and adoption of innovations and reform across the teaching profession" (LantzAndersson et al., 2018, p. 303). However, it seems online groups are now more of an everyday experience for most educators and it is important to understand ways in which teachers are interacting in online spaces and how are these experiences are impacting their practices (Kelly $\&$ Antonio, 2016; Lantz-Andersson et al., 2018; Macià \& García, 2016; Turvey \& Hayler, 2017). An online learning space is a digital space across various social media platforms where educators can interact with one another synchronously or asynchronously. These platforms could include blogs, Facebook, Twitter, and Google Communities, to name a few, and can appear in private form or open access. Spaces are created and initiated in a number of ways including small groups by teachers themselves, educational companies or websites, school districts, spaces for a university course, or by educational organizations. The field of online learning spaces in education is really quite vast.

Referencing the comprehensive review of online spaces from Lantz-Anderson et al. (2018), 52 studies of formal and informal online spaces were studied from 2000-2018. Various theories were used in these studies including communities of practice, affinity spaces, grounded theory, constructivism, evaluation framework, or sociocultural theory. Furthermore, methods used to study these online spaces included qualitative, quantitative, and mixed methods. Data were obtained through multiple sources including interviews, surveys, participant observations, and online content analysis. The four most common findings from the studies in this review included: support and collegiality, exchanging new ideas and resources, professional practice, 
and supporting classroom practices. However, five studies reported specifically that not all exchanges were positive, and participants noted the exchanges seemed phony or lacked depth and critical interactions. In the following sections, I will take a closer look at the research regarding online learning spaces considering both the benefits and challenges.

\section{Benefits of Online Learning Spaces}

As research of online learning spaces continues to grow, a number of benefits have been shared through various studies. There is a strong need to study these spaces as many teachers are engaging in online learning spaces and it is not clear how these interactions are impacting their practices and professional learning. As Booth (2012) suggested, "scholars call for further research that will provide reliable evidence about how, when, and why online education communities do or do not support teachers' development of new knowledge and practices" (p. 2).

\section{Sharing Resources and Gathering New Ideas}

One benefit often reported in studies of online learning spaces is the ability to share resources and gather new ideas from various people and places worldwide in a rapid amount of time. In online spaces, educators often ask questions from other participants and share links and resources from personal sites including their own blogs or pay for product sites (Booth, 2012; Britt \& Paulus, 2016; Brown, 2007; Carpenter \& Krutka, 2015; Deryakulu \& Olkun, 2007; Duncan-Howell, 2010; Hur \& Brush, 2009; Kelly \& Antonio, 2016; Macià \& García, 2016; Powell \& Bodur, 2019; Prestridge, 2019; Ranieri, Manca, \& Fini, 2012; Visser, Evering, \& Barrett, 2014; Xing \& Gao, 2018). Within this sharing of ideas and resources, the collective engagement of various participants is often suggested as being a critical benefit of the online space. The more active the members, the more positive the interactions are suggested to be. 
Participants have reported they enjoy hearing a variety of perspectives from educators that have a wide range of teaching experiences. Xing and Gao (2018) reported, "large numbers of cognitive and interactive tweets in a given chat indicated that the participants actively contributed to the collaborative problem-solving process. Such process allows participants to gain new knowledge and skills that could be applied to their classrooms" (p. 15). The moderator and the reputation of the authors in the online spaces are also noted as important pieces of the collective with online groups (Booth, 2012; Ranieri et al., 2012).

\section{Improvement of Practices}

Some studies have indicated that participation in online learning spaces have directly impacted educators' practices in the classroom. In fact, participants from a study by Carpenter and Harvey (2019) reported, "93.1\% crediting their social-media-facilitated learning with leading to improvements in their teaching, and 58.3\% identifying related impacts on their students' learning" (p. 4). Prestridge (2019) concurred, "there is evidence of transferring what is gained online to curriculum appropriation as their engagement is focused on curriculum development and innovation" (p. 154). However, in most instances these findings have been self-reported through surveys and interviews. Therefore, this should be considered when presuming improvement of practices as a benefit of participating in online spaces (Bergviken Rensfeldt et al., 2018). While conversations and online spaces vary, studies indicated that the thinking aloud that happened through discussions online helped teachers reflect on their practices (Brown, 2007), develop a more critical stance on topics (DeWert et al., 2003), and helped teachers feel more confident in taking risks (Trust et al., 2016). Overall, participants felt they were exposed to new ways of thinking, new pedagogies, resources, strategies, and assessment practices that improved their teaching (Bergviken Rensfeldt et al., 2018; Brown, 2007; Carpenter \& Harvey, 
2019; DeWert et al., 2003; Duncan-Howell, 2010; Macià \& García, 2016; Prestridge, 2019; Trust et al., 2016; Visser et al., 2014).

\section{Collegial Support and Encouragement}

The affective benefits or emotional support in online spaces is well documented in literature among active participants as well as, "lurkers" those who often follow online spaces but do not consistently engage in discussions (Bergviken Rensfeldt et al., 2018; Booth, 2012; Britt \& Paulus, 2016; Brown, 2007; Carpenter \& Krutka, 2015; Chen, Chen, \& Tsai, 2009; Davis, 2013; Deryakulu \& Olkun, 2007; DeWert et al., 2003; Duncan-Howell, 2010; Hur \& Brush, 2009; Macià \& García, 2018; Powell \& Bodur, 2019; Prestridge, 2019; Ranieri et al., 2012; Trust et al., 2016; Visser et al., 2014). Respondents from a study by Davis (2013) described the affective benefits, "as a way to seek advice and ask for emotional support for frustrating classroom experiences or to deal with difficult students and/or parents, and to build relationships with other educators" (p. 7). Overall, participants felt engaging in online spaces can help prevent feelings of isolation and loneliness. Some studies even suggested that online spaces allowed participants to share things they did not feel comfortable discussing with people at their own school (Hur \& Brush, 2009; Macià \& García, 2018) and helped participants feel more confident allowing them to take more risks in their own schools and teaching (Booth, 2012; Brown, 2007; DeWert et al., 2003; Powell \& Bodur, 2019). The feeling of being connected with many people around the world and having a space to build relationships (Carpenter \& Krutka, 2015; Chen et al., 2009; Trust et al., 2016; Visser et al., 2014) were other reported benefits as to why teachers participate in online spaces. In some instances, educators even went further and described their participation in an online space as a way to help them give back to the profession and foster the profession of education (Booth, 2012; Prestridge, 2019). To expand upon this 
further, Prestridge (2019) sought to understand more about the profiles of educators who engaged in online spaces and found various identities. One in particular is the vocationalist. A vocationalist was described as one who, ...engages in social media as a professional learning process to build the profession. Their social reasoning is to engage as a member of a community of learners and their interactivity reasoning is to contribute to the growing body of new knowledge. (p. 154) Furthermore, participants of online spaces also appreciated the diversity of ideas from various perspectives (Chen et al., 2009; Macià \& García, 2018; Trust et al., 2016), as well as the opportunity to talk with like-minded educators when they felt that was lacking at their own schools.

\section{Individual Needs}

The final theme of benefits reported from various studies of online spaces included the ability to meet the individual needs of participants. As I previously stated and is documented in the literature, professional development initiates are often not tailored towards individual teacher needs (Bernhardt, 2015). However, since online spaces are often sought out by teachers from their own motivations, engagement in these spaces often helps them build their understanding of topics and questions that are of interest to them personally (Booth, 2012; Brown, 2007; Carpenter \& Krutka, 2015; DeWert et al., 2003; Duncan-Howell, 2010; Hur \& Brush, 2009; Lundin et al., 2017; Trust et al., 2016; Zhang \& Liu, 2019). According to Zhang \& Lui (2019) "teachers were more likely to engage in online learning activities if they believed that online learning task [sic] were relevant to their teaching practice and professional development" (p. 152). Statements similar to this were echoed in other studies of online spaces as well. Educators felt the online spaces allowed them to ask questions specific to their needs and discuss topics 
relevant to them (Booth, 2012; Duncan-Howell, 2010; Hur \& Brush, 2009; Zhang \& Liu, 2019). Developing a professional voice was also noted as a benefit in some studies (DeWert et al., 2003; Lundin et al., 2017; Trust et al., 2016). In a study of a Facebook online learning space, Lundin et al. (2017) reported, "Our analysis shows that for some members extensive professional identity work takes place in the studied FB-group, providing these teachers with the possibility to learn and develop in professionally relevant manners" (.p. 26)

As online learning spaces become more prevalent in education, understanding the motivations and benefits teachers perceived when participating in them is important. Above, I have shared four major themes common across numerous online learning spaces from the last two decades. I will now address the challenges and drawbacks reported from the literature of online learning spaces.

\section{Challenges of Online Learning Spaces}

While there are many benefits reported in studies of online learning spaces, not everything regarding teacher's use of these sites is "sunshine and roses." Bergviken Rensfeldt et al. (2018) cautioned, "empirical literature to date has tended to frame teachers' uses of social media as relatively straightforward and unproblematic" (p. 231). From the studies of online spaces, the reported drawbacks or challenges faced by educators included: time, a lack of critical conversations, and the quality of interactions with others.

\section{Time}

The freedom of time and getting to the online space at one's own convenience was reported as a benefit of engaging in online learning spaces, but the lack of time perceived in the profession of education was seen as a challenge to participants when engaging in online learning spaces (Bergviken Rensfeldt et al., 2018; Britt \& Paulus, 2016; Carpenter \& Harvey, 2019; 
Carpenter \& Krutka, 2015; Duncan-Howell, 2010; Powell \& Bodur, 2019; Xing \& Gao, 2018). In fact, the word, "overwhelming" appeared quite frequently in reported findings as teachers felt it was hard to keep up with all of the posts and discussions taking place in online learning spaces. According to Xing and Gao's (2018) study of Twitter, “participants may have to exert extra effort to identify the tweets that are relevant and important" (p. 15). Some teachers even felt pressure to respond to comments posted in online learning spaces and neglected other duties or felt the space took away from their planning periods (Carpenter \& Harvey, 2019; Powell \& Bodur, 2019). Furthermore, it is often celebrated when teachers take their own time to engage in online learning spaces and are motivated to seek their own professioanl development. Bergviken Rensfeldt et al. (2018) cautioned teachers are spending unpaid time engaging in online spaces, thus, free labor, and suggested that teachers may be spending too much unpaid time in online learning spaces. While both a benefit and a drawback, time continues to be a prevelent drawback in education and online learning spaces.

\section{Lack of Critical Conversations}

While educators often reported a benefit of online learning spaces as a place to engage in conversations with others and a place to seek out resources and new ideas, one drawback reported about online leaning spaces was the lack of critical conversations taking place (Bergviken Rensfeldt et al., 2018; Carpenter \& Harvey, 2019; Carpenter \& Krutka, 2015; Kelly

\& Antonio, 2016; Xing \& Gao, 2018). More specifically, Bergviken Rensfeldt et al. (2018) noted this pitfall as well,

Rather than being a site of dialogue and discussion, the dominant communication patterns were notably one-way and devoid of substance, with only occasional elaborated 
discussions. Moreover, most users were consuming content with little or no reciprocal exchange of their own knowledge. (p. 246)

In addition, Carpenter and Harvey (2019) reported cases of teachers feeling offended when one would attempt to engage in critical conversations along with instances of people being too polite. Also related to this, is the report of homogeneous comments in the conversations of like-minded participants where agreeing is common and differing perspectives that could help push one another's thinking is not always the norm of online spaces (Bergviken Rensfeldt et al., 2018; Carpenter \& Krutka, 2015; Trust et al., 2016). Kelly and Antonio (2016) suggested a lack of trust among participants in large open social media sites could be contributing to the lack of critical conversations and support their finding, "the results show scant evidence of online support for reflection on practice, feedback about practice or modelling of practice, all forms of support that the theory stresses as important for teachers" (p. 149).

\section{Interactions with Others}

Educators have reported that they appreciated being able to engage in conversations with other educators from a variety of backgrounds. However, studies of online learning spaces also indicated the interactions with others as being a drawback to the online conversations (Bergviken Rensfeldt et al., 2018; Carpenter \& Harvey, 2019; Duncan-Howell, 2010; Kelly \& Antonio, 2016; Macià \& García, 2018). This theme encompasses various findings reported from online studies. Duncan-Howell (2010) found some participants reported they did not like certain people in the online spaces controlling the conversations and "pushing a personal agenda" (p. 338) and a concern for supporting commercial products or advertisements for personal pages, including resources on teacher sales websites, being promoted on social media sites took away from the conversations that could be taking place (Bergviken Rensfeldt et al., 2018; Kelly \& Antonio, 
2016; Macià \& García, 2018). Carpenter and Harvey (2019) specifically noted, "the dissemination of teaching and learning materials of dubious quality via Pinterest, participants in our data expressed frustration with other educators sharing problematic teaching practices via social media" (p. 7). In other findings, teachers were made to feel inferior when they read what others were doing in their classrooms and were left feeling like they were not doing enough. In addition, there was an unease for people mostly concerned with their own personal growth and not giving back to the collective of the community (Carpenter \& Harvey, 2019).

The benefits and challenges associated with online learning spaces have been presented. It is noted that there is overlap among these findings from various studies and reported benefits of online learning spaces can also be seen as challenges to participants. The lack of critical conversations and superficial sharing of ideas or advertisements points to a need to encourage more critical discussions and gets at the theory and practice gap I mentioned earlier in the chapter. In addition, while there were various theoretical frameworks and methodologies from these studies including case studies, surveys, and interviews, it was difficult to find studies that used the lens of thirdspace.

\section{Conclusion}

Within chapter two, I presented a discussion of a perceived gap in education among practices and theories as well as a history of thirdspace theory and how it is being used in education. Furthermore, I shared studies regarding student teachers, university supervisors and mentor teachers followed by a discussion of teacher learning. The chapter concluded with a review of the literature on the benefits and challenges of online learning spaces. All these aspects helped inform the development of an online Facebook group I created for teachers as a space for learning, critical discussions, and reflections. 


\section{CHAPTER III: METHODOLOGY}

In this chapter, I outline my research design, theoretical framework that guided this study, and the methods I employed for data collection and analysis. Employing action research for my methodology, I sought to understand how an online thirdspace could support preservice and inservice teachers to move beyond traditional approaches to mentoring and how an online space could provide a place for critical reflection and conversations among teachers. The following questions guided my study:

1. In what ways can an online collaborative thirdspace support in-service and preservice teachers' learning? How do teachers navigate connections/disconnections across coursework and classroom practices? How do teachers critically reflect on their own classroom practices?

2. What interactions occur among in-service and preservice teachers when they engage in a thirdspace? How do participants construct understanding related to knowledge of teaching, knowledge of learners, and knowledge of subject matter and curriculum in a thirdspace? What roles do participants assume within the online space?

3. How do teachers describe their experiences with an online thirdspace? How do participants reflect on their own learning and professional agency?

The questions that I crafted for this study added to the field of education because previous literature suggested a need to study small closed social networking sites (Kelly \& Antonio, 2016) and thirdspace theory suggested a need to study a place where connections and disconnections between two spaces can be explored for reflection and renewal (Cuenca et al., 2011; Forgasz et al., 2018; McDonough, 2014; Taylor et al., 2014; Williams, 2014). Also, using the framework for understanding teaching and learning (Bransford, Darling-Hammond, et al., 2005) as part of 
question two helped me examine how participants were or were not making connections between theory and practice and understand the types of discussions happening among teachers in this online space. Additionally, while it is known that teachers engage in online learning spaces, it is not yet known how these spaces influence their work in classrooms (Kelly \& Antonio, 2016; Killeavy \& Moloney, 2010; Macià \& García, 2016; Turvey \& Hayler, 2017). This study helped to examine how discussions in an online space can inform teaching practices in the classroom

\section{Research Paradigm-Constructivism}

As a researcher, it is important to be aware of the beliefs that I hold true about the world and how this has influenced my research. Philosophical positions ask researchers to consider their ontology, or beliefs about how reality is constructed; and epistemology, or how knowledge is gained; as well as methodology, or how we investigate knowledge (Maxwell, 2013). A paradigm, as defined by LeCompte and Schensul (1999) "constitutes a way of looking at the world; interpreting what is seen; and deciding which of these things seen by researchers are real, valid, and important to document" (p. 41).

This study is grounded in a social constructivist paradigm, as I believe individual realities are constructed through our own experiences and are influenced by people and settings we encounter (Creswell, 2014; LeCompte \& Schensul, 1999). Creswell (2014) described this as, "individuals seek understanding of the world in which they live and work" (p. 8). Meanings constructed by participants within this paradigm are often shifting and influenced by the social, political, and cultural characteristics of those around them. In this study, I sought to understand what and how knowledge was constructed during online interactions among participants, while at the same time value the historical, cultural, and social norms that have impacted the participants' lives. I understood that each participant brought their own lived experiences into 
our interactions and discussions. These impacted the way we constructed meaning as we interacted in the online collaborative thirdspace. I examined the interactions among educators within this online setting to understand how participants were conversing about teaching and learning. More specifically, acknowledging times of connections to coursework and/or instances of critical reflection on teaching practices. Furthermore, it was my role as a researcher to understand the perspectives of participants regarding how they felt this online space impacted their teaching as well as understand how they interacted in this online thirdspace. In addition, my long-standing commitment to the school district and this particular Professional Development School (PDS) partnership was considered, as I interpreted the findings through my own personal lenses, which will be addressed later in the chapter when I describe my positionality.

\section{Theoretical Framework}

In this section, I will describe the theoretical frameworks that guided the development and facilitation of this thirdspace. I will describe the components within the framework for understanding teaching and learning (Bransford, Darling-Hammond, et al., 2005) as well as discuss teacher agency, as I sought to provide a space where novice and experienced teachers could enact agentic principals to encourage critical reflection on their teaching.

\section{Framework for Understanding Teaching and Learning}

A set of guiding principles is common in many professions, such as the medical field, to ensure that the people served, such as medical students, are receiving quality instruction no matter where they are served. In the profession of education, Bransford, Darling-Hammond et al. (2005) suggested that teachers should have: knowledge of learners and their development, knowledge of subject matter and curriculum, and knowledge of teaching. One aspect informing my research was this framework for understanding teaching and learning. Within this 
framework, teachers have knowledge of learners, content and curriculum, and teaching. It is suggested that these three areas should be part of any educators' preservice teacher education and continue to impact practicing teachers' philosophies and pedagogies. I explore each area of knowledge below.

\section{Knowledge of Learners and Their Development}

Within the umbrella of knowledge of learners three main ideas are pertinent: learning, human development, and language (Bransford, Darling-Hammond, et al., 2005). Knowledge in this area includes how learners develop not only in schools but also outside of schools in certain social contexts as well as how their language develops. A teacher must be in-tune with the learners' abilities, motivations, cultural background, and needs. Assessment is one avenue for learning about students. The community of learning a teacher sets up is also an important part of this type of knowledge. Bransford, Darling-Hammond et al. (2005) argued that "students learn more effectively in contexts where they can use the resources of their peers and where they believe their efforts matter to the welfare of the group" (p. 33). Individual as well as overall developmental patterns of students are critical for the planning and implementation of effective instruction. This planning should also include a thorough understanding of language development including non-standard and academic language. Furthermore, this knowledge of learners should ultimately be applied to the kind of instruction a teacher provides.

\section{Knowledge of Subject Matter and Curriculum}

The next part of the framework for understanding teaching and learning, consists of understanding curriculum and subject matter. As suggested by Bransford, Darling-Hammond et al. (2005) this includes, "the curricular understanding that enables teachers to organize the subject matter and skills they will teach in light of the goals they are aiming for. The focus here 
is on what to teach and why" (p. 34). The major goals of this piece of the framework include educational goals and purposes for skills, content, and subject matter. Standards and curricular goals are both critical components of this type of knowledge. It is common for schools to provide teachers with curricular sets and materials, but teachers should not simply follow the directions printed in these materials. According to Bransford, Darling-Hammond et al., teachers need to understand how the curriculum and their knowledge of learners in their particular setting can be interwoven effectively. In addition, a commitment to the social purposes of schooling as well as providing an equitable experience for all learners in a democratic educational system are essential to curricular knowledge.

\section{Knowledge of Teaching}

The third element in the framework involves a general knowledge of teaching. The main ideas of this section include teaching subject matter, teaching diverse learners, assessment, and classroom management (Bransford, Darling-Hammond, et al., 2005). Pedagogy in this context according to Bransford, Darling-Hammond, et al. (2005), "involves the skillful teaching that enables all learners to access the curriculum. The overall goal is to teach in ways that optimize learning for all students" (p. 35). A variety of strategies are necessary for teaching subject matter to make it relevant and accessible for learners. Teachers have knowledge of student understandings and misunderstandings in each subject area. Diversity is present in all classrooms in different ways. Knowledge of culture and learning differences, as well as how to provide scaffolds for students' success are pertinent to be an effective teacher. In addition to informing their own teaching practices, both formative and summative assessments should permeate the curriculum, so teachers can provide feedback and enhance the performance of individual learners. 
Classroom management is often a significant concern for novice teachers. However, what some educators forget is that, "effective classroom management starts with the creation of curriculum that is meaningful to students and with teaching that is engaging and motivating" (Bransford, Darling-Hammond, et al., 2005, p. 37). Within the framework, researchers suggested rules and regulations alone will not manage a classroom. A safe community, purposeful learning activities, and structure help create a setting where students desire to engage and learn, thus providing a context with minimal disruptions. Teachers are well equipped with multiple strategies for various settings and learners in order to create a climate of respect and rapport.

\section{Agency}

While these tenants of teacher education are considered important, Fairbanks et al. (2010) asserts that just having this knowledge is not enough to encourage thoughtful teaching. Therefore, also informing my design of an online thirdspace for teachers was a consideration of agency. Within the thirdspace I conceptualized, I sought to engage participants in online collaborations that encouraged professional agency. Although this is debated, Priestley et al (2013) suggested agency is not something that one simply has within them. Instead agency can be thought of as "something that is achieved through specific contextual conditions" (p. 188). By developing this online thirdspace, I intended to provide a specific context for critical conversations and developing a sense of agency, as I began to do through my roles in teacher education and interactions with other educators discussed in chapter one.

The definition of agency that I most closely aligned with this study comes from Toom et al. (2017):

professional agency is manifested in having the understanding and will to collaborate, build a community, develop through shared professional work for the best of student 
learning, solve problems and challenges together via discussions, utilize feedback received from the peers, support others as well as the ability to be supported. (p. 127) From this and my own experiences, I interpret professional agency as recognizing critical reflection and opportunities for learning in one's own practices. This can be achieved through our own self-reflections or among interactions with others. This may also include conversations and experiences with others, or ourselves, that make us feel uncomfortable and move beyond polite, surface level conversations because we are too worried about hurting another's feelings (Brown, 2018).

When developing this space, it was important to know about previous studies that have sought to understand more about teacher agency. When reviewing the literature, I considered their findings and implications for the future. While there is much research on teacher agency, I will share a few studies that impacted the development of the online thirdspace I created for this dissertation research. Priestley et al. (2016) asserted, "agency is always enacted in a concrete situation, therefore both being constrained and supported by cultural, structural and material resources available to actors" (p. 138). Teachers were likely to demonstrate agency in instances where they felt insufficient in their teaching and knowledge, when they felt the quality of the social interactions was impactful (Toom et al., 2017). Therefore, agency developed as teachers moved from a critical resistance to a shift in understanding and more constructive approaches to changes they were first opposed to (Sannino, 2010). Lasky (2005) asserted agency can happen in social contexts, therefore the sociocultural approach to this study was an important tenant of developing this space. Our own lives and beliefs may influence how we interact but when individuals develop more agentic practices, they can break through traditional societal constraints and push back against practices that have long standing traditions to counter the 
dominant discourse (Priestley et al., 2013). While brief, this consideration of the literature on teacher agency was an important part of the development of the online space, as I sought to provide a space for preservice and in-service teachers to engage in critical conversations and reflection.

\section{Researcher Positionality}

My interest in this research has evolved from being actively involved in the Professional Development School (PDS) partnership for 13 years and has been shaped by my experiences as an intern, mentor, teacher, and university faculty. Maxwell (2013) acknowledges this and suggested, "Any view is a view from some perspective, and therefore is shaped by the location (social and theoretical) and 'lens' of the observer" (p. 39). My journey began as an intern and has continued as a mentor, doctoral researcher, classroom teacher, and university faculty. These multiple roles have given me a unique perspective in the field of education. My vision of this thirdspace was influenced by personal experiences that I interrogated in chapter one. I recognized that it was difficult for me to step out of the traditional roles and expectations that often play out in teacher education. I have been a part of this system since I was a young child. Fairbanks et al. (2010) acknowledged that and suggested this system places numerous demands upon teachers within the political realm, community influences, and school policies, to name a few. As a teacher who desired to grow and change, I found through my own experiences, stepping out of traditional roles and social spaces that have been in place for long periods of time can be difficult to navigate on my own.

Along with this is my view of collaboration and critical conversations with colleagues. As mentioned in chapter one, I longed for more critical conversations with my mentors and peers early in my career and still to this day appreciate honest conversations with colleagues. Collegial 
coaching, as described by Garmston (1987) highlights what I have longed to achieve as a professional educator, "the major goals of collegial coaching are to refine teaching practices, deepen collegiality, increase professional dialogue, and to help teachers think more deeply about their work" (p. 20). Ultimately, with a goal of engaging in reflective self-coaching to improve teaching. In the online thirdspace, I shared with participants an expectation of the group was to engage in critical dialogue with the hope that we would challenge ourselves to think critically about our teaching practices and consider the theories that influence our practices. I believe that we as humans should be able to have honest conversations with one another to help each other grow. Some educators that I trust the most and learn the most from are the ones that have been honest with me and challenge me to think deeply about the decisions I make as a teacher. It is with a few close colleagues that I feel I can engage in open conversations where we say what we are thinking and feel comfortable agreeing and disagreeing with one another. I envisioned collegial coaching to occur in the online thirdspace.

The participants in this study were colleagues within the district, some were friends of mine, and others were workplace collaborators. As colleagues, we regularly participated in professional development activities within and outside of the district. Due to this, Banks (1998) would define my position as an indigenous insider of the school culture; meaning I am an active member of this district's culture and have an insider's perspective of the happenings of the schools within the district and the Professional Development School (PDS). Moreover, I began my career in education as a PDS intern while an undergraduate, which gave me a unique perspective of the PDS program from three different positions: intern, mentor, and most recently researcher. While I was engaged in this study and data analysis, I encountered times where my knowledge of a colleague influenced my perceptions of the data. I noted specifics times of this in 
my researcher journal and worked hard to remember to let the data speak for itself.

Conversations with my committee chair also helped me recognize times when my own knowledge was affecting my analysis.

\section{Research Design}

In order to understand the role of a collaborative online thirdspace with in-service and preservice teachers, a qualitative approach was employed for this study. Hatch (2002) reminds researchers, "Qualitative studies try to capture the perspective that actors use as the basis for their actions in specific social settings" (p. 7). I sought to understand the potential of providing an additional collaborative space for preservice teachers and in-service teachers to interact with one another. The embedded nature of this thirdspace in a specific context with a small sample of teachers called for a qualitative design to examine the process through a data-driven approach.

\section{Action Research}

Action research was my methodology in this study as I designed, facilitated, and participated in a thirdspace where theories and practices could be critically explored within a collaborative online community. Participants used a Facebook platform for asynchronous communication during the spring 2019 semester from January through April. Kemmis and McTaggart (1988) defined action research as:

a form of collective self-reflective enquiry undertaken by participants in social situations in order to improve the rationality and justice of their own social or educational practices, as well as their understanding of those practices and the situations in which the practices are carried out...The approach is only action research when it is collaborative, though it is important to realize that action research of the group is achieved through the critically examined action of individual group members. (pp. 5-6) 
Action research was coined by John Collier as he sought to support Native American communities in 1930's-1940's. However, because of his work in social psychology and a desire to include participants in a reflective cycle for social change, Kurt Lewin is often credited for developing action research in the 1930's-1940's after he fled Nazi Germany. The field of education was introduced to action research in the 1950's through a professor at Teacher's College, Stephen Corey. He asserted, "educational change will not take place unless practitioners are involved in developing curriculum and instructional practices, drawing on the experiential knowledge they gain through inquiry" (Efron \& Ravid, 2013, p. 6). I agree with this contention as the traditional hierarchies in mentoring and student teaching (Wang \& Odell, 2007; Zeichner, 2010) have been in place so long, it can be difficult to see a different approach. In addition, teachers working in their own classrooms do not always have time for critical reflective conversations within the time constraints of their day and traditional professional development models (Bernhardt, 2015; Carpenter \& Harvey, 2019).

Action research was well suited for this study as Hatch (2002) suggested, "It is undertaken for the sake of investigating practice, usually in concert with those working on the front lines, and improving practice based on what is discovered" (p. 31). In chapters one and two, I argued that various approaches beyond traditional student teaching experiences should be explored for different opportunities for preservice and practicing teachers. I also considered the research on teacher professional development and agency when planning and enacting this space. The use of action research as my methodology aligns with my research paradigm of social constructivism because as Efron and Ravid (2013) asserted, action researchers "are capable of making informed decisions based on their own inquiries and able to assume responsibility for their own research-based actions" (p. 7). Engaging participants in action research permitted them 
the opportunity to understand how an additional space for collaboration was beneficial for them and encouraged critical reflection in order to support their professionalism. In addition, my findings are unique to this study because of the participants involved and their own views of the world that they brought to the study. Although the findings from this study can be transferred to similar contexts, it may not be possible to generalize to all teachers.

\section{Research Setting}

The site for this research was chosen based on convenience (Merriam, 2009). A convenience sample is employed when location and availability are a factor. Although the site selection was based on convenience, participants were chosen purposefully. This is discussed further in the section, participant selection criteria. I have worked in this district as a first-grade teacher for 14 years, and I am a doctoral student at the partnering university. I was an intern as an undergraduate in the PDS program and have served as a mentor for 12 interns in the last 14 years. Eleven schools comprise this district: one preschool, six elementary, two intermediate, and two middle schools. Two hundred fourteen teachers serve the 3,633 students and $57 \%$ of the students in the district are considered low income. Ninety-nine percent of the teachers are white and $89 \%$ of the staff are females and there is an $88 \%$ retention rate among teachers. The students are $90 \%$ White, $1 \%$ Black, $3 \%$ Hispanic, and $6 \%$ are other or two or more races (Illinois State Board of Education, 2018).

At the time of the study, the local school district and university had been partners for 18 years, graduating over 500 interns (Pekin Public Schools, 2018). The website purports a yearlong immersion in the school district and indicates an in-depth experience for interns. During the fall semester, interns (preservice teachers) were in classrooms two to three days per week while taking senior year university methods coursework on site. Some courses invited teachers to 
interact and other courses were designed just for interns. During the following spring semester, interns were completely immersed in their assigned classrooms during the student teaching semester, gradually taking over all areas of teaching. Mentor teachers and interns were paired by the university site coordinator. These pairings were made using interviews and online questionnaire forms completed by both parties. During the last few weeks of the semester, student teachers were moved to another grade level placement, so they could experience some time in a different setting and grade level.

\section{Professional Development in the District}

Teachers in the district and preservice teachers from the PDS program engage in professional development via monthly school meetings, grade level curriculum planning and reflection meetings four times a year, as well as school-based and district-based early release improvement days. Teachers are often asked to provide input via Google forms to suggest ideas and activities to engage in during these times. Teachers typically choose from a predetermined list of options for some meetings. In other instances, open-ended responses are sought by the district where teachers can name specific topics and the most suggested ones are then chosen. At the meetings, teachers are assigned which sessions to attend. In addition, teachers are asked to give feedback after each professional development time in order for coaches and administrators to plan for future learning times together. While there is some input from teachers that is considered, it can still be difficult to meet the specific needs of individual teachers when there are over 200 teachers in the district. Furthermore, teachers rarely have unstructured time to talk to one another about topics of their choosing, instead conversations among teachers are guided by the facilitators' questions and plans during the sessions. 


\section{Participant Selection Criteria}

Participants for this study were selected based on their willingness to participate and convenience (Merriam, 2009). As the name implies, a convenience sample is selected based on location, accessibility, funding, and time. A typical sample was chosen purposefully as this site was specifically selected for research. Participants had to be current classroom teachers employed by the district or preservice teachers completing their student teaching semester in a mentor's classroom in the Professional Development School (PDS). Notification of the study was presented to employees in the district in fall 2018 via email to all certified classroom teachers and PDS interns. Included in the email was a brief letter from me and slide show video created by me describing the study, the online space, and the expectations of the participants (see Figure 1). Interested candidates were then asked to complete an online form to obtain contact information. Informed consent was obtained via an online form provided through Qualtrics (https://www.qualtrics.com). 


\section{Figure 1}

\section{Participant Recruitment Slide}

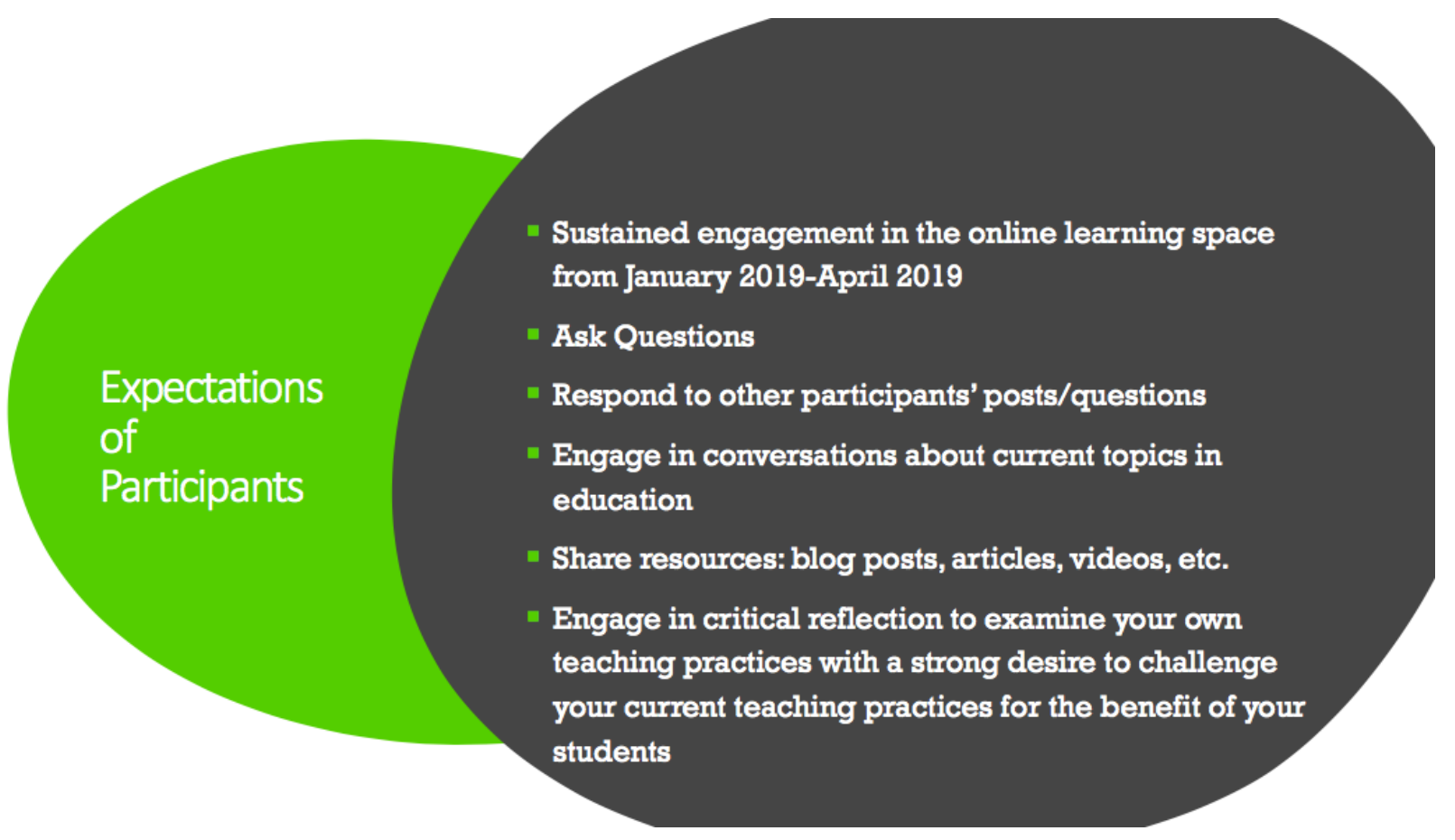

Since this study included classroom teachers, those teachers who were not already mentoring an intern were given priority in the selection of participants. In my initial proposal, I thought I may need to exclude some classroom teachers who were already mentoring interns in the PDS program, because previous studies (McIntyre \& Hobson, 2016; Nafziger, 2006) have found that teacher candidates were hesitant to communicate openly when they felt other participants, perhaps a mentor, were evaluating them. However, there were no instances of mentor and intern teams among those who completed the initial questionnaire.

A total of nine educators, seven classroom teachers (including myself) and two preservice teachers, chose to participate in this study. Initially the study consisted of three teacher candidates who completed the study interest form online and gave informed consent. However, after multiple emails were sent, one teacher candidate did not reply and therefore was not invited 
to join the online space. Of the classroom teacher participants, there was one kindergarten teacher, four first grade teachers, one primary special education teacher, and one fourth grade teacher from four different schools within the district. The two interns were working in a second and third grade classroom from one school. There was a wide range of years of experience including teachers in their first year of teaching and those with up to 15 years of teaching. The majority of teachers in the study had taught anywhere from 11 to 15 years. Two teacher participants had chosen teaching as a second career later in their life and two others had left the profession for a short time to care for their own children at home. The two interns were of typical college age and finishing their senior year coursework at the partnering university within the PDS program. Table 1 displays the demographics of participants.

\section{Table 1}

Participant Demographics

\begin{tabular}{cccc}
\hline Name & Position & Grade & Years of Experience \\
\hline Anna & Teacher & First Grade & $0-2$ \\
Elizabeth & Teacher & Kindergarten & $11-15$ \\
Gretchen & Teacher & Fourth Grade & $11-15$ \\
Laurie & Special Education & Second and Third & $11-15$ \\
Teacher & Grade & $11-15$ \\
Lavendar & Teacher & First Grade & $11-15$ \\
Lyn & Teacher & First Grade & 0 \\
MaryAnne & Preservice Teacher & Second Grade & 0 \\
Nicole & Preservice Teacher & Third Grade & \\
\hline
\end{tabular}




\section{Online Site}

The online space began during mid-January 2019 and concluded at the end of April 2019, lasting approximately four months, during the student teaching semester for interns. The actual site of this study was virtual, taking place within a secret group via Facebook. Facebook was chosen for this study because it is a platform that many people engage with daily and time is often seen as a commodity in education (Davis, 2013; Ranieri et al., 2012). Previous studies that implemented online learning communities suggested small private groups on Facebook need to be studied more carefully (Kelly \& Antonio, 2016). In my own personal use, I have seen teachers frequently engaging with "educational pages" on Facebook. For example, the educational application, Seesaw, has a Facebook page for each grade level and first grade alone has over 6,000 members and sees numerous posts and comments each day. These engagements come from administrators of the site as well as members and teachers asking questions to other members. Moreover, before Davis (2013) began a study of online learning spaces, a survey was conducted and $65 \%$ of participants named Facebook as their preferred online learning space. It was my hope that using this platform would encourage participant engagement, as they may be inclined to respond to posts as they scrolled through the newsfeed potentially on a daily basis. Therefore, not having to use any additional social media sites for engagement. Since a secret group was established online, no outside participants were able to interact in the group or even see the group on Facebook. Facebook defines this type of group as a "Secret Group" where only members can find the group, see who is in the group, and see what is posted by participants. Permission was secured from the university's Institutional Review Board (IRB) to use Facebook as the online platform. 
Discussions in the online group began with participants introducing themselves in order to build a rapport with one another. Initial posts were created by me or other participants and participants then had the option to react, comment, or reply to one another via online discussions. Throughout the study, I kept a spreadsheet of quantitative data to include the number of posts, reactions, and broad topic overviews from the online learning community. Thirty-five posts were made during the four-month discussion group and 177 comments and 39 reactions (likes or loves) were recorded and analyzed. An overview of this will be presented along with the findings in chapter four. Children's literature, classroom examples, reading, technology, and social justice were among the common topics discussed in the thirdspace. These interactions will be more thoroughly discussed in the findings chapter.

\section{Data Collection Methods}

In any qualitative study, specifically action research, a single source of data would not give a thorough picture of a phenomenon occurring within a setting. Multiple sources must be considered to fully understand the complex processes of the population being studied (Hatch, 2002; Merriam, 2009). In order to better understand the intricacies among participants within the online thirdspace, various data sources were obtained including observations of online posts, interviews, questionnaires, and a reflexive journal in which I recorded my thoughts as the space was happening. This included observations I documented among participants in the space and changes made to the initial proposal based on the online interactions and technological encounters I did not expect. As I analyzed these data, I worked to understand how each one of the sources related to the others giving a comprehensive view of the online space. 


\section{Questionnaires}

Questionnaires were distributed to all participants, both classroom teachers and preservice teachers to answer via the IRB/university approved platform, Qualtrics (https://www.qualtrics.com) (see Appendix A). Two separate pre-study questionnaires were crafted; one for classroom teachers and one for preservice teachers. Both had similar questions asking demographic information about the participants such as number of years they have taught, grade level(s) taught, and how many interns and student teachers they have hosted. Preservice teachers were not asked to name their years of experience teaching or name grade levels taught. Instead, they were asked to list all grade levels they had experiences in previously. In addition, I also asked for participants' understanding of the role of a mentor along with questions related to their hopes and dreams for the online thirdspace and why they chose to join the study. Previous research from Zhang and Lui (2019) used a pre-study survey to understand participants' desires for the online space and knowing why they joined the space can be beneficial for the online community.

Halfway through the study I felt it was necessary to include a mid-study questionnaire in order to gain a better understanding of how the participants were engaging with the online space and what else they wanted during the next two months (see Appendix B). This was not originally included in the proposal but was added to better fit the needs of the participants. This is typical in action research as participants' input is a vital part of understanding the unit of analysis through cycles of action and reflection (Hatch, 2002). The questions in this questionnaire asked participants how well they were enjoying the space, how much they felt they were learning from the online posts, and what other changes or adjustments they would like to see made. 
At the end of the online learning community, participants were asked to complete a questionnaire to reflect on their participation in the online thirdspace (see Appendix C). I asked participants to describe their experiences, describe what they felt they learned in the group, identify posts they found to be significant to them personally within the online space, describe any barriers they encountered, suggest changes for future groups, and reflect on times they felt empowered or challenged by the online discussions. The final question on the post-study questionnaire asked participants if they were willing to be interviewed regarding their experience in the study. Exploring how the participants perceived the experience in the online thirdspace was important to help me answer the research questions as well as the implications of this study. As I discuss below, I observed the online environment, however, those observations were filtered through my own worldview and perceptions. The use of questionnaires, both mid-study and endof-study, helped me understand how the participants experienced the online thirdspace that I was not able to observe from the online discussions and answer research questions one and three.

\section{Observations}

Typically, observations are completed by spending time in the participants' setting. Since this was an online setting, I observed the online interactions among participants virtually. Merriam (2009) says observations are beneficial because "observational data represent a firsthand encounter with the phenomenon of interest rather than a second-hand account of the world obtained in an interview" (p. 117). However, my role was not just that of an outside observer, instead I was a participant observer (Merriam, 2009). In this role, I was a learner, mentor, and classroom teacher actively engaging in the online posts. While observing the space online, I kept notes in my journal on the following things: identifying active participants, topics 
being discussed, discussions regarding theory and practices, evidence of reflection, instances of developing agency, and discussions about shifting practices.

Exploring these ideas helped me understand if the online thirdspace with teachers could lead to new possibilities for preservice teachers as they transition from university coursework to placements in a classroom setting and to study in-depth reflective practices with teachers. Observations of the online space also helped me address research questions one and two. I remained flexible in this observation process and open to ideas that emerged that I may not have anticipated. One aspect I did not anticipate was the low participation among preservice teachers. I will discuss this further in the findings section. Although I coded these online discussions later, as I participated in the online learning community, I kept my observational notes in my reflexive journal. As noted previously, my positionality stems from my own personal experiences in my various roles in education so a reflexive journal helped me keep track of my thinking and be aware of this position.

In addition, numerical data of the online posts were collected and recorded on a spreadsheet. The number of posts, comments, and likes were recorded during the study. After the study, this numerical data was examined more thoroughly to consider which posts had high participation, and high comments. This data will be presented in the numerical analysis section of chapter four.

\section{Interviews}

Interviews were conducted in May 2019 with those participants willing to be interviewed as indicated on their post-study questionnaire. Participants had the option to participate in a faceto-face interview or an interview via an online setting such as Skype or Zoom. Often times an interview can elicit thoughts and beliefs of participants that were not observable in the online 
setting (Merriam, 2009). Or as Hatch (2002) suggested, "qualitative researchers use interviews to uncover the meaning structures that participants use to organize their experiences and make sense of their worlds" (p. 91). A semi-structured, or otherwise coined formal (Hatch, 2002), interview approach was taken when meeting with participants (see Appendix D). Including interviews as a data source helped me answer research questions one and three. The interview included questions that were developed ahead of time as a guide for the researcher. These questions were open enough to elicit a conversation but were flexible to allow for further questioning based on the responses of participants (Hatch, 2002; Merriam, 2009). This flexibility also aligned with the constructivist paradigm I employed during this study (Hatch, 2002). When forming interview questions, I was careful to create open-ended questions that I hoped made participants feel comfortable sharing their stories. Often times participants feel the researcher is looking for the "correct" answer, therefore, I wanted to create questions that allowed for elaboration and further probing as needed (Hatch, 2002).

As I mentioned previously, the final question of the post-study questionnaire asked participants if they were willing to be interviewed regarding their experience in the study. Five participants, classroom teachers only, agreed to be interviewed. Most happened at the beginning to the middle of May with one happening at the end of May due to scheduling conflicts. Four were completed in person at a time and location suited the participants, and one via phone, per the participant's request. Each participant was emailed a copy of the interview questions ahead of time, in order to help them feel comfortable during the interview (Merriam, 2009). Interviews lasted anywhere between about 12 and 36 minutes, with three interviews being between 15-19 minutes in length. Table 2 shows each participant's interview length. 


\section{Table 2}

Participant Interviews

\begin{tabular}{ccc}
\hline Participant Name & Interview Length & Interview Type \\
\hline Laurie & $36: 57$ & Phone \\
Lavendar & $19: 44$ & In Person \\
Anna & $17: 43$ & In Person \\
Lyn & $15: 58$ & In Person \\
Elizabeth & $12: 00$ & In Person \\
\hline
\end{tabular}

I began interviewing with background questions or throw away questions (Hatch, 2002) which included questions about demographics, participants' teaching experiences, backgrounds, and student teaching, to help put participants at ease and open the conversation focusing on their experiences in the online group. While the first question mainly asked about backgrounds, participants shared stories regarding their experiences in student teaching and early experiences in education.

Following the background questions, I began asking essential questions which dove deeper into the purpose of the study (Hatch, 2002). From these essential questions, I then followed up with probing questions to encourage reflection and honest responses from participants regarding their experiences in the online group. While interviewing, I was also aware of how the participants were responding and reacting to questions in order to provide a quality environment for the interview, ensuring the participants felt as comfortable as possible. I also kept notes as I interviewed, as I thought this would help me capture anything the audio recording could not and to keep track of important ideas the participants noted. However, after 
analyzing the interviews and reviewing these notes, I did not gain any additional understandings from the notes.

\section{Reflexive Journal}

Since I was also a participant in this research study, I kept a reflexive journal. Doyle (2013) said, "Reflexivity is often posited as a means of ameliorating the tendency for power to be weighted in favor of the researcher" (p. 252). I brought certain biases and emotions to this study since my own personal experiences in multiple realms of education were influencing this thirdspace. This journal provided a space for me to keep track of my thinking, including confusions, problems that arose, breakthroughs, as well as provided a way for me to monitor my own personal experiences throughout this study (Hatch, 2002). I wrote in the journal in an ongoing basis throughout the online group phase, data analysis phase, and writing process.

Within this reflexive journal, I kept an audit trail of how I engaged in this research process, which is discussed further in the trustworthiness section of this chapter. My journal also provided a space for me to note the shifts and changes made throughout the study that were not anticipated during the proposal phase.

\section{Data Analysis}

In order to begin data analysis, I needed to be organized and meticulous. Most data were collected electronically; therefore, backup copies of the data were securely stored on a password protected computer. Since multiple types of data were collected, I used computer assisted qualitative data analysis software, NVivo (QSR International Pty Ltd. Version 12, 2018) to store and manage data. As suggested by Miles et al. (2013), NVivo did not do the analysis for me, but instead provided a platform for storage and retrieval of data before, during, and after the analysis process aiding in my analytical thinking. As data were being collected and organized, I read 
documents from the online database multiple times and began coding to familiarize myself with the data. I read the comments and posts in the online space, then read them again as I copied and pasted the online posts from the Facebook page to a Word document and then again as I moved the data from the Word document to NVivo for initial coding. During this time, I also began taking notes in my reflexive journal for initial analysis as suggested by Maxwell (2013).

To begin data analysis, the online posts were copied and pasted directly from the Facebook group page and secured in a Word document. This method was chosen as downloading posts directly from a Facebook Secret Group was not an option. The dates and links and all exact words from the page were obtained in this manner. I also included a word count for each post and comments made. These four documents, one from each month of the study, were then uploaded to NVivo (QSR International Pty Ltd. Version 12, 2018) for coding. The coding process will be discussed below. Initially, I had intended to begin data analysis as discussion posts wrapped up. However, as participants went back to comment on older discussions, I found it best to wait to begin coding after the completion of the study and instead collect and download the data as it was posted, keeping notes in my reflexive journal as I did so. During data analysis, I defined a post as the entire discussion on one topic including the initial post made by a participant and the all of the subsequent comments and reactions. An initial post was considered only the first post in a thread to the page including the words from the participant and the content, if a link or additional resource was shared. Comments were considered all the comments made by participants following the initial post. The discussion among participants occurred in the comments of each post (see Figure 2). 


\section{Figure 2}

\section{Facebook Post Visual}

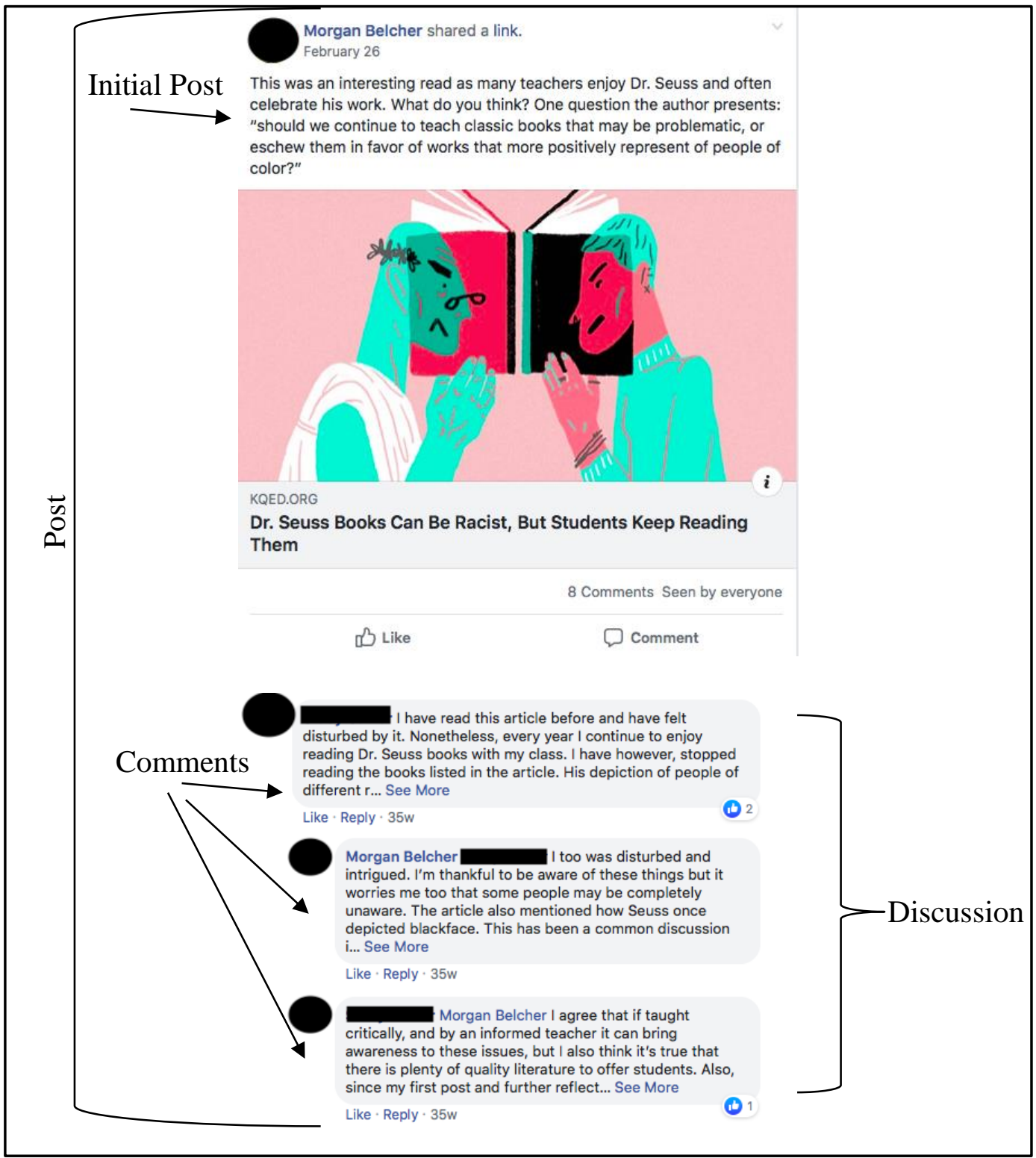

Note. Participant names and profile pictures have been blocked for confidentiality.

Another part of analysis included the interviews. All interviews were audio recorded and later transcribed by me for analysis. To begin transcription, I first just listened to the interviews to get closer to the data and really hear what the participants were saying. I transcribed using an 
application on my phone to slow down the speed of the recording and typed as much as I could as I listened. The recordings were then replayed to check for accuracy. After all interviews were transcribed, I listened to each recording again and checked for accuracy again. It was also during this time that I began to make notes in my reflexive journal about what I noticed among the participants' comments during interviews in conjunction with their online discussions and questionnaires. Interviews were then read again as I coded the data.

\section{Inductive Coding}

Since I was interested in what was happening during discussions between participants in an online context, I used inductive coding to analyze data. An inductive approach allowed me to see what was happening within the space. Miles et al. (2013) described coding as a method of assigning meaning to chunks of data as one reflects on and interprets the data outlined and two stages of coding. The first cycle allowed me to begin the initial summary of data chunks to understand repeated patterns. During the initial coding cycle, I assigned codes to data using what Miles et al. (2013) call descriptive coding. A descriptive code is typically a single noun used to describe the main idea of a chunk of data. Some examples of these types of codes included: reflection, classroom, assessment, agency, recommendation. This type of coding was especially beneficial, in this study, as I was looking at multiple types of data (e.g., interviews, questionnaires, observations). At times I did find it difficult to use only one word for some initial coding descriptions. I tried to keep the codes as brief as possible and provide a definition of each code in my codebook in NVivo (QSR International Pty Ltd. Version 12, 2018) should anyone have questions about my internal thoughts while coding (see Appendix E).

Subcoding was also applicable for analysis in this study. Miles et al. (2013) advised that "Subcoding is also appropriate when general code entries will later require more extensive 
indexing, categorizing, and subcategorizing" (p. 80). Since the first coding cycle was primarily used for summarizing chunks of data, the second coding cycle allowed me to cluster my summaries into categories or themes (Miles et al., 2013). These categories included codes related to classroom topics, personal reflections, examples of classroom interactions, and recognition of areas of growth. This was all completed in NVivo (QSR International Pty Ltd. Version 12, 2018) as a way for me to quickly store and retrieve the data. After the second round of coding was completed, I went back through all the data looking carefully at each code and the piece of data attached to the code. In some instances, codes were removed or added. I also changed the names of some codes. In places where there were large amounts of data with the same code, I looked carefully again to see if any of the data needed to be broken down into smaller codes. In these instances, I created parent and child codes in NVivo. For example, the parent code, classroom examples, included seven child codes: classroom design, classroom discussions, classroom management, classroom reference, classroom student collaborations, classroom students, and classroom teaching example. This allowed me to keep this data in the initial code but also break it down into further defined codes for more careful analysis.

While I was coding data, I kept a copy of my research questions with me to aid in my coding and a fresh copy of the codebook was also available for reference as I was examining the codes over again. After data were coded, I ran various crosstab queries. This feature in NVivo (QSR International Pty Ltd. Version 12, 2018) allowed me to see my data in different ways, highlighting the frequency of codes overlapping with one another. The example below includes the crosstab query of the codes related to shifting practices to the knowledges in the framework for understanding teaching and learning (see Figure 3). 


\section{Figure 3}

NVivo Crosstab Query Results

\begin{tabular}{|l|r|r|r|r|}
\hline Nodes & $\begin{array}{r}\text { KnowledgeOfLea } \\
\text { rnersKOL }\end{array}$ & $\begin{array}{r}\text { KnowledgeOfSub } \\
\text { jectMatterKOS }\end{array}$ & $\begin{array}{r}\text { KnowledgeOfTea } \\
\text { chingKOT }\end{array}$ & Total \\
\hline Desire to learn & $35.71 \%$ & $28.57 \%$ & $35.71 \%$ & $100 \%$ \\
\hline Recognition of area for growth & $28.12 \%$ & $18.75 \%$ & $53.12 \%$ & $100 \%$ \\
\hline Shifting Practic...line Discussions & $20 \%$ & $30 \%$ & $50 \%$ & $100 \%$ \\
\hline Specific Learning Example & $0 \%$ & $0 \%$ & $0 \%$ & $0 \%$ \\
\hline Total & $30 \%$ & $\mathbf{2 4 . 2 9 \%}$ & $\mathbf{4 5 . 7 1 \%}$ & $\mathbf{1 0 0 \%}$ \\
\hline
\end{tabular}

\section{Deductive Coding}

After all data was coded inductively, I used a deductive coding approach, or a predetermined list of codes that were generated before data collection. These codes were based on a conceptual framework or theory guiding the study (Miles et al., 2013). The codes I used deductively, arose from a framework for understanding teaching and learning (Bransford, Darling-Hammond, et al., 2005). Within this framework, Bransford, Darling-Hammond et al. (2005) identified three broad categories of teacher knowledge: knowledge of teaching, knowledge of learners, and knowledge of subject matter and curriculum. A more in-depth description of these categories can be found in the theoretical framework section of chapter three. Using these deductive codes helped me understand what kinds of discussions happened within the online space. Each post in the online group was deductively coded as a whole, including the initial post and its content along with the subsequent comments. This allowed me to understand what was occurring between the participants and what may be needed in future work. Miles et al. (2013) suggested coding is "working through iterative cycles of induction and deduction to power the analysis" (p. 93). Therefore, I had to be aware that all patterns and codes generated during this study did not fit neatly into these three categories. I remained flexible in this process and often went back to the original text including the framework (Bransford, 
Darling-Hammond, et al., 2005) to be consistent in my analysis. A few days after the initial deductive coding, I went back and analyzed the posts again making sure I agreed with my initial codes and checking the framework again as I moved through this second cycle. Some posts included more than one type of knowledge. Of the 35 posts on the Facebook group, 25 were coded as knowledge of learners, 16 as knowledge of subject matter, and 29 as knowledge of teaching. Eleven posts were considered to include all three knowledges from the framework. These posts will be explored more in the findings chapter.

Both deductive and inductive codes were then compared with one another. Using NVivo crosstab queries helped me compare how these codes did or did not overlapped on the same pieces of data from the discussions in the online learning space.

\section{Research Questions}

My analysis of the data should also help answer the research questions I crafted for this study. Within my inductive coding of the posts in the online learning space, I addressed research question number one: In what ways can an online collaborative thirdspace support novice and experienced teachers' learning? How do teachers navigate connections/ disconnections across coursework and classroom practices? How do teachers critically reflect on their own classroom practices?

In addition, research question number two was addressed in the inductive coding: What interactions occur among novice and experienced teachers when they engage in a thirdspace? The cycles of coding allowed me to categorize these descriptions into themes which provided insight for answering my research questions. As I mentioned before, I kept a copy of the research questions nearby as I was coding so the questions were prevalent in my mind as I worked through all cycles of coding. 
The second part of question two: How do participants construct understanding related to knowledge of teaching, knowledge of learners, and knowledge of subject matter and curriculum in a thirdspace? What roles do participants assume within the online space? were addressed as I deductively analyzed the data using the codes from the framework for understanding teaching and learning: knowledge of learners and their development, knowledge of subject matter and curriculum, and knowledge of teaching (Bransford, Darling-Hammond, et al., 2005). Finally, the third research question, How do teachers describe their experiences with an online thirdspace? How do participants reflect on their own learning and professional agency? was addressed as I transcribed and coded interviews as well as coded participants' responses on the questionnaires. I will describe the findings in chapter four.

\section{Exploratory Display}

A way to display and organize the data was beneficial, as I collected data through various methods. Miles et al. (2013) described this step as exploratory displays, or a way to begin organizing data analysis. As I investigated the data collected, I chose an exploratory display using a spreadsheet that best fit my qualitative study to keep my data organized. As a novice researcher, I found data collection and analysis to be overwhelming. Therefore, I reviewed my tentative plan from my proposal throughout the study and engaged in conversations with my doctoral chair to help me with my confusions and frustrations.

\section{Trustworthiness}

Qualitative researchers have a responsibility to show their work is valuable and rigorous (Merriam, 2009). Data collection, analysis, and interpretations of this study were all filtered through my own personal lens. Therefore, I have an obligation to others to show that my study was trustworthy. Lincoln and Guba (1985) identified four components of a trustworthy study: 
credibility, transferability, dependability, and confirmability. Credibility within a study addresses the truth of the findings compared to reality, asking if the findings are actually portraying what is happening within this population (Lincoln \& Guba, 1985; Merriam, 2009). Transferability in a qualitative study suggests the findings are not isolated to one study but instead are valuable within the field and can be applied to other settings (Merriam, 2009). Dependability addresses the question of finding the same results if the study were to be duplicated (Merriam, 2009). Finally, confirmability assures others that the study was interpreted through the data and not the researcher's own bias or personal agenda (Lincoln \& Guba, 1985). Trustworthiness in this study were addressed through the following methods.

\section{Triangulation}

In order to establish credibility in this study, I triangulated my data sources. Triangulation is most commonly described as analyzing multiple data sources in order to establish findings across sources are consistent (Hatch, 2002; Merriam, 2009). By triangulating data sources (e.g., interviews, online posts, questionnaires), I was able to see how these sources related to one another in different spaces and times. Data from questionnaires, online posts, and interviews from participants were all considered alongside one another as connections between these data sources were constructed in my findings, which will be shared in chapter four.

\section{Member Checking}

One type of data collection I employed included interviewing. Therefore, I used member checking to ensure trustworthiness with my interpretation of the interviews. After transcription and analysis of the interviews, participants were given the opportunity to review the analysis to ensure I captured their stories from their perspectives (Lincoln \& Guba, 1985). More specifically, this included emailing the five participants who agreed to be interviewed a copy of 
the transcription and analysis of their interview and then allowing participants to provide feedback/comments in an email response back to me. Two participants responded to the email and said they agreed with the comments and had no additional comments. One final reminder email was sent to the remaining three participants and no further responses were received. The use of member checking was important in my social constructivist paradigm, as I worked to coconstruct meaning with participants (Hatch, 2002).

\section{Peer Debriefing}

Another essential component I implemented to establish trustworthiness in this study was peer debriefing. Defined by Lincoln and Guba (1985), peer debriefing "is a process of exposing oneself to a disinterested peer in a manner paralleling an analytical session and for the purpose of exploring aspects of the inquiry that might otherwise remain only implicit within the inquirer's mind" (p. 308). While members of my committee were not "disinterested peers," those who read and talked with me were valuable peers in this process as they read what I was writing and listened to my analysis. Their feedback helped me see beyond my own ideas because they were not as close to the data as me. In addition, I asked a trusted colleague not involved in the study, here a "disinterested peer," to read my findings from the study to confirm my own positionality was not interfering with data analysis.

\section{Thick Description}

The use of thick description in my writing allowed readers to get an in-depth picture of the entire research process. As described by Efron and Ravid (2013), “This thick description allows the audience to perceive authentically the participants' views and 'enter' into their world by seeing, hearing, and sensing their experiences" (p. 71). A detailed description of the research 
setting, and the findings, have been included in this dissertation, so that the research moves beyond a superficial account of the research proceedings.

\section{Reflexivity}

Since my motivation for this study's implementation revolves around my desire to explore different possibilities for collaboration and critical conversations with teachers, reflexivity was an important part of establishing trustworthiness. Reflexivity involves the researcher critically reflecting on their own self because all researchers will interpret their findings through their own positions, intentionally or unintentionally (Lincoln \& Guba, 1985; Merriam, 2009). This was especially important to me as a researcher, as I was engaging in the online thirdspace and my passion for this research study comes from my own personal experiences as a former teacher candidate, mentor, and classroom teacher. I continuously explored and reflected upon my personal characteristics and position as a researcher throughout the study. Within this reflexive journal, I also kept an audit trail of how I engaged in this research process. Merriam (2009) explained an audit trail is a detailed description of, "how data were collected, how categories were defined, and how decisions were made throughout the inquiry" (p. 223). Implementation of an audit trail essentially gives researchers a running record of how their study evolved over time as data were analyzed. Outsiders can then see a picture of my personal thinking, questions, reflections, and the decisions I made as I analyzed data and wrote about my findings.

\section{Prolonged Engagement}

The length of time I spent in this research setting accounts for prolonged engagement. Creswell (2014) notes that this type of trustworthiness ensures the researcher can "convey detail about the site and the people that lends credibility to the narrative account" (p. 202). Not only am 
I a long-term employee of this district, I also spent a significant amount of time within the online learning space with participants which helped me understand the intricacies happening among participants.

These six methods, triangulation, member checking, peer debriefing, thick description, reflexivity, and prolonged engagement, described how I worked to ensure trustworthiness within my study, so my research can be seen as valuable and informative within the educational community. It is important that trustworthiness be established through multiple methods in order to assure readers of the truthfulness of the study.

\section{Ethical Considerations}

As a researcher, I am bound to a code of ethics to do no harm to any participants. The benefits of this research should outweigh the potential risks participants may experience (Efron \& Ravid, 2013; Miles et al., 2013). The first step in minimizing risk to participants was being upfront with ethical considerations. I obtained approval from the Institutional Review Board (IRB) at the university, before any research was conducted. I also sought permission from administration at the local school district to complete this study. Participants were recruited voluntarily; therefore, information regarding their participation, the study's goals, and their rights as participants were shared initially through informed consent. A sample of the informed consent form is included (see Appendix F).

In addition, I know that time can be a commodity in education. This study asked teachers and student teachers to devote a little more time to reflection within an online thirdspace. However, this in-depth reflection and analysis could have been beneficial to the in-service teachers and preservice teachers to become more self-aware of their teaching practices and overall could have led to improvement in teaching as well as benefit the students they 
encountered. Risks to participants remained minimal, as every effort was taken to ensure confidentiality. Data were stored on a password protected computer and were only accessed by me and members of my dissertation committee as needed. Pseudonyms were used for all participants and contextual descriptions. However, there is a chance that colleagues could decipher who is being described in the findings. This could cause apprehension from participants, as they may not want to be judged by their colleagues. Every effort was made to minimize these risks as each participant chose their own pseudonym. If a participant did not indicate a preferred pseudonym, I chose one for them. All of these potential risks were described to all participants before the study and all participants agreed to these minimal risks.

\section{Summary}

In this chapter, I presented the methodology, context for the study, data collection techniques, and data analysis procedures in order to understand how an online thirdspace can support preservice and in-service teachers to move beyond traditional approaches to mentoring and develop a sense of agency as teachers work in classrooms. In addition, I also shared how I ensured trustworthiness and minimized risks to participants within the online interactions. The findings from the study will be presented in the next chapter. 


\section{CHAPTER IV: FINDINGS}

Hatch (2002) advised when reporting qualitative findings writers should, "take readers inside the research settings, reveal understandings jointly constructed with participants, and clarify connections between what was found and what has been previously reported" (p. 234). Within this chapter, I will present my findings from the qualitative study I conducted on an online learning thirdspace with in-service and preservice teachers via Facebook. Findings were constructed from my analysis of the content of the posts in the online learning space, the participants' responses on the pre- and post-study questionnaires, and the analysis of interviews with five participants. I have divided the chapter into four sections: the participants, the numerical analysis of the space, interactions and change themes in thirdspace, and participant reflections on the space.

In order to add to the field of education, my findings should address the research questions I crafted for this study and outlined in chapters one and three. Research question one, In what ways can an online collaborative thirdspace support novice and experienced teachers' learning? was addressed through the qualitative analysis of the posts in the online space, the post-study questionnaires, and the post-study interviews. This is reflected in the interactions and change themes including cordial conversations, resisting moment of critical conversations, shifting practices, and developing agency. The second research question, What interactions occur among novice and experienced teachers when they engage in a thirdspace? was addressed through the quantitative and qualitative content analysis of the online learning space. More specifically, the quantitative lens used while counting the interactions of the posts and the deductive coding I completed using the framework for understanding teaching and learning (Bransford, Darling-Hammond, et al., 2005), allowed me to address this question and is 
presented in the numerical analysis section of this chapter. Finally, I addressed the third research question, How do teachers describe their experiences with an online thirdspace? through the interviews and questionnaires and is addressed in the change themes as well as the participant reflections of the online space. I will now begin my presentation of the findings I outlined above.

\section{Participants}

The participants were an integral part of the study and their willingness to join the study was greatly appreciated. Each participant brought their own lived experiences in education and their personal lives to the online space. By sharing about the participants, I intend to give the reader a more thorough picture of who was in this space and how this initial analysis helped me understand the scope of the participants and their engagement in the online space to begin answering my research questions. In chapter three, I shared a table outlining the demographics of the participants. Below I will share a more thorough description of the participants as their stories influenced the space, and therefore, the findings.

As I mentioned previously, there were seven in-service teachers including myself and two preservice teachers from grades kindergarten to fourth from four different schools in the district that participated in the online thirdspace. Below I will describe the participants in more depth based on the stories they shared in the online space and their responses to the pre- and post-study questionnaires, as well as post-study interviews, if applicable.

\section{Anna}

At the time of the study Anna was a first year, first grade teacher. She went back to school later in life to pursue a career in education. She has an 11-year-old son who is enrolled in a different school district and she says much of what she does in her classroom is different than what she has seen in her own son's schooling. She indicated she does not like the traditional 
behaviorist approaches she has noticed in his school, including rewards/punishments for homework completion and the use of online reading test scores as rewards for field trips. Anna stated in her questionnaire and interview that she really liked the online Facebook group and felt the group helped her gain confidence. In her interview, Anna talked about being a new teacher. She at first felt she was a "low man on the totem pole" within the online space but felt affirmed by the discussions in the group and that helped her feel more confident and empowered. When asked about her experiences in education, she described her student teaching experience as a "joke" and did not feel her mentor teacher allowed her to try out new ideas from her coursework, nor did she even really appreciate what Anna was bringing to the classroom. They did not have a collaborative relationship and Anna mentioned during her interview how her student teaching desk was positioned away from her mentor in the classroom. She left student teaching feeling unprepared to teach and chose to spend a year substitute teaching to gain more experience. She said she valued long-term substitute positions the most during this time and she enjoyed seeing a variety of classrooms.

Although Anna liked the space, she did offer some critiques including a hesitancy to type comments on her phone and a desire to have more critical conversations, as she stated everyone was "too polite." From her participation in the online space, Anna mentioned feeling empowered in three different ways: helping another teacher in her school, planning with her co-teachers, and feeling a boost of confidence when others would agree with her comments. She liked that the space included teachers with various levels of experiences, from various schools, and grade levels. In her questionnaire, she also mentioned that some of the posts felt "out of her league." She appreciated that the group was always available, and she could get to it in her own time. 
Anna acknowledged her appreciation that this was a closed group and only trusted teachers read what she wrote. However, she did not elaborate on how she defined trusted.

Anna initiated four of the 35 posts and shared a total of 1,677 words in her posts and comments during the entire length of the online learning space. Her largest word count, 301, came from a discussion of boy books and girl books.

\section{Elizabeth}

At the time of the study Elizabeth was in her thirteenth year of teaching and had her master's degree. She spent five years teaching first grade in another district, and eight years at two different schools in her current district. She attended college for education after high school and took some time off after her first five years to care for her own children. Elizabeth shared during her interview that her own childhood and experiences in school played a role in who she is as a teacher today. She decided to be a teacher because she remembered the teachers who did not give up on her and provided her with a safe space. She desired to do this for her own students as well. She stated that her student teaching experience was difficult, and her mentor teacher left her on her own after two days. She received encouraging words from her supervisors but did not truly feel supported. Elizabeth enjoys collaborating with a variety of educators but is not interested in "playing games" or cliques among teachers.

Elizabeth liked the convenience of having the group on Facebook because it was an application she already engaged with regularly and she liked that she could get to the posts at her own time. However, she mentioned that sometimes it could be a couple days before someone responded to her posts, which was a drawback in her opinion. She would like to have more participants from a variety of schools and backgrounds engaging together which she thought could lead to "richer" discussions. Elizabeth said that knowing the participants was a good thing 
too, perhaps she felt comfortable conversing online with people she already knew. Elizabeth named three topics from the online group that were significant to her and caused her to think more carefully about these areas: gender roles, kindergarten words, and Dr. Seuss.

Elizabeth initiated five posts during the study and had a total word count of 1,397 words in her posts and comments. Her highest number of words, 186, came from a comment in a post she initiated asking for support and resources for a new student.

\section{Gretchen}

At the time of the study, Gretchen was in her twelfth year of teaching at the same school, working in a fourth-grade classroom. Gretchen did not complete a post-study interview but did complete both pre- and post-study questionnaires. Gretchen commented that the online group helped her think more carefully about some of her practices but also reaffirmed her thinking and practices in other areas. She specifically mentioned thinking purposefully about what assignments teachers give to students and being cautious about assigning "fluff" projects. She also purchased new books for her classroom from the recommendations in the online posts. Gretchen appreciated the various perspectives of teachers at different grade levels as well as connecting with new people she did not know yet. She stated the discussions in the online space, "helped me reflect on the decisions I make as an educator- the words I use, the books I choose, how I organize materials, projects I assign, and so on.” Gretchen did not enjoy using Facebook like she thought she would initially because it was not easy to access at school and she preferred to do this kind of work at school rather than on her own time. Gretchen did not initiate any posts in the online group and had a total word count from comments of 1,472. Her highest word count was 277 words in a post regarding Dr. Seuss. 


\section{Laurie}

Laurie has been teaching special education for twelve years. After attending high school and college right after, she began her career in another district where she taught instructional and resource special education classes in both second and third grade. She then stayed home for ten years to care for her children. She has been teaching in her current district as an elementary special education teacher for seven years. Laurie said she had a variety of experiences in student teaching including different classrooms, schools, and grade levels, and noted times where she was left on her own in the classroom during student teaching without a mentor teacher. She discussed times at the beginning of her career where she felt like she was "floundering." She named a particular experience observing another teacher that helped her feel more confident and gain ideas for what to do in her own classroom. She initially became familiar with her current district from a master's cohort and appreciated that teachers from this district were talking about more than just student behavior, because that is what was happening in the school she was teaching at during that time.

Laurie expressed she did enjoy the online learning group and it helped push her thinking on topics that were not "on her radar." She also appreciated the ability to talk with other teachers outside her school as topics were brought up that her "core group" were not talking/thinking about. She mentioned several times throughout the interview and in the post-study questionnaire that she was concerned about people interpreting her thoughts correctly. During the post-study interview she said, "I think it was just challenging to make sure I'm portraying what I'm really thinking... when you talk to someone [in person] and you've got them in front of you, you're able to add in what you mean." At the end of her interview, she said that she enjoys meeting face to face with people but believes the discussions can be more in-depth when they are online 
because you have more time to think and respond. Laurie did enjoy the convenience of the online group and being able to get to the posts on her own time. One barrier she identified was typing on the phone. She thought she could be more thoughtful if she were typing on her computer.

Laurie was very passionate about caring for the special education students in her class. She thought critically about what resources she used, and she said she was not one to just jump on bandwagon of "new ideas," so to speak. She did find some articles from the Facebook group that reminded her to use a balanced literacy approach in her classroom and just because someone says we should do something, we have to consider other things too and be professional in our decision making. Laurie says the online group helped push her thinking on new literature for her students and she learned she can talk about diverse topics while keeping a focus on comprehension. She indicated a hesitancy to discuss certain topics with her students that are young based on her own personal experiences with her own junior high aged children but has shifted her perspective because of the online discussions from the Facebook group.

Laurie did not initiate any posts during the online group and said she did not feel comfortable doing so because of the technological aspects. She had a total word count from comments of 1,054 and her highest word count in one comment was 158 words in a post regarding recommended must-read book selections for preservice teachers from NCTE.

\section{Lavendar}

Lavendar had been teaching first grade in the district for 13 years at the time of the study. She attended college for education after graduating high school. She obtained her master's degree while teaching first grade. She worked as a camp counselor for many years prior to being a teacher. Lavendar enjoys learning and is interested in gathering new ideas. She has engaged with online learning groups before and likes to share with others. She said initially she began 
using online groups to help her better understand and utilize the resources the district gave her as she did not feel she was fully supported and stated, "they just handed it to us" and "didn't really dive into it." She was hesitant to upset others and may have sometimes not said what she was thinking if she was worried it may hurt someone else. In one part of her interview she stated, "I was afraid to share it with [a colleague] because I didn't know if that would like offend [them].” At the beginning of the group, Lavendar said she was mostly observing and then, as she felt more comfortable, would engage in discussions. She stated that she posted comments within the group when she felt like she was knowledgeable in that area and could add to the discussion.

Lavendar said her student teaching was fine, but she feels she learned the most about being a teacher from her camp counseling days. She does not think her undergraduate coursework prepared her at all for teaching as she said, “I don't really feel like I use what I learned." Lavendar liked how the Facebook group offered her a larger audience, outside of her co-teachers at her school, for talking and asking questions. She did indicate that she felt affirmed in her teaching decisions from some posts and comments within the group. She suggested the group could be even better if there were more people from a variety of backgrounds to communicate with. However, she articulated that in the larger online groups she already participated in, sometimes the posts are not as innovative as she would like and even described some posts as "hard to stomach sometimes" and "very old school." Lavendar indicated she does not learn as much from some online spaces because other participants are more traditional in their teaching approaches.

Lavendar initiated three posts on the Facebook group and had a total word count of 730 for posts and comments. Her highest word count in the comments was 85 with a post regarding play in kindergarten. 


\section{Lyn}

Lyn was in her thirteenth year of teaching at the time of the study. Lyn chose education as a second career. She returned to college to study education later in life after spending ten years in the banking industry. She spent her first year teaching in a kindergarten classroom and the 12 years after that in first-grade, all at the same school. Lyn obtained her master's degree early in her career. Lyn said she enjoys learning and has come to realize that she has changed a lot about her own mindset from when she first started teaching. She says her mentor teacher, while student teaching, used behaviorist approaches and Lyn mimicked this when she started teaching but noticed some changes in her teaching as she became more experienced and read/learned more. She enjoyed being part of the online group and said she learned a lot and was excited to try new ideas in her classroom. During her interview, Lyn noted two specific instances of learning during her participation in the online space from the posts about diverse books and play in kindergarten. She said these two posts helped her make changes to practices in her classroom. She mentioned a significant area of learning for her was how it is important for teachers, herself included, to think about the source of the information "before we put it out there."

While engaging in the online space, Lyn liked the convenience of the group and getting to it at her own time. She liked that each participant got to have a voice and people were not interrupted when they wanted to share. She also noted discussions could still be respectful even when people disagreed. She said the space allowed her to have conversations she might not have otherwise. She also felt the space helped her confidence as people would agree with her and she felt she gained new sources to help support her practices in the classroom. Perhaps these reminders of considering the source and the boost of confidence allowed Lyn to develop 
beginning stages of her own agency, as Lyn did not comment on critical discussions in the group and most comments she made were neutral or encouraging to others.

Lyn initiated three posts within the online study and posted a total of 516 words in her posts and comments. Her highest number of comments was from a post regarding kindergarten words where she had a word count of 91 .

\section{MaryAnne}

MaryAnne was a preservice teacher working in a second-grade classroom in the Professional Development School (PDS) and was completing her student teaching semester during the online learning group. MaryAnne did not complete a post-study interview but did complete both pre- and post-study questionnaires. She said that she read articles and posts in the online group. She appreciated getting book suggestions and enjoyed the posts related to suggestions for first year teachers. MaryAnne specifically named that she shifted her thinking about classroom décor from the discussions online. She felt the group helped open her mind to other teaching practices and gather ideas for her future classroom as she stated, "I was able to read articles and take part in discussions that showed me ways I can improve in classroom instruction." She did express a desire to participate more in the discussions if she were to be in a group like this again but did not indicate why her participation in the space was sparse.

MaryAnne did not initiate any posts in the group and had a total word count from comments of 114. Her highest word count in a comment was 97 on a post regarding the use of various fonts and classroom décor. She commented on two posts and liked other posts throughout the group.

\section{Nicole}

At the time of the study, Nicole was completing her student teaching in a third-grade classroom within the PDS program. She did not complete the post-study questionnaire, nor did 
she agree to be interviewed. She did complete the pre-study questionnaire. Nicole did not initiate any posts in the online group and had a total word count in comments of 187 . She interacted in three posts from the online group in January and February and none during the other months. Her highest word count in one comment was 71.

To answer my research questions, I first had to understand the space with regard to its participants and the scope of their engagement. I have done so in the previous section by providing a thorough description of individual participants in the study utilizing their responses from the pre- and post-study questionnaires as well as post-study interviews, if they participated in one. Knowing each participant allowed me to think about all the research questions during the analysis. Moreover, the participants' reflection of the space helped me answer research question three. I also gave a brief overview of word counts so readers could see one more aspect of each participants engagement online. It is not surprising that the descriptions were richer when the participants completed the post-study interviews. In the next section, I will provide a quantitative description of the online space.

\section{Numerical Analysis: A Quantitative Look at the Online Space}

As I mentioned in chapter three, I maintained a spreadsheet throughout the study to keep track of the quantitative data associated with the online learning space. While this was not a mixed methods study, keeping track of the number of posts, comments, likes, and types of posts helped me see various aspects related to the interactions of the online space. The numerical analysis aided in answering my research questions as I considered which posts had high comments or high participation, for example, and consider why these posts were more engaging. This numerical data also aided in my data analysis because I was able to correlate qualitative codes with posts in the space that were named as significant by participants or posts that had 
high numbers of comments or participants. Looking at these numbers helped me zoom in on particular posts and answer research questions number one and two. In this section, I will describe the various ways I used the quantitative data to highlight specific posts from the online space. I will tell about the topics of the posts, the criteria for how a post was identified as having high participants or high comments, describe how posts were categorized as theoretical or practical, identify the knowledges from the framework for understanding teaching and learning (Bransford, Darling-Hammond, et al., 2005) of each post, identify the posts participants named as significant, and take a closer look at the four posts from the online space that reflected multiple quantitative indicators described throughout this section, as these posts stood out as the most significant to participants' learning in multiple ways.

In order to give the reader an overall picture of the space, Figure 4 includes an overview of all the posts that were created during the four months of the study and includes: the title of the post, the date each post was created, who initiated the post, the type of post (question, article, infographic, book recommendation, reflection, and classroom example), and the number of comments, likes, and loves the post received. Additionally, the figure includes which posts had high comments and high participants, as defined in following section, along with how many participants named the post as significant during their final interview or post-study questionnaire. The bold and italicized posts are ones that included multiple indicators from the quantitative analysis, four by four posts, and will be discussed more thoroughly later in the chapter. 


\section{Figure 4}

\section{Online Space Postings Overview}

\begin{tabular}{|c|c|c|c|c|c|c|c|c|c|c|}
\hline Original Post Title & $\begin{array}{l}\text { Date } \\
\text { Posted }\end{array}$ & $\begin{array}{l}\text { Posted } \\
\text { By }\end{array}$ & Type of Post & $\begin{array}{l}\text { Ĕ } \\
\text { E⿱ } \\
\text { Ĕ }\end{array}$ & 茕 & ఏุ̆ & 訔 & 兽惑 & 들 & 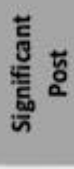 \\
\hline MLK & $1 / 21 / 19$ & Morgan & $\begin{array}{l}\text { Infographic } \\
\text { Question }\end{array}$ & 5 & 2 & 0 & 4 & $x$ & & \\
\hline 22 Children's Books That Teach Kids to Be Kind & $1 / 23 / 19$ & Morgan & $\begin{array}{c}\text { Article } \\
\text { Book } \\
\text { Recommendation }\end{array}$ & 4 & 4 & 0 & 3 & & & 2 \\
\hline Every Kid Needs A Champion & $1 / 27 / 19$ & Morgan & $\begin{array}{l}\text { Question } \\
\text { Video } \\
\text { Reflection }\end{array}$ & 4 & 1 & 3 & 3 & & & \\
\hline BAS (Benchmark Assessment System) & $1 / 30 / 19$ & Morgan & $\begin{array}{l}\text { Infographic } \\
\text { Question }\end{array}$ & 29 & 1 & 0 & 6 & $x$ & $x$ & \\
\hline Reading Comprehension Article & $2 / 4 / 19$ & Lyn & Article & 9 & 3 & 0 & 2 & & $x$ & \\
\hline Brighten Up A Student's Day & $2 / 6 / 19$ & Morgan & Infographic & 0 & 2 & 4 & 0 & & & \\
\hline $\begin{array}{c}\text { NCTE Must Read Books for Preservice } \\
\text { Teachers }\end{array}$ & $2 / 10 / 19$ & Morgan & $\begin{array}{c}\text { Book } \\
\text { Recommendation }\end{array}$ & 11 & 0 & 2 & 6 & $x$ & $x$ & 2 \\
\hline Freire & $2 / 11 / 19$ & Morgan & $\begin{array}{l}\text { Article } \\
\text { Question }\end{array}$ & 5 & 2 & 0 & 3 & & & \\
\hline Random Question-Fonts & $2 / 16 / 19$ & Anna & Question & 9 & 4 & 0 & 5 & $x$ & $x$ & \\
\hline Sesame Street Fish to Infinity & $2 / 22 / 19$ & Lyn & $\begin{array}{l}\text { Video } \\
\text { Reflection }\end{array}$ & 3 & 1 & 0 & 2 & & & \\
\hline Boy Books and Girl Books & $2 / 23 / 19$ & Elizabeth & Article & 16 & 3 & 0 & 4 & $x$ & $x$ & 1 \\
\hline $\begin{array}{c}\text { Dr. Seuss Books Can Be Racist but Students } \\
\text { Keep Reading Them }\end{array}$ & $2 / 26 / 19$ & Morgan & $\begin{array}{c}\text { Article } \\
\text { Book } \\
\text { Recommendation }\end{array}$ & 8 & 0 & 0 & 4 & $x$ & $x$ & 4 \\
\hline Children's Books That Celebrate Diversity & $3 / 2 / 19$ & Lyn & $\begin{array}{c}\text { Book } \\
\text { Recommendation }\end{array}$ & 7 & 0 & 0 & 3 & & $x$ & 3 \\
\hline It's Time to Talk About Dr. Seuss & $3 / 4 / 19$ & Morgan & Article & 0 & 2 & 0 & 0 & & & \\
\hline New Student & $3 / 4 / 19$ & Elizabeth & Question & 6 & 4 & 0 & 0 & & $x$ & 1 \\
\hline Reading Celebration & $3 / 4 / 19$ & Lavendar & Question & 7 & 0 & 0 & 4 & $x$ & $\mathrm{x}$ & 1 \\
\hline Academic Language Infographic & $3 / 10 / 19$ & Morgan & Infographic & 0 & 2 & 0 & 0 & & & \\
\hline First Year Changes & $3 / 10 / 19$ & Anna & Question & 5 & 1 & 0 & 2 & & & 1 \\
\hline Theory Reflection & $3 / 15 / 19$ & Morgan & Question & 2 & 1 & 0 & 1 & & & \\
\hline New Student Update & $3 / 17 / 19$ & Elizabeth & Question & 5 & 1 & 0 & 3 & & & \\
\hline Leprechaun Traps & $3 / 18 / 19$ & Morgan & Question & 9 & 0 & 0 & 5 & $x$ & $\mathrm{x}$ & \\
\hline 5 Strategies to Demystify the Learning Process & $3 / 19 / 19$ & Morgan & Article & 0 & 0 & 0 & 0 & & & \\
\hline 2018 Notable Children's Books & $3 / 22 / 19$ & Morgan & $\begin{array}{c}\text { Book } \\
\text { Recommendation }\end{array}$ & 0 & 0 & 2 & 0 & & & 2 \\
\hline Reading and The Dyslexic Child & $3 / 24 / 19$ & Morgan & Article & 2 & 2 & 1 & 2 & & & 1 \\
\hline Kindergarten Words & $4 / 2 / 19$ & Morgan & $\begin{array}{l}\text { Question } \\
\text { Reflection }\end{array}$ & 7 & 2 & 0 & 5 & $x$ & $x$ & 1 \\
\hline The Science of Literacy Learning is Not A Thing & $4 / 6 / 19$ & Elizabeth & Article & 4 & 2 & 0 & 2 & & & \\
\hline Challenge is A Part of Learning & $4 / 7 / 19$ & Anna & Article & 1 & 1 & 0 & 1 & & & \\
\hline Summer Reading & $4 / 7 / 19$ & Lavendar & Question & 1 & 0 & 0 & 1 & & & \\
\hline Diorama Photos & $4 / 8 / 19$ & Morgan & $\begin{array}{l}\text { Classroom } \\
\text { Example }\end{array}$ & 0 & 1 & 1 & 0 & & & \\
\hline Meeting Each Student Edutopia Infographic & $4 / 11 / 19$ & Morgan & Infographic & 0 & 2 & 0 & 0 & & & \\
\hline Every Kindergartener Deserves Play & $4 / 23 / 19$ & Elizabeth & Article & 10 & 4 & 0 & 4 & $x$ & $x$ & 2 \\
\hline The Biggest Lessons of My First Year & $4 / 26 / 19$ & Morgan & Article & 0 & 0 & 0 & 0 & & & 1 \\
\hline Organizing Materials & $4 / 27 / 19$ & Anna & Question & 2 & 0 & 0 & 2 & & & 1 \\
\hline The Sneeches Are Problematic & $4 / 29 / 19$ & Lavendar & Article & 0 & 1 & 0 & 0 & & & \\
\hline Totals & & & 35 Posts & 177 & 26 & 13 & & & & 14 \\
\hline
\end{tabular}




\section{Content of the Interactions}

Previous studies of online spaces in education indicated a need to understand what is discussed within the spaces and how participation affects teachers' practices (Kelly \& Antonio, 2016; Killeavy \& Moloney, 2010; Macià \& García, 2016; Turvey \& Hayler, 2017). A content analysis of the online posts and comments in the online space was completed. Posts were coded to look at topics discussed, types of posts, and types of comments (e.g., theoretical or practical, framework knowledges, critical comment, or agreeing). The types of posts were recorded in the spreadsheet and denote 13 articles, 5 infographics, 15 questions, 4 book recommendations, 2 videos, 2 classroom examples, and 8 reflections were posted to the group. It is important to note that there was a total of 35 posts, and some may have represented more than one type. For example, an article may have been posted with an additional question asked by a participant.

\section{Topics of Posts}

Digging deeper into the discussions, comments and posts were coded for topics discussed. Initial posts and comments included a wide range of topics including, assessment, children's literature/book recommendations, classroom management, organizing classroom spaces, reading, math, technology, and writing (see Table 3). Thirty-two percent of the discussions in this group revolved around topics related to examples from participants' classrooms. Additionally, $20 \%$ of the posts had to do with reading or children's literature. Participants reported the sharing of resources, especially books to use in the classroom, as a favorite topic. 


\section{Table 3}

Codes Indicating Topics of Posts

\begin{tabular}{|c|c|c|}
\hline Code & Number of Codes & Percentage of Codes \\
\hline Classroom Students & 43 & $14 \%$ \\
\hline Reading & 38 & $13 \%$ \\
\hline Parents Home Family & 24 & $8 \%$ \\
\hline Children's Literature & 21 & $7 \%$ \\
\hline Classroom Design & 20 & $7 \%$ \\
\hline Classroom Teaching Example & 19 & $6 \%$ \\
\hline Materials & 16 & $5 \%$ \\
\hline Connection to Literature & 14 & $5 \%$ \\
\hline Social Justice & 12 & $4 \%$ \\
\hline Classroom Reference & 11 & $4 \%$ \\
\hline Technology & 11 & $4 \%$ \\
\hline Curriculum Resource & 10 & $3 \%$ \\
\hline Personal Experiences & 9 & $3 \%$ \\
\hline Theory & 9 & $3 \%$ \\
\hline Writing & 8 & $3 \%$ \\
\hline Classroom Discussions & 5 & $2 \%$ \\
\hline Classroom Management & 5 & $2 \%$ \\
\hline Classroom Student Collaborations & 5 & $2 \%$ \\
\hline Assessment & 4 & $1 \%$ \\
\hline Connection to Coursework & 4 & $1 \%$ \\
\hline
\end{tabular}




\begin{tabular}{lll}
\hline Code & Number of Codes & Percentage of Codes \\
\hline Connection to Community & 3 & $1 \%$ \\
ESL & 3 & $1 \%$ \\
STEM & 3 & $1 \%$ \\
Math & 2 & $1 \%$ \\
Common Core State Standards & 1 & $0 \%$ \\
\hline
\end{tabular}
300

\section{High Comments, High Participants, and Significant Posts}

I also reviewed the discussions on the Facebook page for posts that included a high number of participants making comments. I decided a post was considered to have high participants when more than half of the group members (excluding myself), four or more, contributed. Eleven posts were considered to have high participants. Posts with a high number of comments included posts with six or more comments. I found the average of the number of comments to be 5.57 and the mode to be zero, as there were nine posts with zero comments. Then looking only at posts with comments, excluding zeros, the mode was five comments occurring the most frequently on four posts. Therefore, I determined 13 posts to have high comments. There was overlap on 10 of these posts that included both high participants and high comments. Participants were also asked to name posts that were significant to them during interviews and the post-study questionnaire. Fourteen posts were identified by participants as being significant or ones that they felt they learned the most from. Looking across all three of these, six posts included all three: high comments, high participants, and were identified as significant. This data can all be referenced in Figure 4 above and will be more thoroughly discussed later in the chapter. 


\section{Theoretical and Practical Posts}

Since I intended for this to be a space of critical reflection and a space for theory and practices to be examined, I also kept track of which posts were considered to be mostly theoretical and mostly practical. A post was named as theoretical when it included a reference to a theory or theorist or a discussion of theories influencing one's practices. Discussions named as practical included posts with references to practices one used or would like to use in their classroom. Thirty-one posts were considered practical and nine posts were theoretical and of these, six posts included both theoretical and practical. Only one post coded as theoretical regarding play in the classroom was named as significant by participants and four theoretical posts- BAS (Benchmark Assessment System), play, leprechaun traps, and kindergarten words had high comments and high participants. In most instances, the theoretical part of a post was found in the initial post and the comments in the discussion were mostly practical.

\section{Framework Knowledges}

In order to understand more about the interactions of the online thirdspace, when the online group was no longer active, I looked at each post and the subsequent comments to analyze the type of knowledge addressed the discussion (knowledge of subject matter, knowledge of learners, and knowledge of teaching). Bransford, Darling-Hammond et al. (2005), identify these as relevant for all teachers in their framework for understanding teaching and learning, which I outlined in chapter three. I included the content of the comments made, content of the comments in the initial post, and content of the article or video in the initial post, when applicable. Each post could have addressed more than one knowledge. Of the 35 posts made, I coded 11 posts with all three knowledges, 25 posts with knowledge of learners (KOL), 16 posts with knowledge of subject matter (KOS), and 29 posts with knowledge of teaching (KOT). The high number of 
posts including knowledge of teaching, coincides with the topics discussed above, as $32 \%$ of the online posts included classroom examples (see Table 4).

\section{Table 4}

Number of Posts of Framework Knowledges

\begin{tabular}{cccc}
\hline $\begin{array}{c}\text { Knowledge of } \\
\text { Learners } \\
(\text { KOL })\end{array}$ & $\begin{array}{c}\text { Knowledge of } \\
\text { Subject Matter } \\
(\text { KOS })\end{array}$ & $\begin{array}{c}\text { Knowledge of } \\
\text { Teaching } \\
(\text { KOT })\end{array}$ & $\begin{array}{c}\text { Posts coded with all three } \\
\text { knowledges }\end{array}$ \\
\hline 25 & 16 & 29 & 11 \\
\hline
\end{tabular}

To expand on this, Table 5 shows the titles of the posts that were coded with all three types of knowledge. Looking across my quantitative analysis, there were four posts that had high participant engagement, high comments, were named as significant by participants, and included all three knowledges from the framework as indicated by an asterisk after the post title. I consider these four posts significant with regard to my research questions because they include all of the criteria listed above and demonstrate opportunities for learning and shifting practices among participants. I will examine them further in the next section. 


\section{Table 5}

Posts with all Three Framework Knowledges

Title of Posts Coded with Three Framework Knowledges

\section{MLK}

NCTE Must Read Books for Preservice Teachers*

Freire

Sesame Street Fish to Infinity

Boy Books and Girl Books*

Dr. Seuss Books Can be Racist but Students Keep Reading Them*

Theory Reflection

Leprechaun Traps

Reading and the Dyslexic Child

The Science of Literacy Learning is Not a Thing

Every Kindergartener Deserves Play*

\section{Four by Four Posts}

The four online posts from the quantitative analysis above that were identified as including all four indicators of the quantitative analysis: high participants, high comments, were named as significant by participants, and included all three knowledges from the framework thus titled, four by four posts, will be discussed in this section. Previous research from Lundin, et al. (2017) suggested a need to study conversations in online spaces that vary from the norm. The four by four posts from the online learning space were titled: NCTE Must Read Books for 
Preservice Teachers, Boy Books and Girl Books, Dr. Seuss Books Can be Racist but Students Keep Reading Them, and Every Kindergartener Deserves Play. After noticing these posts included all of these indicators from the quantitative analysis, I took a closer qualitative look at these to understand what made these posts different from others in the online learning space. To begin, they all included articles shared from other educational Facebook pages including: National Council Teachers of English (NCTE), We Are Teachers, Heinemann, and Mindshift, thus making these topics relevant in education at the time of the study. Figure 5 displays the top five codes in these posts as well as the number of times each code appeared in the four by four posts.

\section{Figure 5}

Top Five Codes in Four by Four Posts

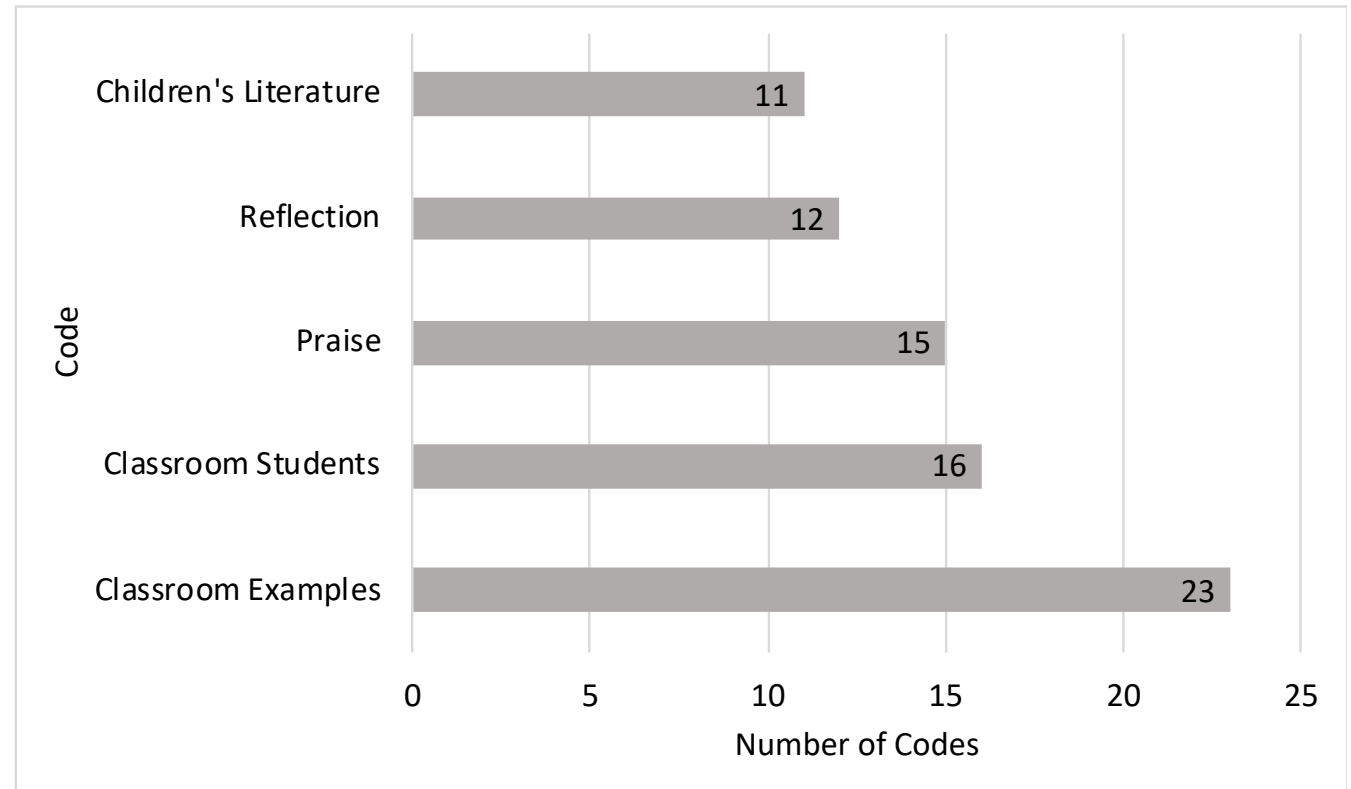

Moreover, these four posts have multiple comments sharing specific examples from classrooms. In fact, when I examined the codes associated with these posts, I found that $10 \%$ of the data in these four posts were coded as classroom examples, which included stories of interactions and conversations among students as well as practices implemented in classrooms. 
This aligns with the high number of posts including knowledge of teaching from the framework and a high number of topics coded related to classroom examples discussed above. Some examples of the comments from the four by four posts relating to classroom examples included this one from Anna from the NCTE Must Read Books post, "I love A Bike Like Sergio's and just bought it at the book fair. I read it to my class at the beginning of the year after one of my kiddos started talking about stealing." Lavendar also shared a general example from her classroom on the play post, "This is the first year that I integrated play/exploration time and have no regrets! I'd love to have more time for imaginative play. I think it would really help in other subject areas especially writing." In another example from the Boy Books and Girl Books post, I shared a comment highlighting instances when I had overheard children countering stereotypes of boys and girls,

On Friday one boy opened the toy/game closet and he said 'what's that girl game doing there?' One girl replied back, 'there is no such thing as girl and boy games. Anyone can play that game.' I just smiled and felt excited she had replied back in an appropriate way. Furthermore, participants shared some reflections on their teaching in these posts as well. One came from Lyn on the play post, "I know choice is so important in all areas. I personally struggled with making choices as I became an adult, because so many of mine were made for me. It's an important life skill.” Another reflection came from me in this same post, This article has me thinking about when I am having play time... And what else can I shift in my practices to allow for more choice and creativity? I know I can't do it all so instead I am thinking, what small shifts can I make to approach more of an inquiry based learning environment? 
Another common pattern among the four by four posts were the number of questions asked in each discussion. Discussions may have ensued in these posts because there were multiple times that one participant asked a direct question to another. In one example from the Boy Books and Girl Books post, I specifically asked a question to Gretchen,

I always wonder how does this carry on in the children's lives as they get older?? Since you teach at the intermediate school do you see any instances of children using empathy from books they have read? Do they ever talk about books they read when they were younger? Just curious! Or do you think the 'tolerance' for others that are different decreases as kids get older? I do hope that what I share with them translates into the rest of their lives but I don't really know how to investigate that so I'd love to hear your perspective.

Or, there were some instances where a general question was asked to the group like with Anna's question from the same post,

With Morgan's story about the [parent] wanting to be notified of the book, do you guys think it is necessary to relay this information to parents ahead of time? If so, how do we determine which books may or may not cause a reaction?

Above I have highlighted some common patterns found in the four by four posts. The quantitative analysis from above helped me focus on posts that were most relevant in the online space and helped me address my research questions. In the following section, I will elaborate more on the qualitative analysis of the posts from the entire online learning space. In addition, the qualitative themes in the four by four posts will be more thoroughly discussed at the end of the next section, interactions and change themes. The quantitative analysis in conjunction with 
the qualitative coding I completed helped me identify themes and findings from the online learning space.

\section{Interactions and Change in Thirdspace}

In this section, I will highlight themes that were constructed from my qualitative analysis of the full data set. The interactions theme relates to cordial conversations and discourse of agreement, as well as resisting moments of critical conversations. Whereas the change themes relate to shifting practices and developing agency. Then I will share explicitly how these interactions and change themes were present in the four by four posts. I will conclude the chapter with participant thoughts about the interactions of the online space.

\section{Interactions Theme}

The interactions theme of this study highlights the comments, discussions, posts, and reactions among participants' in the posts from the online thirdspace during the four-month time period as well as some participant reflections from the interviews and questionnaires. The two overarching interaction themes were cordial conversations and the discourse of agreement and resisting moments of critical conversations.

\section{Cordial Conversations and Discourse of Agreement}

Through multiple iterations of coding and reexamining the data, I found a major overarching theme of praise, encouragement, and appreciation to be prevalent in this online learning space. It was when I began coding participant interviews that I noticed a connection between the qualitative codes of the online posts from the inductive cycle and the strong appreciation participants noted in their interview and post-study questionnaire comments. Participants in the online community stated they appreciated the support from other educators at 
various stages in their careers. For example, the following from Laurie's post-study interview indicated this:

Participation in the group brought up topics I would not have normally have had on my radar and helped me see different points of view. I often work closely with the same people at my school or friends from other schools - participation widened my 'circle.' Anna described a similar appreciation, "I gained confidence in myself as a new teacher. To post questions or articles and have trusted veteran teachers respond to them as a peer gave me a little boost." It was statements like these that helped me recognize the need to examine the comments coded as praise, encouragement, and appreciation, thus the cordial conversations, from the online space meticulously because there was a strong sense of appreciation across multiple data sources.

Looking more closely at the qualitative analysis of the online posts, the code praise, agreement, and encouragement appeared in 70 comments, which is nearly $40 \%$ of total comments made in the online space. In these instances, the discussions take on a discourse of agreement and remain cordial. Comments with praise and encouragement were sometimes simple statements of agreement or encouragement. Some examples include: "Glad you brought this up!”; "I agree with Laurie!”; “Love it!”; “Ooh I like this! Thanks for sharing your perspective!"; "This was a great idea for a post!"; "Your bottom suggestion is great!!"; and “Thank you for your ideas!” Some other comments included a little more explanation naming what a participant was agreeing with: "I'm so glad you shared with colleagues."; "I agree with what has been said so far. I have always had this distaste for them as well."; "Thanks for the info Morgan! I got FlipGrid up and running today.”; “Thank you Laurie! Miss [teacher's name] was a great resource."; "Loved all the book recommendations from everyone's posts."; and "What a great short article Elizabeth!" 
Furthermore, other comments were stronger and more direct, naming exactly what the participant was agreeing with and usually included words such as yes, or I agree. One example includes this comment from Anna, "If I were to sum up all of my thoughts in a word, YES! 'Yes' in that we need to let children think and explore and create and make and take apart and do, do, do!" Another example came from a comment from Elizabeth, "I agree! I like how they started the day with play then carried that experience through the day into academic areas." While discussing the use of fonts Lyn stated, "I agree with Laurie! While seeing a variety is good just to expose them to more, I think consistency is so important." In another post, I shared a comment replying to Lavendar on her reflections of the work of Dr. Seuss, "What a good comparison! Don't you feel so much better after being informed, even though it was disturbing. Obviously his work is important but I think a critical eye is important too!” Another encouraging comment came from Laurie and her thoughts on a TED talk shared to the group, "Love, love this TED talk. Each time I watch it, it helps me refocus on the grandness of teaching (the influence, impact we have on little lives, the unique needs of students, the power of our words, etc.)."

Some praise included further details such as an explanation or rational for one's agreement or support. For example, in the post of Boy Books and Girl Books, Gretchen responded to a comment within the discussion of gender roles in her classroom by saying, “That's great that you are challenging your students' assumptions about gender, like with the spider example, and that your students also feel comfortable challenging each other, like the girl did with the game." In another example, Elizabeth commented, "I agree that if taught critically, and by an informed teacher it can bring awareness to these issues." In a post discussing diverse texts to use in the classroom, Lavendar commented "I haven't heard of ANY of these...teacher shame...," and my reply to her stated: 
Education is always changing, new books are always being made. It is hard to keep up with everything. That is why I think collaborating and conversations with other educators are so important! I learn from you so much at our meetings. I implemented demonstration notebooks because of your sharing.

In a final example, Gretchen responded to a post on the creation of leprechaun traps being assigned to students as homework,

I think the idea is cute and fun, but I agree with what many of you said about competition, parents doing most of the work, the inequality in support students have at home, etc. I try to avoid assigning projects as homework for those reasons. When we do projects, I give students time to work in class and provide the materials they need.

These participants gave a general agreement within a thread of comments and included further detail in their agreement. While there were a high number of comments that included praise and encouragement and perpetuate the discourse of agreement, there were also instances where participants offered a counter opinion but did not use strong disagreeing words. This will be explored in the following section.

\section{Resisting Moments of Critical Conversations}

As I was coding the online discussions, I noticed participants used strong words (e.g. I agree, yes, thank you) when they agreed with one another. However, there was a lack of strong words when a participant offered a different opinion in their comments within the Facebook posts, indicating that participants were less comfortable engaging in critical ways. There were 14 instances coded where a participant offered a counter opinion or a critical response to what was previously said. The following examples highlight discussions that had multiple comments from participants and the comments offered a differing opinion from others. For example, Laurie said, 
"But... Tbh [to be honest], I am leery when the term 'social justice' is used in education... So, I think we, as educators, need to be very careful." Here she is providing a counter opinion to a post I shared about problem posing education from Paulo Freire. While she may not be disagreeing with the work of Freire, she did offer a counter narrative on the term social justice but did so in a respectful way without using a strong disagreeing word, like was present in the cordial conversations data. She later added a follow up comment, “Of course, I'm probably speaking more about older students - jr high, high school... as they learn about deep, social issue type topics at school and the influences their teachers have over shaping their understanding." This second comment seems to be a way to soften the previous comment. Two comments following Laurie's comment were from me sharing examples of theories in action in my classroom but did not address her counter opinion, thus resisting moments of critical conversations. This post included all three framework knowledges but was not considered to have high comments or high participants as only three participants including myself commented on this post.

In another post, Anna asked everyone to share their opinion on the use of various fonts she sees on worksheets and posters. This discussion was identified as having high comments and high participants and addressed one knowledge from the framework, knowledge of teaching. Three participants made comments suggesting too many fonts can be overwhelming for students. However, Elizabeth offers a counter statement and shares why she thinks a certain way and how she uses them in her classroom, "I think teaching flexibility in fonts is important. We use lots of environmental print in kindergarten which contain a variety of fonts. I'm also a believer of material being visually engaging. Fonts can be a tool to learning." Again, the counter opinion did not include a direct word to disagree like was prevalent in the coding of praise and encouragement. This critical comment was posted two days after the initial post and after three 
participants had already commented. Comments that followed this one regarding fonts came from two participants that had not yet commented, including one from MaryAnne, "I also find it interesting how scripted and cursive fonts are popular right now. I would think it would be hard for students to read it?" The discussion concluded with this comment from Gretchen,

I do think it's important to help them learn to be flexible and expose them to a variety of fonts, but that should happen in a developmentally-appropriate way. I can see how crazy fonts would be very confusing to a kindergartner who was still learning how to form her letters.

Most critical comments or those that offered a differing perspective of previous comments included additional explanations to support their thinking but did not typically respond back directly to the critical comment, again an instance of resisting critical conversations. One final example highlights a counter perspective regarding the use of Dr. Seuss's works in classrooms. Recently some critiques (Jenkins \& Yarmoskey, 2019; Lukoff, 2019) have come forth suggesting his work should not be celebrated as much as schools often do. Within the online space, we were engaging in a discussion regarding an article on this topic. This particular post was one that was identified as a four by four conversation, meaning it had high comments, high participants, named as significant by participants, and included all three knowledges from the framework. One comment within this discussion came from Elizabeth where she was reflecting on a previous comment, "Since my first [comment] and further reflection on the topic, I'm thinking about my purpose behind the text choices. Perhaps there is a better way to incorporate some of his books more purposefully." A comment after this one from Lavendar stated, “I still read his books. However, I don’t idolize him as much in the classroom. I try to embrace all authors during read across America week especially those with diversity." 
Other participants noted a hesitancy to use his works now but are not completely throwing him out the door, Gretchen offered her counter opinion by saying,

I think it's fine to look at these works of art through a critical lens and teach children to do the same, but I don't think we should completely drop an author like Seuss, whose work has many redeeming qualities, from the curriculum just because some of his illustrations are questionable.

In this example, there were counter opinions made in the discussion, however, only when participants agreed with another comment did they reference back to a previous comment. There were not instances of a direct reference back to a previous comment when a counter opinion was made.

One particular scenario that I found interesting included a post and comments in the online space from Lyn. She was one of the first people in the group, besides myself, to initiate a post where she shared an article on reading comprehension. The post itself collected three likes and nine comments with ongoing dialogue happening among two participants in those comments. It also included two framework knowledges, knowledge of subject matter and knowledge of teaching, and was considered to have high comments. Within the ongoing dialogue, Elizabeth and I stated we both agreed with most of the article but had some concerns about a few statements and proceeded to look up the author to find out more about the source. Later within the online space, Lyn shared a link regarding diverse texts to use in the classroom. This post included two framework knowledges, knowledge of learners and knowledge of teaching, was identified as having high comments, and significant to participants. Throughout the comments it was noticed that many participants were saying they had not heard of these books and some even felt embarrassed to be out of the loop. Lavendar commented, 'I haven't 
heard of ANY of these...teacher shame..." and Lyn replied, "I felt the same way! It's so hard to keep up with all the new stuff!! There's only so much we can do. Lol [laugh out loud] At least we know about them now!" After my own initial disappointment that I was not aware of many of these texts either, I reflected and posed a critical comment:

I hadn't heard of many of these book [sic] either and at first I felt maybe I am out of the loop. But then I was wondering are these books that awesome? They might be. Maybe? Maybe not? The only way to find out would be to investigate the texts ourselves. This link is from a national news source, not an educational source so thats [sic] another perspective to consider. And how many times have we seen something with a tagline saying how wonderful it is but only to find its maybe not so wonderful? I'm thinking back to the reading comprehension post Lyn made awhile back that Elizabeth and I discussed in the comments and even looked more closely at the author.

There were no follow-ups to this comment which was posted seven days after the initial post was made by Lyn. What I noticed about this particular post as I was coding the online discussions, was that Lyn's engagement in the group declined after this and she never again initiated a post.

Even more interesting was that Lyn identified a major area of learning for her during participation in the online environment was the need to consider a source and where something is coming from before one decides if it is quality or not. More specifically, in her interview when I asked if there was ever a time she felt challenged in the online learning space, Lyn stated, Well just the time with that article. Like that I shared and and didn't really pay attention to where it came from. But that was a positive thing. I mean, that's what those kind of groups are for. To help us remember that kind of stuff. And learn that kind of stuff. 
This reflection suggests she was grappling with this desire to learn, yet still resisting moments of critical conversations. Later in the interview she said,

But you can still have people disagree. You can still have people agree. You can still have a conversation as long as its respectful. That but that's that is a problem with online stuff. You don't always know how to take what's being said.

So, while I cannot know for sure if her decline in engagement in the online group was directly related to the critical comments made in this post or her own development of agency, this pattern seems to connect with the findings of cordial conversations and resisting moments of critical conversations.

\section{Change Themes}

The change themes of this study highlight the comments, discussions, posts, and reactions among participants' in the posts from online thirdspace. The comments and reflections made by participants in the post-study questionnaire and post-study interviews also highlight instances where participants noted changes or shifts they made as a result of participating in the online space. This theme will be broken down into two sections, shifting practices and developing agency.

\section{Shifting Practices}

Recent literature on online spaces suggested there is a need to understand how online spaces are actually affecting teachers' practices as they are becoming more and more popular in the world of education (Booth, 2012; Carpenter \& Harvey, 2019; Kelly \& Antonio, 2016; Lundin et al., 2017). The first question on the post-study questionnaire asked participants to rate how they think participation in the online space impacted them as educators. Using a rating scale of 1- 
5, with one being no impact and five being significant impact, $85 \%$ of participants that took the survey selected four on the rating scale (see Figure 6).

\section{Figure 6}

\section{Post-Study Questionnaire Results}

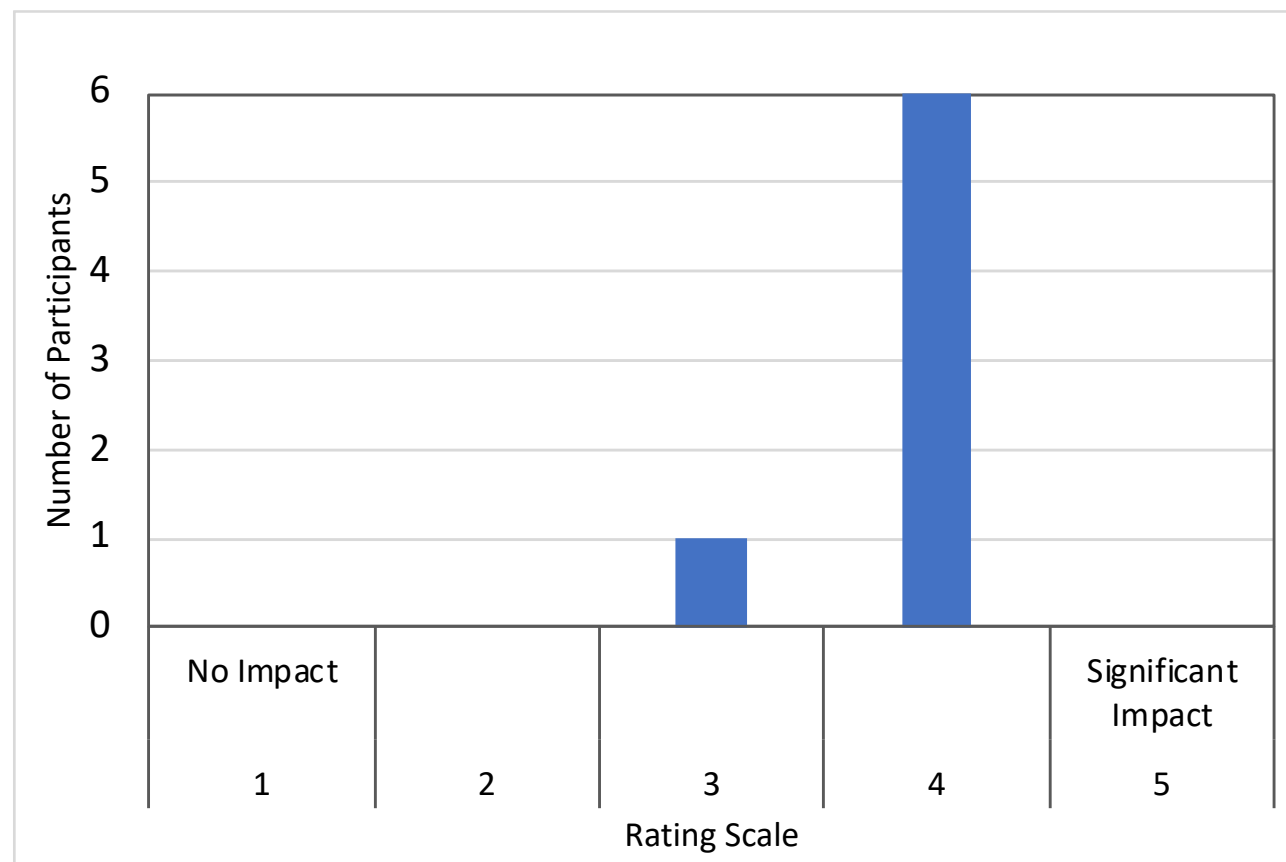

Note. One participant did not complete the post-study questionnaire.

Previous studies have typically included surveys asking how participants feel an online space is affecting their practices but suggested an implication to research beyond self-reports of how participants feel (Bergviken Rensfeldt et al., 2018; Carpenter \& Krutka, 2015; Davis, 2013; DeWert et al., 2003; Duncan-Howell, 2010; Ranieri et al., 2012; Trust et al., 2016; Visser et al., 2014; Zhang \& Liu, 2019). In this study, I used three data sources to better understand how participation in an online space affected the practices of those educators involved. These data sources included the online Facebook posts, interviews with five participants, and post-study questionnaires. While all three of these revealed that all teachers felt participating in this space 
affected their practices in some way, an analysis of interviews and post-study questionnaires provided a more in-depth perspective on this matter.

Using a crosstab query in NVivo (QSR International Pty Ltd. Version 12, 2018), I compared three codes directly related to movement in teachers' thinking and/or practice and their rate of occurrence in the posts named as having high comments and high participants. Results indicated the codes desire to learn, recognition of area for growth, and shifting practices from the online discussions had a high number of codes in posts that were also identified as having high comments and high number of participants, indicating that posts from the online space with more engagement may have allowed for greater learning opportunities for participants (see Figure 7). More specifically, $51 \%$ of the discussions included the code recognition for area of growth and the code desire to learn was found in 30\% of the high participant and high comment posts. It is likely that when discussions were engaged in online with more people and more comments, more learning or reflection took place. This may be connected to some participants' desire to engage in discussions with more people and more diverse populations as indicated during interviews and questionnaires. 


\section{Figure 7}

NVivo Crosstab Query Results: Posts with High Comments and High Participants

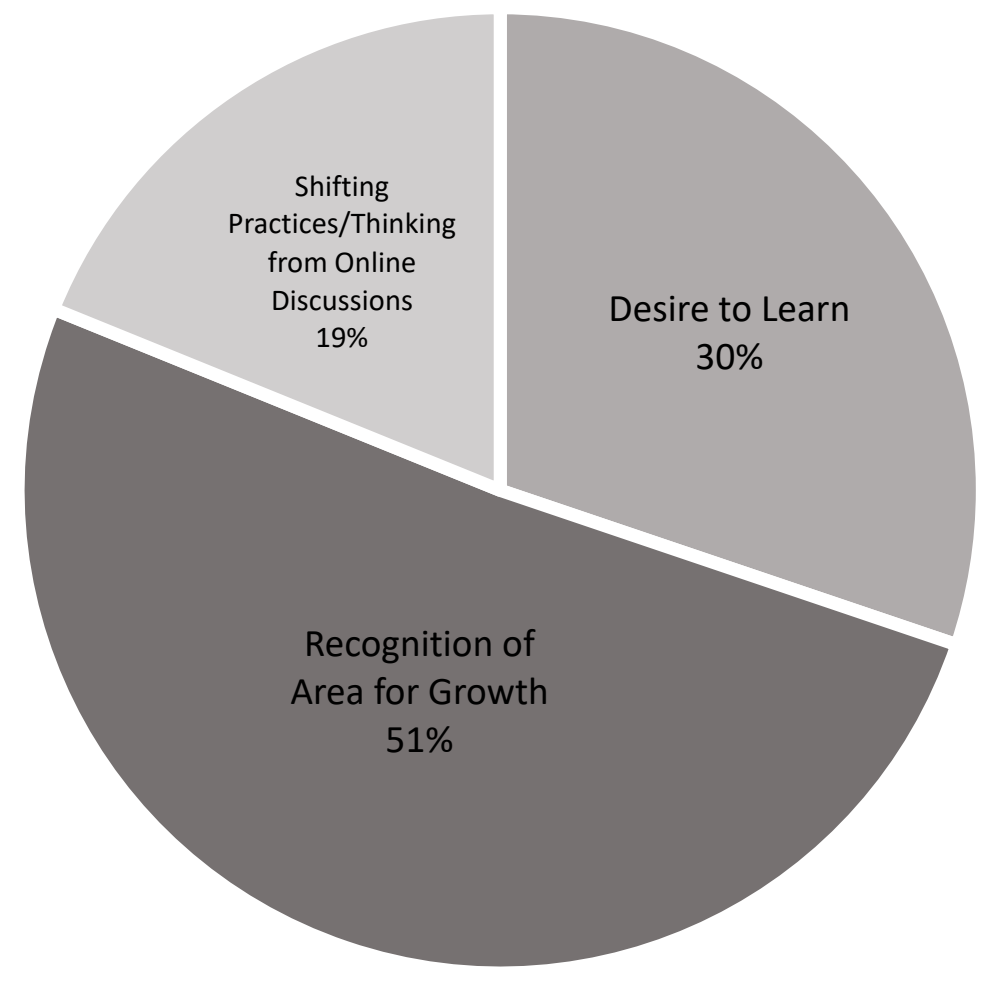

Previous literature suggested a need to understand how the use of online spaces affects teachers' practices beyond just how they feel it is impacting them (Bergviken Rensfeldt et al., 2018; Carpenter \& Krutka, 2015; Kelly \& Antonio, 2016; Lundin et al., 2017; Powell \& Bodur, 2019). Based on this implication from previous research, I included a question on the post-study questionnaire and post-study interview asking participants to name specific times when they learned something or made changes to their classroom practices as a result of a post from the online space. Each participant named at least one specific post from the online learning space that caused them to rethink or shift the practices in their classrooms. Below I will share some of the learning examples participants named through the online posts, the participant interviews, and the post-study questionnaire. Of the 35 total posts made in the online space, 14 posts were 
identified as being significant to the participants. A significant post was one identified by participants as being meaningful to them or impactful to their practices. An article about play time in classrooms, four posts about diverse texts/children's literature recommendations, and an article discussing the merits of Dr. Seuss's works and racism, were posts considered significant by multiple participants. It is not surprising that three of these posts were also four by four posts identified as having a high number of comments and high number of participants and included discussions that encompassed all three of the knowledges from the framework for understanding teaching and learning (knowledge of teaching, knowledge of learners, and knowledge of subject matter) (Bransford, Darling-Hammond, et al., 2005). One additional post regarding boy books and girl books was also named as significant by one participant and was noted for having high comments, high participants, and all three framework knowledges addressed, another four by four post.

Participant Stories of Shifting Practices. Anna indicated she mostly appreciated the posts about book recommendations as she was a new teacher at the time of the study and began making a list of books to use in her teaching. She began reading some of the books that were suggested and commented on how amazing it was to listen to the conversations the children were having about the texts. During her interview she also indicated the book recommendations from articles and from other participants helped her, "it just made it a lot easier than like narrowing it down from like millions." Gretchen echoed a similar sentiment in her post-study questionnaire noting the book recommendations were helpful and specifically she referenced a shift in practices, "I have also thought more critically about books and authors I've read with my students in the past." She did not elaborate on what "more critically" meant, but it does seem an awareness about this topic had been brought to her attention. 
Lavender indicated three times where she specifically learned from posts in the online group. As an avid Dr. Seuss fan, she indicated that the article shared in the group helped her think more critically about his texts and reminded her to use a variety of books and authors during Read Across America week instead of just books by Dr. Seuss. She also implemented play time in her classroom previously but the article shared helped her feel more confident in her choice and gave her new ideas for this time in her room, "imaginative play is one big area I want to try to like touch and tap into because I feel like it could really help boost other subject areas." One final area of learning for Lavender from the online group, was the use of Flipgrid for recording student reading responses. Even after a recommendation from the online space, Lavender was hesitant to implement this. Though her desire to do so was strong, her fear of technology was interfering with her actual implementation. However, she sought out additional support from an in-building colleague and together they collaborated to get Flipgrid started with the students.

Another participant Lyn also indicated she changed some practices in her room regarding play time from the article that was shared in the group. During the interview I asked what specifically she changed in her classroom as a result of reading the article and the other comments from participants online and she said,

My mornings are umm much more flexible. Well they [the students] came in and umm they had to write in their journals. Like that was just what they did. And then read. Where now I want them to get those iPads out and explore things on them, whether they look up their comments on Seesaw. Whether they go to Brain Pop. Whether they do Epic and read some books. They can get on the computer and do their, some options there. 
However, as indicated previously, her most significant learning came from times when she was reminded to consider the source and the author of a resource.

While Elizabeth did not name a specific time when she changed a practice in her classroom, she did indicate a time where she was forced to think about her language. In a post where I posed a question about the term "kindergarten words" where educators deem certain words as being words that kindergarteners should know, Elizabeth commented that she does call certain words by this term, but the question posed online and the discussion from participants caused her to rethink this language and consider how it might make the students feel to hear that term. Elizabeth provided a rationale for why she initially started using that term,

I started calling them kindergarten words because when I came to [a previous school] that was how they were referred to and that's how they are on the report cards and so that just became our language and I think that conversation helped enlighten me that those aren't just kindergarten words they're everybody's words.

Elizabeth also indicated that the article and discussion on "boy books" and "girl books" helped her feel more empowered to talk about this topic with students and with parents, if needed.

Laurie indicated how her thinking on topics regarding social justice and diversity were pushed and at first, she indicated she would be hesitant to talk about those things in schools. But then stated during her interview,

...by reading through some of the articles and just some of the other perspectives, it was like you know wow those are some very important things and I hope those things can be presented and approached in those younger grades.

She went on to share how she asked the school librarian to order some of the texts we discussed and plans on using the texts in her small group discussions in the future. 
While MaryAnne, a student teacher, was not an active participant online, her post-study questionnaire indicated she did learn from the group as she simply stated, "I have changed my thinking on classroom decor, I have a new list of books."

\section{Developing Agency}

In developing this online space, I sought to create a space for teachers to engage in critical conversations and support one another as I felt I was not getting what I needed in terms of support from the professional learning experiences that I was exposed to in all my realms of education I discussed in chapter one. I had to take ownership of my own learning and was beginning to develop agency on my own. As I previously stated, teacher agency defined by Toom et al. (2017)

is manifested in having the understanding and will to collaborate, build a community, develop through shared professional work for the best of student learning, solve problems and challenges together via discussions, utilize feedback received from the peers, support others as well as the ability to be supported. (p. 127)

While participants indicated they felt involvement in this space did help them learn and grow as teachers, I also specifically asked participants to share times when they felt they were empowered from a post online, beyond just making changes to their own practices but times they spoke out on a topic or felt more confident to do so in the future. Anna indicated that she felt empowered when she was talking with a new teacher in the school, saying she had more confidence in offering her advice or suggestions. Lavendar plans to speak out with her colleagues regarding a tradition in the school, as she now thinks it may lack diversity because of texts the teachers are reading. In addition, Laurie shared about times in school meetings where she felt hesitant about topics that were being pushed onto her that she felt did not align with her 
own beliefs. From the posts online, she now says she has more articles to reference to support her thinking that she can share in future meetings. Finally, even though MaryAnne was not active in the majority of posts online, her post-study questionnaire did state times where she felt empowered,

Some of our discussions have reaffirmed my beliefs about decisions I've made, such as whether or not to assign 'fluff' projects that parents end up doing for their kids (i.e. leprechaun traps) or how to make those projects more meaningful to students.

Here could have been a time where MaryAnne was seeing things happen in her student teaching that she was questioning, and the discussions helped her feel more confident in her choices that may have been different from what she has previously seen in classrooms.

\section{Four by Four Posts}

At the end of the numerical analysis section, I shared about the four by four posts from the online Facebook group that met multiple indicators of the quantitative analysis. In this section, I will highlight how the interactions and change themes in the thirdspace, cordial conversations and the discourse of agreement, resisting moments of critical conversations, shifting practices and developing agency, were prevalent in these posts. To begin, the comments from the posts NCTE Must Read Books, were all cordial and support the discourse of agreement as there were no counter opinions offered. Instead, participants shared examples of times they had read some of these texts in their classrooms and included offers to share texts with others. The discussion ends with me sharing a reflection of how I wonder about the ways that these texts influence children in the rest of their lives. The only instance of a participant noting a change in practice was when Anna described the time she read a new book to her class and it helped promote conversations about stealing and empathy. 
The next post, Boy Books and Girl Books, shares comments from participants classrooms, reflections of their own childhood as readers, and reflections from what they read in the article. Additionally, participants added additional resources to the comments including pictures from another educational Facebook page addressing gender stereotypes through literature and a link to a YouTube video of a book on gender stereotypes to use with children. Questions were also posed to others wondering what is considered a "controversial topic" and if these topics should be addressed with parents ahead of time. The entire post remains cordial, and at the beginning of the discussion, the first few comments include the discourse of agreement with strong agreeing statements. There is only one instance of a counter opinion mentioned when Laurie says, "I want to be sensitive to, and respectful of my students' families who might have different opinions about these issues." There were no further comments to directly address this, demonstrating the theme resisting moments of critical discourse. However, I end the post with a comment including a direct quote from the Common Core State Standards noting that students should be exposed to various experiences and perspectives. There were no specific instances in the comments where teachers named a shift in practices but comments from interviews and questionnaires indicated this post did encourage participants to consider various topics to address with students as well as feelings of confidence to discuss these topics with parents, if needed.

In the post, Dr. Seuss Books Can be Racist but Students Keep Reading Them, I began the discussion with my initial post asking what everyone thought about the article regarding the critiques of Dr. Seuss. The comments in this post share reflections from the article and participants' own use of Dr. Seuss in their teaching. Some share stories of how they have shifted their practices after reading this article and one critical comment offering a different perspective was made by Gretchen to end the discussion. There were instances of the discourse of agreement 
as strong agreeing words were used in comments. From the post-study interviews it was also indicated that this post helped some participants develop agency and speak to other colleagues about certain reoccurring practices at their school.

The final four by four post, Every Kindergartener Deserves Play, maintains a cordial tone and includes some instances of the discourse of agreement, but much less than the other four by four posts. This post includes more questions about how others have implemented play in their day and examples of what it looks like in a classroom. There were no instances of a critical comment made in the comments. There are instances where participants note where they want to make changes to their classroom and are considering how they might do this and some classroom examples of how play and learning are integrated affirming one's desire to shift their practices.

This section presented the qualitative findings and themes from the online posts, poststudy questionnaires, and post-study interviews. The quantitative analysis helped me identify specific posts and discussions to take a closer look at, which illuminated the following interactions and change themes: cordial conversations and the discourse of agreement, resisting moments of critical conversations, shifting practices, and developing agency. I also addressed the interactions and change themes in the four by four posts. I will now describe the participants' reflections and thoughts of the online learning space.

\section{Participant Reflections on Interactions}

It was comments and discussions in the examples shared above that helped me see something was happening here with the discourse among participants when they agreed and disagreed with each other. However, these findings became even more illuminated in the comments made by participants during their interviews and their questionnaires. Relevant to the findings of cordial conversations and discourse of agreement was Lavender's comment, "I was 
trying to make sure like I didn't put someone down.” In this case, the participant stated in her interview that she was hesitant to be the first to respond to a post about creating leprechaun traps as a school project at home. Within the Facebook discussion, she did share her opinion on the topic stating she did not think it was a good practice but this hesitancy at first became a common theme among other participants as well. This sentiment was echoed by Lavender in seven more statements made during her interview and one from her online questionnaire. I will now share examples from the interviews and questionnaires where participants describe their thoughts and reflections regarding the interactions of the online space.

Participants commented on the use of an online environment and how people talked to one another online. Participants acknowledged the cordial conversations and discourse of agreement as they mentioned how they were concerned with how others would interpret their comments. A common sentiment was the inability to interpret what one means through printed text alone. During the post-study interview, I asked participants how they compared the online space to in-person collaborations with peers. Lyn responded,

I think teachers are very aware of that though, so if you're like in an online group with teachers we're all aware that texts [text messages], and online you don't get that, the inflection in the voice, you don't get the context necessarily. So I think that we are very careful with what we say not to offend or (laughs) or disrespect any one because we certainly don't want to do that but that's that is a problem with online stuff. You don't always know how to take what's being said.

Laurie's statement from her post-study interview is similar to Lyn's as she said, I think it was just challenging to make sure I'm portraying what I'm really thinking and all of that I'm thinking in the posts. And do people know what I mean... when I put the 
things I do. That's something that you know that like did I portray out, because you know you when you talk to someone and you've got them in front of you, you're able to add in what you mean.

Anna even commented during her interview that she thought people would be more apt to speak freely in an online space as opposed to speaking face to face. However, each participant indicated that they never felt offended by any posts or discussions and Lavendar stated, "I didn't feel like people were like judging or criticizing." Along with these statements was one from a novice teacher, Anna, who said

If anything, it was almost like everyone was just so, too polite. Like, I mean, umm not that there was anything super controversial or anything. But there wasn't much of dis-, anybody disagreeing with each other. And just the first thing that I thought of was that it was just kind of like everybody's just being polite.

Did she say this because she was hoping to engage in more critical discussions where people would question one another? Another consideration might be due to her being a new teacher and not yet immersed in the discourse of agreement common in educational settings. Elizabeth also indicated a desire to hear more opinions from a wider circle:

I think knowing a lot of people in the group, was good and bad. I, I think it would be nice if the group was larger and you have some different experiences. Umm you had people with different backgrounds. That worked in more diverse schools. I think maybe it could be richer if we weren't coming with a lot of similar thoughts and training.

Lavendar suggested a similar sentiment about wanting more participants in the group, "Because I feel like the more the people the more like the more comments and better conversation you have." 
While participants suggested a hesitancy to offend one another and a desire for more opinions and perspectives, getting at both findings, cordial conversations and resisting critical conversations, participants also appreciated the comfort offered by the members of the group. In her post-study questionnaire Anna stated,

The impact of this group was furthered by the inclusion of teachers in all stages of their career. It was profound to hear advice and opinions from those who are just beginning their career all the way to those who are veteran teachers.

She also indicated she felt empowered and a boost of confidence when people would agree with her statements. Anna continued the same sentiment when she said, "also knowing that there's people out there or think the same way or agree with you on some level. That gives you a sense of power too." This suggests participants want to hear opinions of others but are hesitant to offend others, and at the same time appreciate praise from colleagues but are also interested in having discussions that are not "too polite." These examples demonstrate intersections of both the cordial conversations and discourse of agreement along with moments of resisting critical conversations.

One question on the post-study questionnaire asked, "Were there any specific conversations that you disagreed with but did not comment on in the Facebook group?" All participants indicated "no" and only one participant, Laurie, added an additional comment: "I felt comfortable responding." Considering this particular question, the examples of online posts shared above, and the participant reflections of the interactions, it seems the participants enjoyed learning from one another but also showed concern for not offending others as they engaged in cordial conversations, which may have stood in the way of engaging critically with the topics. Further implications regarding this will be addressed in chapter five. 


\section{Summary}

This chapter presented my findings from the Facebook online learning community. I began by describing how I addressed each research question. Then, I included a background of the participants as well as a quantitative description of the space. Furthermore, the content of the posts within the online space as well as the findings related to interaction and change themes of cordial conversations and the discourse of agreement, resisting moments of critical conversations, shifting practices, and developing agency. In addition, the reflections from participants of the online learning space were described. In the following chapter, I will share the discussion of the findings, implications for the future, and limitations of this study 


\section{CHAPTER V: DISCUSSION}

"If I am willing to look in that mirror, and not run from what I see, I have a chance to gain self-knowledge--and knowing myself is crucial to good teaching" (Palmer, 2015). This quote reminds me that throughout my experiences in education, critical reflective engagements have helped me consider how my own schooling experiences from childhood through adulthood have helped me become the educator I am today and hope to continue to be. My desire to engage in critical conversations with others in education helped me develop and study this online learning space for teachers.

\section{Introduction}

In this study, I created an online learning environment on Facebook as a space for educators, both novice and experienced, to reflect, support, communicate critically, and collaborate with one another. Framing the study in thirdspace theory allowed me to develop an online space to promote connections between preservice and in-service teachers as well as highlight intersections among university coursework, classroom practices, and educational theories. Initially, I created this space as a place for student teachers to engage with teachers outside of their assigned student teaching mentor and other student teachers. More specifically, a thirdspace where they could discuss topics they may not have felt comfortable discussing with their assigned mentor or a space to engage in conversations about the similarities and differences in what they were seeing in classrooms juxtaposed with what they had learned in their university coursework. However, this intention did not play out as I had planned because only two student teachers joined the study, and they did not actively participate in the space throughout its entirety. Nevertheless, the Facebook group did remain a space for teachers to converse and learn from one another. 
In this chapter, I discuss the findings from the previous chapter and share how these findings are connected to previous research of online learning spaces and the implications for practice and research regarding online learning spaces with educators. It is not my intention to present an "answer" to what the field should do as all teachers are different and come from different schools, backgrounds, and teach different students. Therefore, I am not trying to present a one size fits all model from this study, but instead offer suggestions of possibilities and considerations for other educators who wish to engage in online learning groups.

I will start by discussing thirdspace as it was enacted in the space that I created for the study. I will then discuss the quantitative analysis, the interactions theme-cordial conversations and the discourse of agreement and resisting moments of critical conversations; as well as the change themes-shifting practices and developing agency. A discussion of unanswered questions and missed opportunities will follow this. I will also present a graphic display of my interpretations of the findings from the online space. The chapter will conclude with the implications for practice and research, as well as limitations of the study.

\section{Thirdspace}

While I was not able to explore all of the initial research design I had intended regarding thirdspace theory, specifically, creating a space for in-service and preservice teachers to converse and providing a space for coursework connections/disconnections to classroom practices, there were elements of a thirdspace that were enacted in this online learning group. In chapter two, I shared a definition of thirdspace that aligned with my beliefs about thirdspace and how I envisioned this space as, "a place of reflection, renewal, and change in which two supposedly oppositional worlds are re-imagined to identify tensions, conflicts, exaggerations of distance, commonalities across domains, sources of insight, and inspiration for action" (Flessner, $2014 \mathrm{p}$. 
6). The online space itself was a thirdspace as it brought together novice and experienced teachers, "two supposedly oppositional worlds," in a realm outside of their own schools. In addition, participants from various school contexts "exaggerations of distance" were brought together in this Facebook group as a "place of reflection."

When considering the findings, there were times when thirdspace interactions did occur among participants. Instances of thirdspace were enacted when participants were able to address common practices happening in their schools and then describe how posts from this online space encouraged them to rethink these practices. To elaborate, when participants identified common practices in their schools or their own classrooms that did not align with posts or comments from the online discussion, these might be described as "tensions" and the posts and comments from participants in the online space served as "sources of insight" and "inspiration for action." Multiple examples of this were shared in chapter four through the findings "shifting practices" and "developing agency." These examples include when Laurie shifted her thinking on discussing diverse topics with her young students and when Elizabeth shifted her language when thinking about the term, kindergarten words.

\section{Numerical Analysis: A Quantitative Look at the Online Space}

In chapter four, I shared the quantitative analysis of the online space, including the topics of the posts, the posts that had a high number of comments and high number of participants, posts that were considered theoretical and practical, and the breakdown of posts and discussions participants had with regard to the knowledges in the framework for understanding teaching and learning (Bransford, Darling-Hammond, et al., 2005). These intersections of quantitative analysis will be discussed in this section. 
From the quantitative analysis and the framework for understanding teaching and learning (Bransford, Darling-Hammond, et al., 2005), knowledge of teaching was the most common knowledge referenced in the online posts. It was found in 29 of the 35 total posts. It is not surprising to see so many posts within this knowledge, as knowledge of teaching gets at the practice and pedagogy of teaching. Included in this knowledge are the areas of teaching subject matter, teaching diverse learners, assessment, and classroom management (Bransford, DarlingHammond, et al., 2005). This concurs with the top ten topics coded in the online posts which included the codes: classroom students, reading, parents home family, children's literature, classroom design, classroom teaching example, materials, connection to literature, social justice, and classroom reference. In addition, "classroom examples" was the most prominent code in the four by four posts (the posts that were noted for having high participants, high comments, named as significant by participants, and included all three framework knowledges). These four by four posts included links shared from other Facebook educational pages and may have been considered relevant topics in education right now. Previous studies indicated teachers prefer a learning space where they can discuss topics that are relevant to their practices (Booth, 2012; Brown, 2007; Carpenter \& Krutka, 2015; DeWert et al., 2003; Duncan-Howell, 2010; Hur \& Brush, 2009; Lundin et al., 2017; Trust et al., 2016; Zhang \& Liu, 2019). Furthermore, the inclusion of current articles from additional educational sources found in each of the four by four posts also illuminates the suggestion that teachers want to discuss relevant topics.

The next knowledge from framework for understanding teaching and learning (Bransford, Darling-Hammond, et al., 2005), knowledge of learners and their development, was found in 25 of the 35 posts in the online discussions. This knowledge relates to learning, human development, and cultural backgrounds and how teachers apply this to their instruction. The high 
number of posts containing this knowledge suggests teachers in this group were focused on their students. The final knowledge, knowledge of subject matter and curriculum relates to educational goals, content, and subject matter. There were 16 posts, almost half of all posts, that included this knowledge. In previous literature there is much criticism of conversations in online groups that are too "fluffy" or do not really get at a deeper level of teaching (Bergviken Rensfeldt et al., 2018; Carpenter \& Harvey, 2019; Kelly \& Antonio, 2016; Xing \& Gao, 2018). From this analysis using the framework for understanding teaching and learning (Bransford, DarlingHammond, et al., 2005), it seems there were some discussions taking place within this online thirdspace that were not just sharing generic exchanges since 11 posts, nearly one third of all posts from the group, included all three types of knowledge.

Additionally, I analyzed posts and identified if they were practical or theoretical in nature. As discussed in chapter two, a goal of this online space was to consider the perceived gap of theory and practice in education, therefore, I thought it was important to consider which posts were theoretical and which posts were practical as I studied the online discussions. I found six posts that included both practical and theoretical content. I purposefully initiated some posts with an intention of bringing theoretical content to the group and almost $50 \%$ of these posts were interacted with among participants. Furthermore, five of the theoretical posts also included all three knowledges from the framework and four theoretical posts were noted for having high comments and high participants. Previous findings from Hur and Brush (2009) addressed why teachers engaged in online learning spaces, "the reason teachers explored teaching ideas in the communities was that teachers searched for very specific ideas that were appropriate for their unique teaching situations, and their unique needs were often met in the communities" (p. 295). Therefore, as was affirmed in this study, when posts in online spaces are relevant to teacher 
needs and move beyond superficial sharing of ideas, interactions and learning can take place in meaningful ways.

\section{Interactions and Change in Thirdspace}

The findings in chapter four present the interactions theme in the online thirdspace and the change themes participants acknowledged from the online space as well as reflections from the post-study questionnaire and interviews. These findings will now be more thoroughly discussed in relation to the previous research of online learning spaces. In addition, multiple considerations of what may have been impacting the discussions in the online space will be explored.

\section{Cordial Conversations and Discourse of Agreement}

One of the first things I noticed about the discussions taking place on Facebook was the polite tone of the participants and the high number of instances of the praise, agreement, encouragement code. I saw instances where participants used strong words to show their agreement and instances of hesitancy or less directness when one had a different viewpoint in a discussion, these are described as cordial conversations. I chose the word cordial because Merriam-Webster defined cordial as "politely pleasant and friendly," and provided these words as synonyms: amicable, collegial, friendly, and neighborly (Merriam-Webster, n.d.), to name a few. This definition and these synonyms seem to fit with what I noticed was happening in discussions within the online learning space.

When this noticing from the online discussions was combined with reflections from participants in the post-study questionnaires and interviews, I realized this finding had impacted the online learning space. There were minimal instances of critical discussions where participants pushed back when they disagreed. Moreover, Anna described the discussions as "too 
polite" and Lyn's engagement in the group declined after critical comments were made on posts she had initiated. When designing this space, I had intended to create a place for educators to engage in critical reflection and explore and challenge their current teaching practices.

There were several instances where comments were coded as praise, agreement or encouragement. In these places, participants often used strong words to affirm their encouragement or agreement (Yes! I agree! Thank you for your ideas! Glad you brought this up!). Numerous studies from previous online learning spaces suggested a significant finding to be related to the encouragement and support educators feel from participating in online spaces (Bergviken Rensfeldt et al., 2018; Booth, 2012; Britt \& Paulus, 2016; Brown, 2007; Carpenter \& Krutka, 2015; Chen et al., 2009; Davis, 2013; Deryakulu \& Olkun, 2007; DeWert et al., 2003; Duncan-Howell, 2010; Hur \& Brush, 2009; Macià \& García, 2018; Powell \& Bodur, 2019; Prestridge, 2019; Ranieri et al., 2012; Trust et al., 2016; Visser et al., 2014). More specifically, DeWert et al. (2003) reported from their study "the online community provided them [participants] with much needed emotional support and encouragement while diminishing their feelings of isolation and helplessness" (p. 318). Anna's responses in her questionnaire following the study concur that the emotional support and agreements from various educators with different levels of experience helped her feel supported and encouraged in her teaching. In a literature review of online learning spaces, Lantz-Andersson et al. (2018) found online spaces to be places where teachers build confidence, which happens through the encouraging comments of others. MacPhee and Belcher (2019) had similar findings where they noted hesitancies among participants to provide critical feedback and instead noticed praise and encouragement to be dominating post-lesson conversations among university supervisors, teachers, and preservice teachers, "The discomfort with providing constructive feedback... and quick shifts back to 
praising/encouraging, seemed to prevent participants from exploring in-depth, alternative instructional strategies and/or language" (MacPhee \& Belcher, 2019 p. 57). Similarly, Williams (2014) noted examples where university faculty observed practices taking place in classrooms that they disagreed with but did not speak up. When critical comments were left unaddressed in the online thirdspace, did participants in this space brush past critical comments, "just to be polite and avoid conflict" (p.324) as Williams found among participants? Garmston (1987) suggested that perhaps extensive work needs to be done in this school culture to promote collegial coaching, "when teachers' professional dialogue increases, the school system itself becomes capable of change" (p. 21).

Another benefit of this online space reported by participants, was the ability to take time to think and respond to another person's questions or comments. Laurie commented in her post study interview, "I liked having that moment to think about something." And Lyn shared a similar sentiment, "I like the online thing though as opposed to book clubs or reading every week because you can get to it at your own convenience. You can put some thought into what you want it to say." Lyn continued on in her interview sharing a related benefit of the online space, "Nobody can interrupt you. Nobody can cut you off. But you can still have people disagree. You can still have people agree. You can still have a conversation as long as its respectful.” To highlight another example, Elizabeth posted an additional reflective comment to follow up a previous comment in a post, demonstrating how she was shifting her thoughts from her first comment after she had more time to think about the post. I was left considering if this "time to think" that was noted as a benefit of the online space, contributed to the cordial conversations and the discourse of agreement in the online space? Does "time to think" allow participants a processing interval where they can word their responses carefully? Would this have been 
different if the interactions took place face-to-face? In this example, time to think is a benefit of online engagement, but it could also be another factor contributing to the cordial conversations. When considering the factors that could be contributing to the high number of codes of praise and agreement and the theme of cordial conversations, were participants in this space looking for a place to support one another as teaching can be overwhelming, intensification in the workplace is prevalent (Larson, 1980), and the field is often attacked by the media (Coe \& Kuttner, 2018). Participant responses on the pre-study questionnaire indicated they do want to support one another as "respect" was a common word found in the participants' responses to the question: What expectations do you believe should be established for this group? In addition, participants asked that others be "open" and remember "we're all in this together." House (1981) asserted, "certain kinds of social support from certain kinds of people can reduce certain kinds of occupational stress" (p. 59). Therefore, juxtaposing this sentiment from House with the participants' responses, it is not surprising to find so many cordial conversations and comments where participants praise and encourage one another as well as places where critical comments are made but participants do not use strong statements such as "I disagree" as mentioned above. It seems teachers in this space wanted to support one another. While online spaces can provide much needed emotional encouragement for participants in a demanding field (Macià \& García, 2018), it is also important to consider how being cordial or too polite might interfere with deeper dialogue.

Context of Collaboration. Another area to consider in conjunction with the cordial conversations finding is how participants view collaboration. Alongside information available on the district website, my positionality in the district gives me an insight into how collaboration is viewed in the district. Most buildings within the district have a coach whose role, according to 
the district website, is to collaborate with teachers, facilitate school improvement, and coordinate professional development with administrators (Pekin Public Schools, 2019). A common sentiment among coaches is that their role is not to be an evaluator and instead are there to support the teacher. However, at times when I personally have spoken up in meetings to question a practice, I often have been met with polite pushback, suggesting a decision had already been made and other options were not up for discussion, aligning with Hargreaves and Dawes (1990) notion of "contrived collegiality." Since this is the typical culture of the schools in which participants work, this could also provide an understanding of the pattern of discourse or agreement from the online space. Bergviken Rensfeldt et al. (2018) noted similar interactions within online spaces, "Rather than being a site of dialogue and discussion, the dominant communication patterns were notably one-way and devoid of substance, with only occasional elaborated discussions" (p. 246). My positionality as a doctoral student has shown me that collaboration can be more than just talk among people but instead can include critical conversations where friends and colleagues challenge each other knowing that it is for the betterment of practice and not a personal attack on another. However, this may not be the common discourse of collaboration in the field of education as was suggested by the finding of cordial conversations and resisting moments of critical conversations in the online space.

Talk Moves. Another common practice encouraged by this district is the use of talk moves (Chapin et al., 2013) with children in classrooms. Talk moves were introduced to most teachers through the Math Solutions series during professional development workshops, building meetings, and district wide grade level meetings. Within talk moves, teachers are encouraged to show students how to engage in discourse with one another by saying things like, "I disagree because...," "I agree with___ , because..." or "I would like to add on to what___ said...." 
Coaches in this district have come into some classrooms to model lessons using talk moves with students and create anchor charts to hang in classrooms. It is interesting to consider that the teachers who participated in this online learning group have been exposed to the use of talk moves with their students and may be encouraging this kind of dialogue in their own classrooms, but are not yet engaging in this kind of dialogue in their own discourse with other educators, as was noted in the finding of cordial conversations and resisting moments of critical conversations. For example, critical comments were left unaddressed and discussions often ended after a critical comment was posted. Another example includes when Laurie was hesitant to discuss controversial topics with her young students. If she had been using talk moves, she might have said, "I disagree and do not think we should discuss..." instead of "But...Tbh [to be honest], I am leery when the term "social justice" is used in education." Would another participant have responded if the words "I disagree" had been used?

A View of a Mentor. One question asked of participants in the pre-study questionnaire was: "How would you define the term mentor in education?" While this specifically asked about the term mentor, I did think this question could shed some light on the participants' views on collaboration, as a mentor can be a source of collaboration and a source of critical reflection. This became a consideration of mine as I wondered about the theme of cordial conversations and resisting moments of critical conversations within the online discussions. The words guide, role model, and reflect were commonly found in the responses. One student teacher, Nicole, wrote, "To me, the term mentor refers to a person who is experienced in many areas of education and uses their experience to help a new generation of educators grow professionally." Whereas more experienced teacher, Lyn, said, "A person that guides someone new to the teaching profession toward their own teaching style and help them develop into a lifelong learner. Our education isn't 
over when we get that degree. :).” None of the responses mentioned critical comments or engaging in discourse to push each other's thinking. Fresh perspectives, role model, and support were other words woven throughout the responses. The responses on this particular question seem to indicate participants believe a mentor should be safe and supportive. This also aligns with the pattern of strong agreement statements, hesitancy to offend others, and the desire to receive praise and encouragement from others coded in various data sources including online posts, interviews, and questionnaires.

Since these three factors are related to the context of this study and the context of the communities these participants work and engage in daily, they are important to consider alongside the findings as I asked what could be affecting these common instances of cordiality, potentially at the expense of more critical dialogue.

\section{Resisting Moments of Critical Conversations}

In her book, Dare to Lead, Brenè Brown suggested issues centering around being polite as an impediment to the tough conversations necessary for honest feedback and productive growth. More specifically, if we want to change and critically reflect in meaningful ways, we must learn how to be vulnerable. "The courage to be vulnerable is not about winning or losing, it's about the courage to show up when you can't predict or control the outcome" (Brown, 2018 p. xvii). As I mentioned before, most instances of agreement came with strong words to support one's opinion. However, when a different opinion or disagreement was posted in the discussions, these comments often appeared without strong words. In the analysis of online posts, I did not find instances of people saying, "I disagree" or something similar. One example I shared in chapter four from the online discussions came from Gretchen when she offered a counter opinion regarding the works of Dr. Seuss, "I think it's fine to look at these works of art through a critical 
lens and teach children to do the same, but I don't think we should completely drop an author like Seuss.” Here I saw Gretchen name a counter opinion, but no additional comments were posted to follow this. In these instances, I was left wondering if Gretchen had made a stronger case for her disagreement perhaps saying, "I disagree," would further discussion have ensued? Statements from participants' interviews emphasized the discourse of agreement as well and caused me to ask again, is cordiality getting in the way of more critical conversations? Lavendar stated, "I was trying to make sure I like didn’t put anyone down.” I also considered Laurie's statements related to concerns that other participants would not understand what she was trying to convey. If participants were worried about offending others, did they move on from these discussions so as to not rock the boat?

When I designed this space, I had intentions of creating a collaborative online environment where critical discourse could take place and disagreements could happen respectfully. As I mentioned in chapter one, I have always been interested in having more indepth conversations where educators can support and challenge one another. In fact, in the initial recruitment video shared with all staff to introduce the space, I said: “An online space for teachers and teacher candidates to collaborate and critically reflect on teaching practices in order to engage in professional learning through conversations, feedback, and educational resources." Furthermore, the expectations of the participants included this bulleted statement: "Engage in critical reflection to examine your own teaching practices with a strong desire to challenge your current teaching practices for the benefit of your students." The words "critically reflect" and "challenge your current teaching practices" were chosen carefully for the introduction to indicate this was not intended to be a fluffy space for superficial collaboration (Bergviken Rensfeldt et al., 2018; Kelly \& Antonio, 2016) or contrived collegiality (Hargreaves \& Dawe, 1990). 
However, one or two statements may not be enough to challenge the identity of teachers and their culture of collaboration that could be affecting the types of conversations they have in education and particularly in this online space. While I am not suggesting online discussions should be disrespectful or harsh, I am left considering how further critical comments, that may have been brushed over in this space, led to missed opportunities for participants. Could discussions with stronger disagreeing words, like was prevalent in the cordial conversations and agreements, have allowed participants to dig deeper into their own beliefs and practices and engage in critical reflections as I had intended for the space?

Other studies of online spaces note a lack of critical conversation as a critique as well (Bergviken Rensfeldt et al., 2018; Carpenter \& Harvey, 2019; Carpenter \& Krutka, 2015; Kelly \& Antonio, 2016; Xing \& Gao, 2018). Carpenter and Harvey (2019) reported, "Several participants mentioned instances in which they had witnessed other social media users appear to become defensive or offended by what were well-intentioned attempts to deepen conversations through constructive commentary or feedback" (p. 7). When Anna was asked during her interview what she would change about the online space she stated, "It was almost like everyone was just so, too polite...but there wasn't much of dis-, anybody disagreeing with each other." I was left considering, where does this stem from? Participants suggest a desire to engage in critical discussions, but even more noticeable was the hesitancy to be critical at the risk of offending someone. I wondered if this related to the participants' understanding of collaboration and what it means to them or is it connected to the context of the environment and culture of the school district or on an even larger scale the culture of the profession of education. Since Anna was a new teacher, I considered if her reflection of being "too polite" stemmed from the fact she had not been immersed in the culture of education or this district as long as other participants? 
Previous studies indicated a sense of trust is important in online spaces (Booth, 2012;

Kelly \& Antonio, 2016). While the space did begin with introductions and a discussion for participants to get to know one another, was it possible for participants, some complete strangers, to fully trust one another in short amount of time? Anna acknowledged the use of a secret group on Facebook helped her feel comfortable in the space and even specifically stated in her interview, 'It's not like people elsewhere are going to be reading what I say. It's only people that I know are trusted teachers and people that hopefully are all in this for the same thing." Lavendar also indicated she initially observed in the space but as time went on, she engaged more in the discussions. Was she working to establish trust during this time? A consideration of how others begin to trust one another in an online environment should be explored as I am left to wonder if there were connections between trust and the frequency of cordial conversations and the moments of resisting critical conversations.

Furthermore, in a future study it would be worthwhile to do more preliminary work to develop a shared understanding of what critical conversations mean. Watson et al. (2016) concurred, "nurturing the development of criticality is very difficult" (p. 43) and "developing criticality implies a readiness to question beliefs and assumptions" (p. 45). Taken together, the findings related to cordial conversations and resisting moments of critical conversations, along with the discussion of trust, insinuate that participants were more comfortable engaging in a discourse of agreement than they were engaging in critical discourse, despite some participants articulating in interviews and questionnaires a desire for more critical conversations

Role of the Researcher Promoting Critical Discussions. When considering the online space and the cordial conversations taking place alongside the resistance of critical conversations, I do have to wonder if, I the researcher and "leader" of the online space, did 
enough to promote the critical reflections I sought to engage in based on the outlined goals of the study? Were there times when I could have offered a more critical comment when I disagreed? Or probed further into a participant's comment? Looking back at my researcher journal, I did find one specific incident when I reflected after an online discussion took place and said I would have liked to have questioned one specific participant about what they meant in their comment as I had a different opinion. However, I did not want to seem like the "knower" of all information and dominate the group. My own hesitations to speak critically could have impacted the group discussions as well. Another reflection in my researcher journal included a memo I wrote in July (after the Facebook group ended) where I looked back at a post and asked why I did not probe further. My memo asked:

Does this align with your philosophies of education or is it just fun? What do you mean you have a good class? You wouldn't have done this otherwise? - Does this relate to the niceness finding as well? Did I not want to offend my friend?

It is noted in the research that the role of the facilitator is an important factor in the interactions and engagements in online learning spaces (Booth, 2012; Britt \& Paulus, 2016; Ranieri et al., 2012). In future online learning spaces, I (or any other facilitator), may need to "step up" the posting of critical comments. I approached this role with caution as I was hoping to maintain a balance among participants in order to break down the common hierarchies that often play out in education among novices/experts and university/schools (Cochran-Smith \& Lytle, 1999; Flessner, 2014; Korhonen et al., 2017). I did not want to step into the role of an expert or dominate the online discussions. Finding a balance between these two was a challenge as a facilitator. 
Critical Conversations and Other Facebook Pages. Finding a balance between being cordial and critical happens in multiple spaces on social media, not just in this group. In a recent conversation with a colleague and former participant of this online Facebook group, she shared about an experience when she posed a critical comment to heavily followed educator on Facebook. In the comment, she asked the author to elaborate on his perspective of the practice he was promoting- posting student's known sight words in the hallway, as she felt it diminished children's self-worth because some children would have more words than others publicly displayed. While the ongoing discussion remained cordial, tensions did arise, and other comments ensued with fellow commenters taking sides. While this was not her intention to create a "conflict" she simply wanted to engage in a critical conversation because a post conflicted with her own philosophies of education. It is times like this that I think the realm of politeness and being cordial can get in the way of learning and why it may be important to study the leaders of these pages and ask ourselves, how critical are we being of what we see on social media and what are we doing to change the discourse of agreement and cordiality online, therefore, allowing for reflection and critical conversations to be the norm? Carpenter and Harvey (2019) echoed a similar sentiment as they cautioned, "While interacting with colleagues from outside one's school and district can expose educators to new learning and networking opportunities, it also puts them into contact with other individuals whose expertise, trustworthiness, and authenticity are unknown or uncertain" (p. 7).

If we continue to be offended when one offers a suggestion of disagreement, are we just purporting a notion that educators should do something because they found it on an educational website, or they were presented with a practice to implement from administration or a coach? Hargreaves and Dawe (1990) explained instances like this and the cordial conversations that took 
place within the online space as "contrived collegiality" and suggested these interactions, "deprofessionalize and disempower teachers in denying them opportunity to discuss and debate what and how they teach" (p. 239). Furthermore, in other research studying coaching interactions Hunt (2016) described similar instances as "making nice" and suggested, "Meaningful collaboration requires a degree of risk taking and discomfort because coming to shared understandings involves carefully listening to others, considering multiple perspectives, and trying on new ideas or practices" (p. 341). Sometimes we have to feel some discomfort to be pushed to think more about what we are doing and why we are doing it in our classrooms. This was indicated by participants in this study including Laurie and her thoughts on diverse texts, Elizabeth and her consideration of the term kindergarten words, and Lyn and her recognition of considering a source.

Above I have shared a discussion of the interactions theme regarding cordial conversations and resisting moments of critical conversations. While encouragement and politeness are noted as important to educators in online learning spaces, critical conversations are also of value to participants' learning. Finding a balance between these two can be challenging but rewarding.

\section{Shifting Practices}

By integrating three data sources from this study, I was able to learn more about how participation in this online space affected participants' practices. Previous research indicated a need to study how online spaces are actually affecting teachers practices (Bergviken Rensfeldt et al., 2018; Carpenter \& Krutka, 2015; Davis, 2013; DeWert et al., 2003; Duncan-Howell, 2010; Ranieri et al., 2012; Trust et al., 2016; Visser et al., 2014; Zhang \& Liu, 2019). As I presented in chapter four, when I analyzed the content of the online posts, pre-and post-study questionnaires, 
and post-study interviews, I found instances where participants felt they were impacted by the group and shared specific examples of times they changed a practice in the classroom, or noted times where they planned to make changes in the future. Participants also identified times when they shifted their thinking on topics as a result of a discussion from the online group or even recognized a time when they wanted to learn more about a topic. On the other hand, there were also instances where questions and posts were left unanswered. In these cases, I was left wondering if there were missed opportunities for learning? Previous online learning spaces that have been studied have found participants identify a feeling of being overwhelmed by the posts and not having enough time to get to everything (Britt \& Paulus, 2016; Carpenter \& Krutka, 2015; Duncan-Howell, 2010; Xing \& Gao, 2018).

It is not uncommon to find studies that suggested teachers were benefitting from their engagement in online learning spaces. In chapter two, I shared how participants in online spaces felt they were gathering new ideas and resources, felt they were improving their practices, and appreciated the support they received from other educators (Bergviken Rensfeldt et al., 2018; Booth, 2012; Britt \& Paulus, 2016; Brown, 2007; Carpenter \& Harvey, 2019; Carpenter \& Krutka, 2015; Chen et al., 2009; Davis, 2013; Deryakulu \& Olkun, 2007; Duncan-Howell, 2010; Hur \& Brush, 2009; Kelly \& Antonio, 2016; Macià \& García, 2018; Powell \& Bodur, 2019; Prestridge, 2019; Ranieri et al., 2012; Trust et al., 2016; Visser et al., 2014; Xing \& Gao, 2018). Findings from the interviews and questionnaires in this study report a similar theme-teachers feel their participation in this online group supported their learning or provided them with opportunities to think about changes they could make in their classroom practices. Book recommendations was one area participants Anna and MaryAnne identified a significant part of their learning from this group. 
As I stated at the beginning of this chapter, my initial intentions for this online learning group was to provide a space for student teachers to engage in dialogue with peers and classroom teachers as additional mentors as well as discuss connections and disconnections between what they have learned in their university coursework and what they are seeing implemented in classrooms. Williams' (2014) study of student teachers and mentors shared a finding where student teachers were perpetuating their mentor's practices in their own student teaching even when these practices negated what they had learned in their coursework. Due to the low participation of student teachers in the online learning space, this type of engagement did not occur. There were few instances where the preservice teachers participated in discussions and few instances of discussions of university coursework. While there was little data from preservice teachers in this study, MaryAnne did note an instance of learning for her was rethinking classroom décor due to the online interactions. Without this online group, I am left to wonder if she would have continued to believe one thing about classroom décor based on her own schooling experiences as a child and field experiences if she had not participated in this space? Would she have experienced wavering feelings of internalized adjustment and strategic compliance (Lacey, 1977), as I did early in my career, where she was doing what she thought was expected of her but having some hesitations as well?

Another goal of the online learning space was to reflect on practices and learn from one another. From the findings I shared in chapter four, it seems there were instances where this goal was achieved. Grossman et al. (2001) suggested, "the collective must serve as a training ground for individuals to think in new ways, to learn to listen for and try out new ways of knowing and reading” (p. 975). Previous literature concurred a benefit of online learning spaces related to 
broadening of ideas and practices beyond our own experiences from different schools and people (Brown, 2007; Carpenter \& Krutka, 2015; Duncan-Howell, 2010).

\section{Developing Agency}

In order for teacher learning to be meaningful to educators, they should assume some responsibility in the learning process and not just be expected to participate in hierarchical learning opportunities (Sprott, 2019). Concurring with Cochran-Smith and Lytle (1999) teacher learning and developing agentic identities are quite complex and it is important to understand "people do not merely react to and repeat given practices" (Oolbekkink-Marchand et al., 2017, p. 38) but instead learning is constructed through prior knowledges and social settings. However, when pressures surmount and intensification (Larson, 1980) in the work place is prevalent, in addition to the culture of the school rooted deeply in place (Lacey, 1977; Russo \& Beyerbach, 2001; Zeichner, 2010), teachers may find it hard to critically reflect on their practice and engage in meaningful conversations with peers that move beyond superficial social support (House, 1981). In chapter four, I shared instances where participants said they felt empowered to speak out or share their learning with others including examples of classroom décor, speaking out at meetings, and sharing ideas with new teachers. In times when stakes are high and demands on teachers are ever increasing, developing teacher agency, "strengthens their commitment to being a particular kind of teacher and contributes to their professional development" (Tao \& Gao, 2017, p. 346). From these findings, it seems the social aspect of the discussions online and interactions from multiple perspectives did help some participants feel empowered and push back against common practices that continue to happen in schools.

Analysis of the online posts also revealed instances where participants may have been grappling with agency. As mentioned in the findings, Lyn's engagement in the online space 
declined after she initiated a second post that included a critical comment considering the source of the link shared. I also noticed that Lyn did not post many critical comments or engage in the discussions of the posts where critical comments were made. However, one of her biggest areas of learning according to her post-study interview, was the reminder to consider the source of something before it is shared. Juxtaposing these considerations alongside one another, it leaves me to question, did these instances encourage Lyn to develop more agency as she may not have felt comfortable doing that yet? Did these interactions lead her closer to engaging in more discussions where she feels she can participate in critical conversations? From the data I have, I am not able to answer these questions. However, this consideration does align with a suggestion from Lundin, et al (2017) as they noted, "Our analysis shows that for some members extensive professional identity work takes place in the studied FB-group, providing these teachers with the possibility to learn and develop in professionally relevant manners" (p. 26). This could also be related to previous studies that suggested, "lurkers" those who do not participate directly online, may be processing and benefitting beyond what can be observed online (Brown, 2007).

This section presented a discussion of the interactions and change themes. In order to understand more about the participants and understand how and why they engaged in the online space in the manner that they did, considerations of what may have impacted the discussions in this online thirdspace were also included in this section. The next section will address the posts and questions that were left unanswered or had minimal engagement.

\section{Unanswered Questions and Missed Opportunities}

While the findings indicate there were opportunities of learning from participants, almost $25 \%$ of the posts from the online learning space were left with little to no engagement from participants. These posts may have received zero to one comment from other participants. Nine 
of these were direct questions from initial posts and four were questions made in the comments of the posts. In four of these posts, I specifically tagged group members (mentioned them by name to receive a notification of the comment) to probe for a response, as I thought they might have something to add on. The other unanswered questions were general open-ended questions for all members of the group. Looking at the posts that were left unanswered, I was pondering why were there so many? Why did these particular posts not gain attention like others? The posts all came from various time periods throughout the study. A general answer could be that people were too busy when they were posted and never got back to them. That was indicated on poststudy questionaries' and interviews as a barrier to the group learning. Previous literature suggested the time it takes to respond to everything in online learning spaces can be a barrier to conversations (Bergviken Rensfeldt et al., 2018; Britt \& Paulus, 2016; Carpenter \& Harvey, 2019; Carpenter \& Krutka, 2015; Duncan-Howell, 2010; Powell \& Bodur, 2019; Xing \& Gao, 2018). I think this may account for some of an explanation for why these posts were not taken up, as during interviews some participants noted they felt they did not have time to address all of the posts. Or perhaps another explanation could be the participants were not notified of this post, a minor technological barrier indicated during interviews and post-study questionnaires. In other studies, a common finding from online spaces suggested that some participants did not engage in posts in the online group because they did not like that some members were pushing their own agendas or even promoting their own resources they were selling (Bergviken Rensfeldt et al., 2018; Duncan-Howell, 2010; Kelly \& Antonio, 2016). I did not find anything from this group that would indicate this was a concern from participants.

Thinking more about this, I was reminded of a study conducted by Bergviken Rensfeldt (2018) on the use of Facebook teacher groups. Implications from this research suggested that 
participants were less likely to engage in a post that did not seem to benefit them personally. In one specific post regarding a new ESL (English as a Second Language) student, I was intentionally trying to make a connection to university coursework by asking, "However, I was thinking about how the coursework at [name of university] has placed more emphasis on ESL and maybe Nicole or MaryAnne could offer anything from their coursework, since they were just recently in classes??" This district is an area with low ESL population and the comments previous to this were very supportive and offered well wishes but there was not anything specific enough to fully support the teaching of a new student that Elizabeth specifically asked about. Not many ESL students are in this district, so maybe the ESL discussion on Facebook was not seen as relevant.

To highlight another example, Anna initiated a discussion asking everyone what would they change from their first year of teaching? I added a comment with 502 words discussing how I am still thinking about things I want to change each year. I then added suggestions for classroom organization and releasing responsibility to the students more often. After a few days, no other comments were added to the post, so I tagged other participants to encourage comments, “Any one[sic] else have any ideas to add on here?? Lyn Elizabeth Laurie Gretchen Lavendar :) If you think of something reply back when you have time! I'm sure the interns would appreciate your responses as well." Laurie then added a comment with 132 words indicating over time you will find things that work for your students and suggested surrounding yourself with educators who focus on the positive and they themselves are interested in learning too. Was this post not addressed by many participants because most were over 10 or more years beyond their first year of teaching? This could have been a great place for teachers to not only offer suggestions for another teacher, but also to share ideas with experienced teachers. But more 
importantly it seems this may have been missed opportunity for critical reflection on classroom practices.

Towards the end of April, Lavender initiated a post asking for ideas regarding summer reading with students. She indicated she was interested in doing more than just encouraging students to join the summer reading program at the library. However, this post only generated one comment from me. This too could have been a missed opportunity to learn from one another. However, maybe other participants did not have much more to offer than what was already said. Maybe this is where a larger group with more diverse teachers from different schools could be helpful to generate more ideas. Only three teachers in the group would be considered novice teachers and two of them rarely engaged in the discussions and it was late in the school year when the post about summer reading was made. Was it too close to summer and end of the school year for teachers to be concerned with this? Another possible explanation could be related to another finding from Bergviken Rensfeldt (2018) which indicated that the "work" and time teachers spend in an online group is unpaid work. Gretchen's response on her questionnaire echoes this sentiment as she stated,

I think I would have preferred using a different platform (not Facebook) that I could access more easily while at school. I am more apt to want to talk about education related topics while at school than on my free time at home.

While it is unclear exactly why there were so many unanswered questions, this is one area of the study that could be explored in future research, yet also contradicts the amount of learning that was indicated within the group as well. However, Brown (2007) provided a counter suggestion that, "Reflective online musings, not only helped the individual who verbalized thinking, it also helped those who 'eavesdropped' on this inner conversation" (p. 47). So even though questioned 
were left answered, I cannot know for sure how the online posts affected participants or lurkers even when they did not comment. This could be an area for further exploration in future studies.

\section{Graphic Display of Online Interactions}

From this discussion of the findings, I have developed a graphic of how I interpret the experiences in this study (see Figure 8). The participants are at the heart of the study and the learning; therefore, they are in the center. The boxes around the graphic are all factors that could be influencing the participants, teachers, in this study. These factors are prevalent in my experiences in education as well as the literature as noted by Fairbanks et al. (2010). The arrows show that these factors can be coming into participants lives and going out through their interactions in the online space. For example, a participant's school context/culture may influence how they interact with others in the space but can also be influenced by their interactions online if they share with others what they have discussed. It is potentially a two-way street. The online learning group on Facebook was like a filter for their experiences and all factors that could be influencing them, which is why I chose a light gray dotted color for this section. However, the thick dashed line around the online learning space and the participants acts as a potential barrier to their learning and the interactions that were occurring. I chose a dashed line to represent the cordial conversations, resisting moments of critical conversations, and unanswered questions as there were times when learning occurred (the open part of the lines) and times where learning may have been blocked (the closed part of the lines). Some barriers may have been more prominent than others, hence, why there are thick and thin parts in the dashed line. 


\section{Figure 8}

Graphic Display of Online Interactions

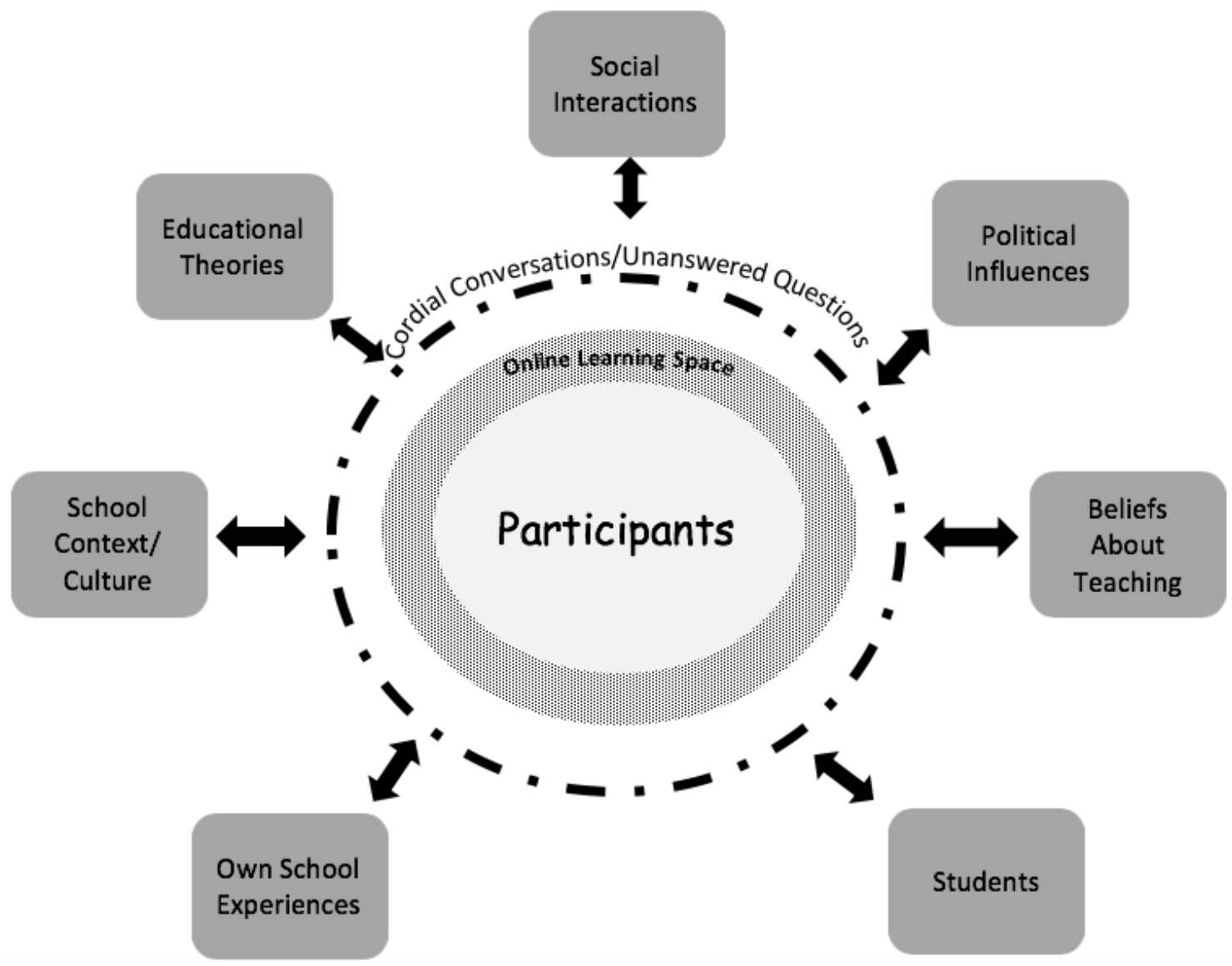

The findings from this study indicate participants enjoyed the time together and appreciated the support and learning from the online posts. Participants also noted times where they learned and shifted their thinking or classroom practices from the discussions during the online group. However, the high amount of cordial conversations, resisting moments of critical conversations, and the numerous posts and comments that were left unanswered do beg the question, were there missed opportunities for learning in this space? Future studies may be able to address these concerns. 


\section{Implications for Practice}

Facebook, Twitter, and Teachers Pay Teachers are just a few online sites that are used among educators. From following blogs, to reading articles, or following teacher created pages, it would be of benefit for educators to investigate who are the leaders of these pages? If teachers are following numerous social media sites, is what they are seeing truly a good model? In an opinion piece recently appearing on Facebook, the author warned against "blindly following educelebrities" on social media (Barnes, 2019). She continued on sharing concerns about educators in these spaces trying to sell their products, educators being more worried about looking good for a photo or video, and educators not really knowing how to teach. I think these are all valid points to consider as teachers continue to engage in professional learning on social media. Anyone can put out anything they want, but how critical are we, the followers, being? While the internet offers convenient and quality forums for professional learning, educators must be critical consumers of what they encounter there. Bergviken Rensfeldt et al. (2018) suggested a similar sentiment, "This might involve heighted awareness of not necessarily replicating standard social media traits and norms (e.g., continuous 'Liking', superficial posting, non-critical engagement). Instead, expected norms might include collective values of openness, mutuality, constructive criticism and debate" (p. 249).

Along these lines, most online learning pages are created by individual teachers or small groups of teachers, or educational companies. What would it look like if schools or districts or universities were creating these pages for their own staff or an even wider audience? After the completion of this study, the participants that I work with in my school shared with the administration how much they enjoyed the online environment. Therefore, one school in the district decided to create a Facebook group to coincide with a book study that was beginning. 
Could this be a beneficial space for teachers to engage with one another? This would be of interest to study as well.

A lack of time to engage in online learning spaces is a common barrier noted in previous research and in this study as well. While having a space to go to at any time is valuable, what would it look like if the space was always open but there was a scheduled post as well? For example, what would engagement look like if participants in the online space knew that on a specific day at a specific time a post would be made? Participants in this study said they would see posts were added to the Facebook page but would not always have time to get to it right away and then would forget about it. What if learning groups kept an open forum but participants also knew they could count on a specific time for a post, perhaps allowing for a time of synchronous engagements? Initially, the \#edchat online learning group on Twitter was a scheduled time for educators to engage in conversations with one another. However, after this open forum grew in popularity too many posts became overwhelming for participants to interact with all of them (Britt \& Paulus, 2016). Would this be different in a small closed group on social media?

Another consideration for participation in online spaces could be the use of the Facebook Live feature where participants interact with one another synchronously, replicating an experience more closely related to in-person interactions, as participants noted a hesitancy to offend others in their comments but felt they could address their intentions more carefully through face-to-face interactions.

No matter how engagements among educators are happening, in person, online, synchronously, asynchronously, an essential reminder of collaboration and learning comes from Grossman et al. (2001), who suggested an important implication for schools, 
Of all the habits of mind modeled in schools, the habit of working to understand others, of striving to make sense of differences, of extending to others the assumption of good faith, of working towards the enlarged understanding of the group--in short, the pursuit of community--may be the most important. (p. 1000)

These are all things that might be considered by future educators who wish to engage in online learning spaces.

\section{Implications for Research}

As online learning spaces and social media sites continue to be popular among educators, it is important to continue to study what is happening in these spaces and understand how they are affecting education. While I created a small, private group specifically designed to provide a space for critical reflection, there are many different ways for educators to engage in professional learning on social media. I had intended to create a space for both student teachers and classroom teachers to interact with one another, however, the space became a place of mostly teacher interactions. It is still of interest to study how an online space like this one could impact student teachers as well and dig deeper into the theory and practice divide that continues to be named as a problem in education. From the data I collected and the lack of interaction from the preservice teachers in this study, I was not able to address this as I had hoped. It would also be of interest to understand what prevented the preservice teachers from engaging more in this space. Was it related to hierarchies of expert/novice? Or perhaps a lack of time while they were student teaching? Research questions to address this implication may include: In what ways can an online space encourage interactions among preservice and in-service teachers? What factors contribute to a participant's engagement or disengagement in an online learning space? 
From the interviews and questionnaires, I was able to see how satisfied people were with the group, but I do not think I did enough to understand why people were not adding on to posts or why they chose to engage in one post and not another. In a future research study, it may be beneficial to take participants back to certain posts in the online space, ones they engaged with frequently and ones they did not engage with, in order to gain a better understanding of why they did or did not engage by asking specific questions about each post. Or, asking how posts and discussions that they did not engage with still impacted them, getting at the notion of learning among "lurkers" (Brown, 2007). Future researchers may also want to understand how participants felt they were impacting others and not just how their engagement in a space impacted their own teaching. Bergviken Rensfeldt et al. (2018) suggested this as an implication as well, asking if an online group can move towards collaboration and collegiality and not just individual benefits? Research questions to address this may include: How do participants describe their engagement in online spaces? How do they reflect on the posts they did or did not engage in? How do participants describe their contributions to the collaborative group?

There are so many different educators and styles of teaching in the field of education. Oftentimes we engage in interactions with others online without really knowing what that teacher looks like in their own classrooms. What would observations in a classroom of teachers who are in an online learning group tell us? In addition to research that is looking at content analysis of online spaces and the perceptions of teachers, could the additional data source, classroom observations, give a better picture of what is happening in the field as a result of teachers participating in online learning groups. Further studies of online learning spaces may want to consider the following research question: How does participation in an online learning 
space affect teacher's practices as witnessed through classroom observations and their own reflections?

\section{Limitations}

As with any study, my findings should be considered with limitations. Limitations are the aspects that may have impacted the findings from this study. There are general limitations applied to qualitative research and are related to researcher bias and transferability. It was not my intention for the findings of this study to be generalizable to all online learning spaces, but instead share instances of what happened in this online space that supported or interfered with participants' engagement and learning. While I cannot remove biases, in chapter three I was upfront about these biases and shared how I worked to ensure trustworthiness in this study.

One limitation of this study was the use of convenience sampling for participant recruitment. Merriam (1998) states that convenience sampling is when "you select a sample based on time, money, location, availability of sites or respondents, and so on" (p. 63). She goes on to say that convenience sampling does not always produce the most informative information and is not highly credible. Along with this, is the sample size. Although there was a total of nine participants (including myself), all participants joined this study on their own willingness and expressed a desire to learn more in their pre-study questionnaires. In addition, the lack of diversity among participants should be considered as a limitation. All participants were white females currently teaching in the same school district. Only two participants had previous teaching experience in another district and all participants had taken courses at the same university in either (or both) their undergraduate or graduate experiences. Therefore, these findings represent my interpretations of these participants' experiences in this one space and time. 
Although three sources of data were triangulated and the use of interviews can provide insights of participants not available through observations (Merriam, 2009), one concern can be related to participant reactivity (Maxwell, 2013) or how participants are affected by the researcher. During interviews I cannot be sure how participants answered the questions; was it to give their best interpretation of what happened during the online space or did they answer in a way to give me answers they perceived I was looking for, especially since I knew many of the participants before the study. Also looking back at the interviews, I would have liked to have asked participants further questions to delve into their responses. When I was transcribing and coding, I was left with questions asking what else the participant meant.

One other aspect to consider is the amount of time, four months, participants engaged in the online learning space. Engaging in this space for a longer period of time could have allowed participants to trust one another more and perhaps engage in more critical conversations. In addition, the time of year the study took place may have impacted the online posts. Other studies may want to consider moving the timing to the entire school year or avoid the beginning and end of the year, as these are often the busiest times for teachers.

\section{Conclusions}

This study brought together teachers within a small-closed group of an online learning space on Facebook. The thirdspace was meant to provide an opportunity for educators to engage in critical conversations and reflections around theories, practices, and knowledges of teaching. The findings from this study support previous findings that suggest teachers enjoy the support and resources they receive when they participate in online learning spaces, which in and of itself is of great value to teachers. The finding of cordial conversations and the discourse of agreement prevalent in the online discussions, leads to further questioning of how educators can begin to 
see critical conversations as a way to encourage deeper thinking about the choices we make in our classrooms. As I end this dissertation and this study, I have thought carefully about how my multiple experiences in education have helped me become the teacher I am today and the teacher I hope I can continue to become. I wish the same for all educators-keep thinking, keep reading, keep learning, keep an open mind, and keep conversing with others who will be honest with you. 


\section{REFERENCES}

Abdal-Haqq, I. (1998a). Professional development schools: Weighing the evidence. Corwin.

Abdal-Haqq, I. (1998b). Professional development schools: What do we know? What do we need to know? How do we find out? Who do we tell?. National Professional Development School Conference.

Afflerbach, P. (2011). Understanding and using reading assessment, $K-12$. International Reading Association.

Allsopp, D. H., DeMarie, D., Alvarez-McHatton, P., \& Doone, E. (2006). Bridging the gap between theory and practice: Connecting courses with field experiences. Teacher Education Quarterly, 33(1), 19-35.

Assaf, L. C. (2005). Staying connected: Student teachers' perceptions of computer-mediated discussions. The Teacher Educator, 40(4), 221-237.

https://doi.org/10.1080/08878730509555363

Banks, J. A. (1998). The lives and values of researchers: Implications for educating citizens in a multicultural society. Educational Researcher, 27(7), 4-17. https://doi.org/10.3102/0013189X027007004

Barnes, S. (2019, September 4). Opinion: Don't blindly follow edu-celebrities. https://theeducatorsroom.com/opinion-dont-blindly-follow-edu-celebrities/

Beck, J. S. (2016). The complexities of a third-space partnership in an urban teacher residency. Teacher Education Quarterly, 43(1), 51-70. https://doi.org/10.1177/0022487105275922

Bergviken Rensfeldt, A., Hillman, T., \& Selwyn, N. (2018). Teachers 'liking' their work? Exploring the realities of teacher Facebook groups. British Educational Research Journal, 44(2), 230-250. https://doi.org/10.1002/berj.3325 
Bernhardt, P. E. (2015). 21st century learning: Professional development in practice. The Qualitative Report, 20(1), 1-19.

Bhabha, H. K. (1994). The location of culture. Routledge.

Booth, S. E. (2012). Cultivating knowledge sharing and trust in online communities for educators. Journal of Educational Computing Research, 47(1), 1-31. https://doi.org/10.2190/EC.47.1.a

Bransford, J., Darling-Hammond, L., \& LePage, P. (2005). Introduction. In L. DarlingHammond \& J. Bransford (Eds.), Preparing teachers for a changing world: What teachers should learn and be able to do (pp. 1-39). John Wiley \& Sons.

Bransford, J., Derry, S., Berliner, D., Hammerness, K., \& Beckett, K. L. (2005). Theories of learning and their roles in teaching. In L. Darling-Hammond \& J. Bransford (Eds.), Preparing teachers for a changing world: What teachers should learn and be able to do (pp. 40-87). John Wiley \& Sons.

Britt, V. G., \& Paulus, T. (2016). "Beyond the Four Walls of My Building": A case study of \#Edchat as a community of practice. American Journal of Distance Education, 30(1), 4859. https://doi.org/10.1080/08923647.2016.1119609

Brown, B. (2018). Dare to lead: Brave work. Tough conversations. Whole hearts. Random House.

Brown, R. (2007). New technologies mean new learning for teachers: Mailring participation and professional development. New England Reading Association Journal, 43(1), 44-49.

Calkins, L. (1994). The art of teaching writing. Heinemann. 
Carpenter, J. P., \& Harvey, S. (2019). “There's no referee on social media”: Challenges in educator professional social media use. Teaching and Teacher Education, 86, 1-12. https://doi.org/10.1016/j.tate.2019.102904

Carpenter, J. P., \& Krutka, D. G. (2015). Engagement through microblogging: Educator professional development via Twitter. Professional Development in Education, 41(4), 707-728. https://doi.org/10.1080/19415257.2014.939294

Chapin, S. H., O’Connor, C., \& Canavan-Anderson, N. (2013). Talk Moves: A teacher's guide for using classroom discussions in math (3rd ed.). Math Solutions.

Chen, Y., Chen, N.-S., \& Tsai, C.-C. (2009). The use of online synchronous discussion for webbased professional development for teachers. Computers \& Education, 53(4), 1155-1166. https://doi.org/10.1016/j.compedu.2009.05.026

Clay, M. M. (1985). The early detection of reading difficulties (3rd ed.). Heinemann.

Cochran-Smith, M., \& Lytle, S. L. (1999). Relationships of knowledge and practice: Teacher learning in communities. Review of Research in Education, 24, 249-305. https://doi.org/10.2307/1167272

Coe, K., \& Kuttner, P. J. (2018). Education coverage in television news: A typology and analysis of 35 years of topics. AERA Open, 4(1), 1-13. https://doi.org/10.1177/2332858417751694

Creswell, J. (2014). Research design: Qualitative, quantitative, and mixed methods approaches. Sage. 
Cuenca, A., Schmeichel, M., Butler, B. M., Dinkelman, T., \& Nichols, J. R. (2011). Creating a "third space" in student teaching: Implications for the university supervisor's status as outsider. Teaching and Teacher Education, 27(7), 1068-1077. https://doi.org/10.1016/j.tate.2011.05.003

Darling-Hammond, L., Banks, J., Zumwalt, K., Gomez, L., Sherin, M. G., Griedson, J., \& Finn, L. E. (2005). Educational goals and purposes: Developing a curricular vision for teaching. In L. Darling-Hammond \& J. Bransford (Eds.), Preparing teachers for a changing world: What teachers should learn and be able to do (pp. 169-200). John Wiley \& Sons.

Darling-Hammond, Linda. (2006). Constructing 21st-century teacher education. Journal of Teacher Education, 57(3), 300-314. https://doi.org/10.1177/0022487105285962

Darling-Hammond, Linda. (2014). Strengthening clinical preparation: The holy grail of teacher education. Peabody Journal of Education, 89(4), 547-561. https://doi.org/10.1080/0161956X.2014.939009

Darling-Hammond, Linda, \& Bransford, J. (2005). Preparing teachers for a changing world: What teachers should learn and be able to do. Jossey-Bass.

Davis, T. (2013). Building and using a personal/professional learning network with social media. The Journal of Research in Business Education, 55(1), 1-13.

Deryakulu, D., \& Olkun, S. (2007). Analysis of computer teachers' online discussion forum messages about their occupational problems. Journal of Educational Technology \& Society, 10(4), 131-142. 
DeWert, M. H., Babinski, L. M., \& Jones, B. D. (2003). Safe passages: Providing online support to beginning teachers. Journal of Teacher Education, 54(4), 311-320. https://doi.org/DOI: 10.1177/0022487103255008

Dewey, J. (1904). The relation of theory to practice in education. In C. A. McMurry (Ed.), The third yearbook of the national society for the scientific study of education (pp. 9-30). University of Chicago Press.

Dewey, J. (1938). Experience and education. Macmillan.

Doyle, S. (2013). Reflexivity and the capacity to think. Qualitative Health Research, 23(2), 248255. https://doi.org/10.2105/AJPH.2018.304404

Duncan-Howell, J. (2010). Teachers making connections: Online communities as a source of professional learning. British Journal of Educational Technology, 41(2), 324-340. https://doi.org/10.1111/j.1467-8535.2009.00953.x

Efron, S. E., \& Ravid, R. (2013). Action research in education: A practical guide. The Guilford Press.

Eisner, P. (2015). What does it mean to say a school is doing well? In A. C. Ornstein, E. F. Pajak, \& S. B. Ornstein (Eds.), Contemporary issues in curriculum (6th ed., pp. 21-32). Pearson.

Fairbanks, C. M., Duffy, G. G., Faircloth, B. S., He, Y., Levin, B., Rohr, J., \& Stein, C. (2010). Beyond knowledge: Exploring why some teachers are more thoughtfully adaptive than others. Journal of Teacher Education, 61(1-2), 161-171. https://doi.org/10.1177/0022487109347874

Feiman-Nemser, S., \& Buchmann, M. (1985). Pitfalls of experience in teacher preparation. Teachers College Record, 87(1), 53-65. 
Flessner, R. (2012). Addressing the research/practice divide in teacher education. Action in Teacher Education, 34(2), 159-171. https://doi.org/10.1080/01626620.2012.677739

Flessner, R. (2014). Revisiting reflection: Utilizing third spaces in teacher education. Educational Forum, 78(3), 231-247. https://doi.org/10.1080/00131725.2014.912711

Forgasz, R. (2016). Rethinking the observation placement: A community/cohort approach to early professional experiences. In R. Bradenburg, S. McDonough, J. Burke, \& S. White (Eds.), Teacher education: Innovation, intervention and impact (pp. 99-116). Springer.

Forgasz, R., Heck, D., Williams, J., Ambrosetti, A., \& Willis, L. (2018). Theorising the third space of professional experience partnerships. In J. Kriewaldt, A. Ambrosetti, D. Rorrison, \& R. Capeness (Eds.), Educating future teachers: Innovative perspectives in professional experience (pp. 33-47). Springer.

Fountas, I. C., \& Pinnell, G. S. (2008). Benchmark assessment system 1. Heinemann.

Freire, P. (1970). Pedagogy of the oppressed. Herder and Herder.

Garmston, R. J. (1987). How Administrators Support Peer Coaching. Educational Leadership, 44(5), 18-26. f5h.

Goodman, K. (1996). On reading. A common-sense look at the nature of language and the science of reading. Heinemann.

Goodman, K. S. (1969). Analysis of oral reading miscues: Applied psycholinguistics. Reading Research Quarterly, 5(1), 9-30. https://doi.org/10.2307/747158

Graham, B. (2006). Conditions for successful field experiences: Perceptions of cooperating teachers. Teaching and Teacher Education, 22(8), 1118-1129. https://doi.org/10.1016/j.tate.2006.07.007 
Greca, I. M. (2016). Supporting pre-service elementary teachers in their understanding of inquiry teaching through the construction of a third discursive space. International Journal of Science Education, 38(5), 791-813. https://doi.org/10.1080/09500693.2016.1165892

Grossman, P., Hammerness, K., \& McDonald, M. (2009). Redefining teaching, re-imagining teacher education. Teachers and Teaching: Theory and Practice, 15(2), 273-289. https://doi.org/10.1080/13540600902875340

Grossman, P., Wineburg, S., \& Woolworth, S. (2001). Toward a theory of teacher community. Teachers College Record, 103(6), 942-1012.

Guskey, T. R. (2002). Does it make a difference? Educational Leadership, 59(6), 45-51. https://uknowledge.uky.edu/edp_facpub/7

Gutierrez, K., Rymes, B., \& Larson, J. (1995). Script, counterscript, and underlife in the classroom: James Brown versus Brown v. Board of Education. Harvard Educational Review, 65(3), 445-472. https://doi.org/10.17763/haer.65.3.r16146n25h4mh384

Hammerness, K., \& Klette, K. (2015). Indicators of quality in teacher education: Looking at features of teacher education from an international perspective. In G. K. LeTendre \& A. W. Wiseman (Eds.), Promoting and sustaining a quality teacher workforce (pp. 182212). Emerald.

Hargreaves, A. (1994). Changing teachers. Teachers College Press.

Hargreaves, A., \& Dawe, R. (1990). Paths of professional development: Contrived collegiality, collaborative culture, and the case of peer coaching. Teaching and Teacher Education, 6(3), 227-241. https://doi.org/10.1016/0742-051X(90)90015-W

Hatch, J. A. (2002). Doing qualitative research in education settings. State University of New York Press. 
Hoffman, J. V., Wetzel, M. M., Maloch, B., Greeter, E., Taylor, L., DeJulio, S., \& Vlach, S. K. (2015). What can we learn from studying the coaching interactions between cooperating teachers and preservice teachers? A literature review. Teaching and Teacher Education, 52, 99-112. https://doi.org/10.1016/j.tate.2015.09.004

Hollins, E. R. (2015). Learning teaching through clinical rotations. In E. R. Hollins (Ed.), Rethinking field experiences in preservice teacher preparation: Meeting new challenges for accountability (pp. 117-150). Routledge.

Holmes Group. (1990). Tomorrow's teachers: A report of the Holmes Group. Holmes Group.

hooks, b. (2009). Confronting class in the classroom. In A. Darder, M. P. Baltodano, \& R. D. Torres (Eds.), The critical pedagogy reader (pp. 135-141). Routledge.

House, J. S. (1981). Work stress and social support. Addison-Wesley Publishing Company.

Hunt, C. S. (2016). Getting to the heart of the matter: Discursive negotiations of emotions within literacy coaching interactions. Teaching and Teacher Education, 60, 331-343. https://doi.org/10.1016/j.tate.2016.09.004

Hur, J. W., \& Brush, T. A. (2009). Teacher participation in online communities: Why do teachers want to participate in self-generated online communities of $\mathrm{K}-12$ teachers? Journal of Research on Technology in Education, 41(3), 279-303. https://doi.org/10.1080/15391523.2009.10782532

Illinois State Board of Education. (2018). Illinois report card: School (K-3). https://www.illinoisreportcard.com/District.aspx $?$ source=profile $\&$ Districtid=5309010800 2 
Jenkins, T., \& Yarmoskey, J. (2019, February 26). Dr. Seuss books can be racist, but students keep reading them. Mindshift. https://www.kqed.org/mindshift/53160/dr-seuss-bookscan-be-racist-but-students-keep-reading-them

Kelly, N., \& Antonio, A. (2016). Teacher peer support in social network sites. Teaching and Teacher Education, 56, 138-149. https://doi.org/10.1016/j.tate.2016.02.007

Kemmis, S., \& McTaggart, R. (1988). The action research planner. Deakin University Press.

Killeavy, M., \& Moloney, A. (2010). Reflection in a social space: Can blogging support reflective practice for beginning teachers? Teaching and Teacher Education: An International Journal of Research and Studies, 26(4), 1070-1076. https://doi.org/10.1016/j.tate.2009.11.002

Klette, K., \& Hammerness, K. (2016). Conceptual framework for analyzing qualities in teacher education: Looking at features of teacher education from an international perspective. Acta Didactica Norge, 10(2), 26-52. https://doi.org/10.5617/adno.2646

Knowles, J. G., \& Cole, A. L. (1996). Developing practice through field experiences. In F. B. Murray (Ed.), The teacher educator's handbook: Building a knowledge base for the preparation of teachers (pp. 648-688). Jossey-Bass Publishers.

Korhonen, H., Heikkinen, H. L. T., Kiviniemi, U., \& Tynjälä, P. (2017). Student teachers' experiences of participating in mixed peer mentoring groups of in-service and pre-service teachers in Finland. Teaching and Teacher Education, 61, 153-163. https://doi.org/10.1016/j.tate.2016.10.011

Lacey, C. (1977). The socialization of teachers. Routledge. 
Lantz-Andersson, A., Lundin, M., \& Selwyn, N. (2018). Twenty years of online teacher communities: A systematic review of formally-organized and informally-developed professional learning groups. Teaching and Teacher Education, 75, 302-315. https://doi.org/10.1016/j.tate.2018.07.008

Larson, M. S. (1980). Proletarianization and educated labor. Theory and Society, 9(1), 131-175.

Lasky, S. (2005). A sociocultural approach to understanding teacher identity, agency and professional vulnerability in a context of secondary school reform. Teaching and Teacher Education, 21(8), 899-916. https://doi.org/10.1016/j.tate.2005.06.003

LeCompte, M. D., \& Schensul, J. J. (1999). Analyzing and interpreting ethnographic data (Vol. 5). AltaMira Press.

Levine, M. (1992). A conceptual framework for professional practice schools. In M. Levine (Ed.), Professional practice schools: Linking teacher education and school reform (pp. 8-24). Teachers College Press.

Lincoln, Y. S., \& Guba, E. G. (1985). Naturalistic inquiry (Vol. 75). Sage.

Lortie, D. C. (1975). Schoolteacher: A sociological study. The University of Chicago Press.

Lukoff, K. (2019, April 11). The sneetches are problematic: Facing the legacy of Dr. Seuss with your students. Medium. https://medium.com/@ heinemann/the-sneeches-are-problematic88b18ab98253

Lundin, M., Lantz-Andersson, A., \& Hillman, T. (2017). Teachers' reshaping of professional identity in a thematic FB-group. Qwerty-Open and Interdisciplinary Journal of Technology, Culture and Education, 12(2), 12-29. 
Macià, \& García. (2016). Informal online communities and networks as a source of teacher professional development: A review. Teaching \& Teacher Education, 55, 291-307. https://doi.org/10.1016/j.tate.2016.01.021

Macià, \& García, I. (2018). Professional development of teachers acting as bridges in online social networks. Research in Learning Technology, 26. https://doi.org/10.25304/rlt.v26.2057

MacPhee, D., \& Belcher, M. (2019). Partners in PDS: Designing, implementing, and examining a collaborative pedagogical model. School-University Partnerships, 12(2), 50-61.

Martin, S. D., Snow, J. L., \& Franklin Torrez, C. A. (2011). Navigating the terrain of third space: Tensions with/in relationships in school-university partnerships. Journal of Teacher Education, 62(3), 299-311. https://doi.org/10.1177/0022487110396096

Maxwell, J. A. (2013). Qualitative research design: An interactive approach (3rd ed.). Sage. McDonough, S. (2014). Rewriting the script of mentoring pre-service teachers in third space: Exploring tensions of loyalty, obligation and advocacy. Studying Teacher Education, 10(3), 210-221. https://doi.org/10.1080/17425964.2014.949658

McIntyre, J., \& Hobson, A. J. (2016). Supporting beginner teacher identity development: External mentors and the third space. Research Papers in Education, 31(2), 133-158. https://doi.org/10.1080/02671522.2015.1015438

McNinch, J. (2015). Working against the grain: Leadership for 21st century teacher education. In J. S. E. Elliott (Ed.), Leadership for change in teacher education (pp. 73-79). Sense.

Merriam, S. B. (2009). Qualitative research: A guide to design and implementation. John Wiley \& Sons. 
Merriam-Webster. (n.d.). Cordial. In The Merriam-Webster.com Dictionary. https://www.merriam-webster.com/dictionary/cordial

Miles, M. B., Huberman, A. M., \& Saldana, J. (2013). Qualitative data analysis: A methods sourcebook (3rd ed.). SAGE.

Mitchell, W. J. T. (1995). Interview with cultural theorist Homi Bhabha. Artforum International Magazine, 33(7), 80-84.

Nafziger, S. L. (2006). Online mentoring of a preservice teacher: Finding one's voice within the culture (Publication No. 3233942) [Doctoral Dissertation, Illinois State University]. ProQuest Dissertations.

National Council for Accreditation of Teacher Education. (2010). Transforming teacher education through clinical practice: A national strategy to prepare effective teachers. http://caepnet.org/ /media/Files/caep/accreditation-resources/blue-ribbon-panel.pdf

Oolbekkink-Marchand, H. W., Hadar, L. L., Smith, K., Helleve, I., \& Ulvik, M. (2017). Teachers' perceived professional space and their agency. Teaching and Teacher Education, 62, 37-46. https://doi.org/10.1016/j.tate.2016.11.005

Palmer, P. J. (2015). The heart of a teacher. In A. C. Ornstein, E. F. Pajak, \& S. B. Ornstein (Eds.), Contemporary issues in curriculum (6th ed., pp. 56-68). Pearson.

Pekin Public Schools. (2018). Professional development school with ISU. http://www.pekin.net Pekin Public Schools. (2019). CLM school coaches. https://www.pekin.net/Page/920

Pervin, B., \& Campbell, C. (2015). Systems for teacher and leader effectiveness and quality: Ontario, Canada. In Linda Darling-Hammond \& R. Rothman (Eds.), Teaching in the flat world: Learning from high performing systems (pp. 45-62). Teachers College Press. 
Powell, C. G., \& Bodur, Y. (2019). Teachers' perceptions of an online professional development experience: Implications for a design and implementation framework. Teaching and Teacher Education, 77, 19-30. https://doi.org/10.1016/j.tate.2018.09.004

Prestridge, S. (2019). Categorising teachers' use of social media for their professional learning: A self-generating professional learning paradigm. Computers \& Education, 129, $143-$ 158. https://doi.org/10.1016/j.compedu.2018.11.003

Priestley, M., Biesta, G., \& Robinson, S. (2013). Teachers as agents of change: Teacher agency and emerging models of curriculum. In M. Priestley \& G. Biesta (Eds.), Reinventing the curriculum: New trends in curriculum policy and practice (pp. 187-206). Bloomsbury Academic.

Priestley, M., Biesta, G., \& Robinson, S. (2016). Teacher agency: What is it and why does it matter? In J. Evers \& R. Kneyber (Eds.), Flip the system: Changing education from the ground up (pp. 134-148). Routledge.

QSR International Pty Ltd. Version 12. (2018). NVivo qualitative data analysis software. Computer Program. https://www.qsrinternational.com/nvivo/home

Quesenberry, A. C., Hamann, K., Sanden, S., Bates, A., \& Hartle, L. (2018). Examining the impact of a year-long university-school partnership. Action in Teacher Education, 40(3), 288-304. https://doi.org/10.1080/01626620.2018.1486752

Ranieri, M., Manca, S., \& Fini, A. (2012). Why (and how) do teachers engage in social networks? An exploratory study of professional use of Facebook and its implications for lifelong learning. British Journal of Educational Technology, 43(5), 754-769. https://doi.org/10.1111/j.1467-8535.2012.01356.x 
Rodgers, A., \& Keil, V. L. (2007). Restructuring a traditional student teacher supervision model: Fostering enhanced professional development and mentoring within a professional development school context. Teaching and Teacher Education, 23(1), 63-80. https://doi.org/10.1016/j.tate.2006.04.012

Russo, P., \& Beyerbach, B. (2001). Moving from polite talk to candid conservation: Infusing foundations into a professional development project. The Journal of Educational Foundations, 15(2), 71-90.

Rust, F. O. (2010). Shaping new models for teacher education. Teacher Education Quarterly, $37(2), 5-18$.

Sannino, A. (2010). Teachers' talk of experiencing: Conflict, resistance and agency. Teaching and Teacher Education, 26(4), 838-844. https://doi.org/10.1016/j.tate.2009.10.021

Skinner, B. F. (1954). The science of learning and the art of teaching. Cambridge, Mass, USA, $99-113$.

Soja, E. W. (1996). Thirdspace: Journeys to Los Angeles and other real-and-imagined places. Blackwell.

Sprott, R. A. (2019). Factors that foster and deter advanced teachers' professional development. Teaching and Teacher Education, 77, 321-331. https://doi.org/10.1016/j.tate.2018.11.001

Stiggins, R. J. (1995). Assessment literacy for the 21 st century. Phi Delta Kappan, 77(3), 238246.

Tao, J., \& Gao, X. (2017). Teacher agency and identity commitment in curricular reform. Teaching and Teacher Education, 63, 346-355. https://doi.org/10.1016/j.tate.2017.01.010 
Taylor, M., Klein, E. J., \& Abrams, L. (2014). Tensions of reimagining our roles as teacher educators in a third space: Revisiting a co/autoethnography through a faculty lens. Studying Teacher Education, 10(1), 3-19. https://doi.org/10.1080/17425964.2013.866549

Teitel, L. (2001). An assessment framework for professional development schools going beyond the leap of faith. Journal of Teacher Education, 52(1), 57-69.

Toom, A., Pietarinen, J., Soini, T., \& Pyhältö, K. (2017). How does the learning environment in teacher education cultivate first year student teachers' sense of professional agency in the professional community? Teaching and Teacher Education, 63, 126-136. https://doi.org/10.1016/j.tate.2016.12.013

Trust, T., Krutka, D. G., \& Carpenter, J. P. (2016). “Together we are better”: Professional learning networks for teachers. Computers \& Education, 102, 15-34. https://doi.org/10.1016/j.compedu.2016.06.007

Turvey, K., \& Hayler, M. (2017). Collaboration and personalisation in teacher education: The case of blogging. Teaching and Teacher Education, 68, 42-52. https://doi.org/10.1016/j.tate.2017.08.003

U.S. Department of Education. (2017). Illinois state board of education state template for the consolidated state plan under the every student succeeds act. https://www.isbe.net/Documents/ESSAStatePlanforIllinois.pdf

Valencia, S. W., Martin, S. D., Place, N. A., \& Grossman, P. (2009). Complex interactions in student teaching: Lost opportunities for learning. Journal of Teacher Education, 60(3), 304-322. https://doi.org/10.1177/0022487109336543 
Visser, R. D., Evering, L. C., \& Barrett, D. E. (2014). \#TwitterforTeachers: The implications of Twitter as a self-directed professional development tool for $\mathrm{K}-12$ teachers. Journal of Research on Technology in Education, 46(4), 396-413.

https://doi.org/10.1080/15391523.2014.925694

Vygotsky, L. S. (1978). Mind in society: The development of higher psychological processes. Harvard University Press.

Wang, J., \& Odell, S. J. (2007). An alternative conception of mentor-novice relationships: Learning to teach in reform-minded ways as a context. Teaching and Teacher Education, 23, 473-489. https://doi.org/10.1016/j.tate.2006.12.010

Watson, C., Wilson, A., Drew, V., \& Thompson, T. L. (2016). Criticality and the exercise of politeness in online spaces for professional learning. The Internet and Higher Education, 31, 43-51. https://doi.org/10.1016/j.iheduc.2016.06.002

Webber, G., \& Miller, D. (2016). Progressive pedagogies and teacher education: A review of the literature. McGill Journal of Education, 51(3), 1061-1080. https://doi.org/10.7202/1039628ar

Williams, J. (2014). Teacher educator professional learning in the third space implications for identity and practice. Journal of Teacher Education, 65(4), 315-326. https://doi.org/10.1177/0022487114533128

Wood-Kofono, K., \& Meyer, R. J. (2017). The search for joy and the realities of wounds in early literacy. In R. J. Meyer \& K. F. Whitmore (Eds.), Reclaiming early childhood literacies: Narratives of hope, power, and vision (pp. 95-104). Routledge. 
Xing, W., \& Gao, F. (2018). Exploring the relationship between online discourse and commitment in Twitter professional learning communities. Computers \& Education, 126, 388-398. https://doi.org/10.1016/j.compedu.2018.08.010

Zeichner, K. (2010). Rethinking the connections between campus courses and field experiences in college-and university-based teacher education. Journal of Teacher Education, 61(12), 89-99. https://doi.org/10.1177/0022487109347671

Zeichner, K., \& Bier, M. (2015). Opportunities and pitfalls in the turn toward clinical experience in U.S. teacher education. In E. R. Hollins (Ed.), Rethinking field experiences in preservice teacher preparation: Meeting new challenges for accountability (pp. 20-46). Routledge.

Zhang, S., \& Liu, Q. (2019). Investigating the relationships among teachers' motivational beliefs, motivational regulation, and their learning engagement in online professional learning communities. Computers \& Education, 134, 145-155. https://doi.org/10.1016/j.compedu.2019.02.013 


\section{APPENDIX A: PRE-STUDY QUESTIONNAIRE}

\section{Student Teacher Questionnaire (Pre-Study)}

1. Name (Last, First)

2. Preferred Pseudonym (a pseudonym is the name that will be used in publications)

3. Grade Level Experiences (Check all that apply)
PreK
$\mathrm{K}$
$\square$ High School
Higher Education

$\square 1$

$\square 2$

$\square 3$

$\square 4$

$\square 5$

$\square 6$

$\square 7$

8

4. Current Student Teaching Grade Level

$\square \quad$ PreK
$\square \quad \mathrm{K}$
$\square \quad 1$
$\square \quad 2$
$\square \quad 3$
$\square \quad 4$
$\square \quad 5$
$\square \quad 6$
$\square \quad 7$
$\square \quad 8$

5. Why did you choose to join this study?

6. What do you hope to achieve from participating in this group?

7. What topics would you like to discuss in this group?

8. What expectations do you believe should be established for this group?

9. How would you define the term mentor in education? 


\section{Teacher Questionnaire (Pre-Study)}

1. Name (Last, First)

2. Preferred Pseudonym (a pseudonym is the name that will be used in publications)

3. Years of Teaching Experience

$0-2$

$\square \quad 3-4$

$\square$ 5-6

$\square 7-8$

$\square 9-10$

$\square \quad 11-15$

$\square \quad 16-20$

$\square 21+$

4. Grade Levels Taught (Check all that apply)

$\square$ PreK

$\square \mathrm{K}$

$\square \quad 1$

$\square 2$

$\square 3$

$\square 4$

$\square 5$

$\square 6$

$\square 7$

$\square 8$

$\square$ High School

$\square$ Higher Education

5. Current Grade Level

PreK

$\square \mathrm{K}$

$\square \quad 1$

$\square \quad 2$

$\square 3$

$\square 4$

$\square 5$

$\square 6$

$\square 7$

$\square 8$

6. Why did you choose to join this study?

7. What do you hope to achieve from participating in this group?

8. What topics would you like to discuss in this group?

9. What expectations do you believe should be established for this group?

10. How would you define the term mentor in education? 


\section{APPENDIX B: MID-STUDY QUESTIONNAIRE}

1. Rate how you think participation in this group has impacted you as an educator.

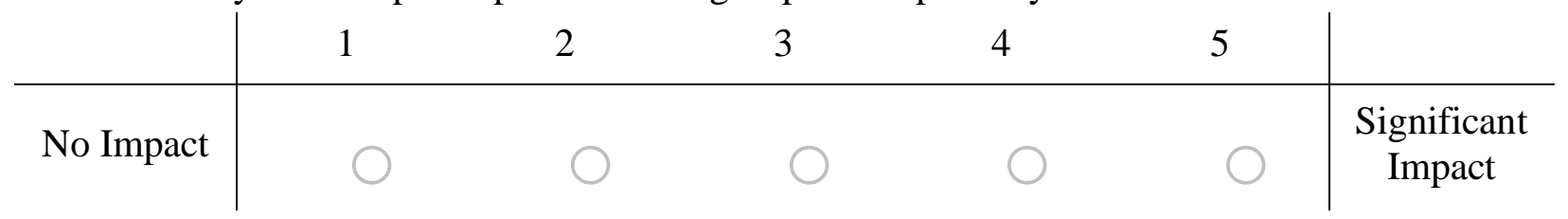

2. I have enjoyed being a part of this group.

$\square$ Very Satisfied

Somewhat Satisfied

- Not Very Satisfied

3. Briefly tell about how your participation in this group has impacted you as an educator. Some things to consider: Are you reading the links provided? Are you reading the comments? Have you implemented anything you have seen on the group? Are you talking with peers about what you have learned from the group? Has anything you read/seen caused you to reflect on your practices/planning?

4. How have you contributed to the group? Are you initiating posts? Are you adding comments to the posts?

\begin{tabular}{c|c|c|c} 
& Often & Sometimes & Rarely \\
\hline $\begin{array}{c}\text { General contributions } \\
\text { to the page }\end{array}$ & $\bigcirc$ & $\bigcirc$ \\
Initiating Posts & $\bigcirc$ & $\bigcirc$ & $\bigcirc$ \\
Adding Comments & $\bigcirc$ & &
\end{tabular}

5. Is there anything posing a barrier to your engagement on the page? (Select all that apply)

\section{1] Time}

Lack of interest in topics

I prefer to read the posts but not share comments

I am not comfortable participating in discussions

I don't feel I have much to add to the conversations

6. Follow up to question 5, other barriers not listed?

7. Do you have any feedback for improvement of this group? What else would you like to see or discuss? 


\section{APPENDIX C: POST-STUDY QUESTIONNAIRE}

1. Name (Last, First)

2. Are you a teacher or student teacher?

Classroom Teacher

Student Teacher

3. Rate how you think participation in this group has impacted you as an educator.

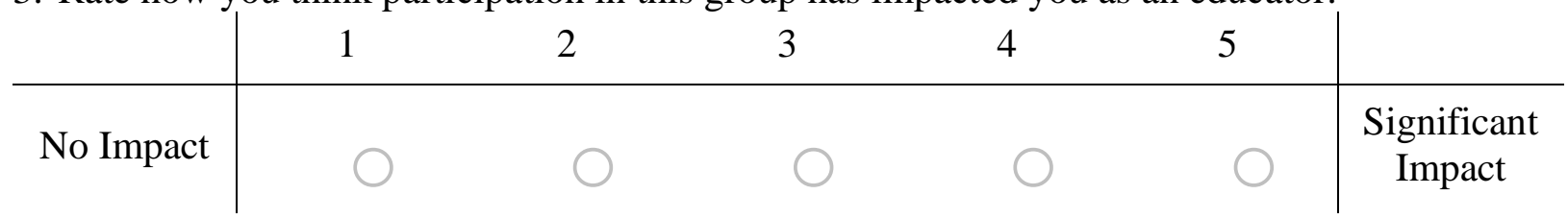

4. Tell about how your participation in this group has impacted you as an educator. (i.e. Have you shared any new insights with colleagues? Have you read new books with your class? Have you changed something you do/say as a result of participating in this group?, etc.)

5. What conversations/topics from this group were most significant to you?

6. Were there any specific conversations that you disagreed with but did not comment on in the Facebook group?

7. Tell about how you contributed to the group.

8. Tell about what you gained from this experience.

9. Did participation in this group help you feel empowered or develop a sense of agency? (i.e. Did you speak out when you disagreed with something at staff meeting or with a colleague?

10. Did you feel more confident when speaking with others about topics related to education?, etc.)

11. Did you encounter any technological issues?

12. Do you have any feedback for improvement of this group? What would you do differently if you were in this group again?

13. Before this group, did you participate in online professional learning communities via a social media platform? (i.e. Twitter, Facebook, etc.)

\section{Yes \\ No}

14. Are you interested in participating in a online professional learning community again?
Yes
Maybe
No

15. Do you consider an online learning community a form of professional development?

Yes

Somewhat

No

16. Are you willing to be interviewed to share about your experiences in this group? (Interviews will be conducted in May 2019)

Yes

No 
17. If yes, would you prefer an in-person interview or an online interview via Skype or Zoom? In Person

$\square$ Online

18. Any other additional comments or questions? 


\section{APPENDIX D: POST-STUDY INTERVIEW}

1. Why don't you start by telling me a little about yourself?

a. How did you get into education?

b. How long have you been teaching?

c. Why did you want to become an educator?

d. What experiences have you had so far in your educational journey?

2. Can you talk about your undergraduate/student teaching experience?

a. Where did you go to school?

b. What do you remember about your student teaching semester?

3. Can you tell me about your participation in the online learning community?

a. Can you describe your role?

4. What is the first post/discussion that comes to find when you think about the online learning community?

a. What was significant about that discussion?

5. Can you comment on what you believe you contributed and/or anything you might have gained from the experience?

a. If applicable, can you provide a specific example of something you learned or changed your thinking/practices?

b. If applicable, can you provide an example of feeling challenged?

c. Did you feel a sense of agency with a topic or discussion?

i. For example, did you speak out on a topic to a colleague or in a meeting that you might not have done otherwise?

6. Can you talk a little bit about the dynamics of the learning community and the online interactions?

a. Was there any time you felt uncomfortable?

b. Was there any time you felt empowered?

7. Are you interested in participating in another online learning community?

a. Why/why not?

8. How was this online space similar to or different from collaborating with your mentor/teaching peers in the classroom/district in person?

9. Is there anything else that you would like to say or ask? 


\section{APPENDIX E: NVIVO CODEBOOK}

\begin{tabular}{|c|c|c|}
\hline Name & Description & $\begin{array}{l}\text { Number of } \\
\text { Codes }\end{array}$ \\
\hline $\begin{array}{l}\text { Asking for } \\
\text { Clarification }\end{array}$ & $\begin{array}{l}\text { Additional Question to Clarify from Another Person's } \\
\text { Post }\end{array}$ & 3 \\
\hline $\begin{array}{l}\text { Asking Questions } \\
\text { to Probe for A } \\
\text { Response }\end{array}$ & $\begin{array}{l}\text { Question to Others to Push the Conversation Along or } \\
\text { Ask for Suggestions }\end{array}$ & 34 \\
\hline Assessment & Subject; General Discussion About Assessment & 4 \\
\hline Attitude & One's Attitude Towards Teaching & 4 \\
\hline $\begin{array}{l}\text { Barrier of Learning } \\
\text { Community }\end{array}$ & $\begin{array}{l}\text { Anything That Hindered or Got in the Way of One's Use } \\
\text { of the Online Learning Space }\end{array}$ & 20 \\
\hline Beliefs vs. Practices & $\begin{array}{l}\text { Discussion That Relates to One Thinking/Talking About } \\
\text { What They Think and How They Enact That or Want to } \\
\text { Enact That in A Classroom }\end{array}$ & 17 \\
\hline $\begin{array}{l}\text { Benefit of Learning } \\
\text { Community }\end{array}$ & Praise or Appreciation of The Learning Community & 30 \\
\hline $\begin{array}{l}\text { Children's } \\
\text { Literature }\end{array}$ & $\begin{array}{l}\text { Topic References or Relates to Use of Children's } \\
\text { Literature/Texts }\end{array}$ & 27 \\
\hline Classroom Design & $\begin{array}{l}\text { Related to the Physical Set Up of Classroom and } \\
\text { Schedule of Classroom }\end{array}$ & 23 \\
\hline $\begin{array}{l}\text { Classroom } \\
\text { Discussions }\end{array}$ & $\begin{array}{l}\text { Related to Conversations Among Students and Teachers } \\
\text { in a Classroom }\end{array}$ & 5 \\
\hline $\begin{array}{l}\text { Classroom } \\
\text { Examples }\end{array}$ & Examples/Descriptions Related to the Classroom & 114 \\
\hline $\begin{array}{l}\text { Classroom } \\
\text { Design }\end{array}$ & $\begin{array}{l}\text { Related to the Physical Set Up of Classroom and } \\
\text { Schedule of Classroom }\end{array}$ & 23 \\
\hline $\begin{array}{l}\text { Classroom } \\
\text { Discussions }\end{array}$ & $\begin{array}{l}\text { Related to Conversations Among Students and Teachers } \\
\text { in a Classroom }\end{array}$ & 5 \\
\hline
\end{tabular}

Table Continued 


\begin{tabular}{|c|c|c|}
\hline Name & Description & $\begin{array}{l}\text { Number of } \\
\text { Codes }\end{array}$ \\
\hline $\begin{array}{l}\text { Classroom } \\
\text { Management }\end{array}$ & $\begin{array}{l}\text { Related to Classroom Community and Routines and } \\
\text { Building Rapport }\end{array}$ & 7 \\
\hline $\begin{array}{l}\text { Classroom } \\
\text { Reference }\end{array}$ & $\begin{array}{l}\text { Participants References Something from Their Own or } \\
\text { Another's Classroom, Not Necessarily a Teaching } \\
\text { Example. May Be an Explanation of Something That has } \\
\text { Happened. }\end{array}$ & 12 \\
\hline $\begin{array}{l}\text { Classroom } \\
\text { Student } \\
\text { Collaboration }\end{array}$ & $\begin{array}{l}\text { Description of Students Working/Talking Together in the } \\
\text { Classroom }\end{array}$ & 5 \\
\hline $\begin{array}{l}\text { Classroom } \\
\text { Students }\end{array}$ & General Description or Discussion Related to Students & 43 \\
\hline $\begin{array}{l}\text { Classroom } \\
\text { Teaching } \\
\text { Example }\end{array}$ & Specific Teaching Example from a Classroom & 19 \\
\hline $\begin{array}{l}\text { Classroom } \\
\text { Management }\end{array}$ & $\begin{array}{l}\text { Related to Classroom Community and Routines and } \\
\text { Building Rapport }\end{array}$ & 7 \\
\hline $\begin{array}{l}\text { Classroom } \\
\text { Reference }\end{array}$ & $\begin{array}{l}\text { Participants References Something from Their Own or } \\
\text { Another's Classroom, Not Necessarily a Teaching } \\
\text { Example. May Be an Explanation of Something That has } \\
\text { Happened. }\end{array}$ & 12 \\
\hline $\begin{array}{l}\text { Classroom Student } \\
\text { Collaboration }\end{array}$ & $\begin{array}{l}\text { Description of Students Working/Talking Together in the } \\
\text { Classroom }\end{array}$ & 5 \\
\hline Classroom Students & General Description or Discussion Related to Students & 43 \\
\hline $\begin{array}{l}\text { Classroom } \\
\text { Teaching Example }\end{array}$ & Specific Teaching Example from a Classroom & 19 \\
\hline $\begin{array}{l}\text { Collaborate with } \\
\text { Other Educators }\end{array}$ & Discussion of Working with Others in the Field & 29 \\
\hline $\begin{array}{l}\text { Common Core } \\
\text { State Standards }\end{array}$ & Direct Reference to CCSS & 1 \\
\hline
\end{tabular}

Table Continued 


\begin{tabular}{|c|c|c|}
\hline Name & Description & $\begin{array}{l}\text { Number of } \\
\text { Codes }\end{array}$ \\
\hline $\begin{array}{l}\text { Connection to } \\
\text { Another Discussion }\end{array}$ & $\begin{array}{l}\text { Participant References Aa Past Discussion from the } \\
\text { Online Community }\end{array}$ & 11 \\
\hline $\begin{array}{l}\text { Connection to } \\
\text { Community }\end{array}$ & $\begin{array}{l}\text { Related to Something Outside of the School in the } \\
\text { Community }\end{array}$ & 3 \\
\hline $\begin{array}{l}\text { Connection to } \\
\text { Coursework }\end{array}$ & $\begin{array}{l}\text { Discussion Related to Something Learned in College } \\
\text { Course }\end{array}$ & 7 \\
\hline $\begin{array}{l}\text { Connection to } \\
\text { Literature }\end{array}$ & $\begin{array}{l}\text { Participant Connects to or Shares an Educational Piece of } \\
\text { Professional Literature }\end{array}$ & 19 \\
\hline Contextual & Describes the Participants Setting & 8 \\
\hline $\begin{array}{l}\text { Coursework } \\
\text { Disconnections }\end{array}$ & $\begin{array}{l}\text { Noticing Something in Education is Different Than What } \\
\text { was Learned in a College Course }\end{array}$ & 5 \\
\hline $\begin{array}{l}\text { Critical Analysis of } \\
\text { Source }\end{array}$ & Participant Questions Integrity/Value of a Source & 11 \\
\hline Critical Response & $\begin{array}{l}\text { Participant Pushed Back or Questions a Post or } \\
\text { Discussion. May Include Some Type of Disagreement }\end{array}$ & 8 \\
\hline $\begin{array}{l}\text { Curriculum } \\
\text { Resource }\end{array}$ & Sharing or Referencing Something Curriculum Related & 10 \\
\hline Desire to Learn & $\begin{array}{l}\text { Participant Describes Wanting to Know More About a } \\
\text { Topic or Mentions They Will Look into Something More }\end{array}$ & 28 \\
\hline Disagreement & $\begin{array}{l}\text { Participant Says Something That Disagrees with Another } \\
\text { Comment. }\end{array}$ & 13 \\
\hline $\begin{array}{l}\text { Educational } \\
\text { Experiences }\end{array}$ & Teaching Experience in the Field & 1 \\
\hline ESL & Subject/Topic Related to English Language Learners & 4 \\
\hline Explaining & $\begin{array}{l}\text { Participant Explains Describes a Scenario or How They } \\
\text { Do Something }\end{array}$ & 33 \\
\hline Future Influence & $\begin{array}{l}\text { Discussion of How What We Do as Educators Impact } \\
\text { Students in the Long Run }\end{array}$ & 8 \\
\hline
\end{tabular}




\begin{tabular}{|c|c|c|}
\hline Name & Description & $\begin{array}{l}\text { Number of } \\
\text { Codes }\end{array}$ \\
\hline Hierarchy & Top Down, Expert/Novice Roles Emerge & 8 \\
\hline Identity & Participant Names Something About Their Self & 26 \\
\hline $\begin{array}{l}\text { Influences from } \\
\text { Others }\end{array}$ & $\begin{array}{l}\text { Participant Acknowledges How Others Have Influenced } \\
\text { Their Teaching/Learning }\end{array}$ & 22 \\
\hline KOL Post & Knowledge of Learners Framework & 18 \\
\hline KOS Post & Knowledge of Subject Matter Framework & 17 \\
\hline KOT Post & Knowledge of Teaching Framework & 29 \\
\hline Language & $\begin{array}{l}\text { Language Teachers Use in the Classroom or with } \\
\text { Students }\end{array}$ & 19 \\
\hline Materials & $\begin{array}{l}\text { Physical Materials Used or Organized in the Classroom } \\
\text { for Classroom Design or Lessons }\end{array}$ & 17 \\
\hline Math & Subject/Topic Discussion Related to Math & 2 \\
\hline $\begin{array}{l}\text { Minimal Answer } \\
\text { Question }\end{array}$ & $\begin{array}{l}\text { Only One or Two Participants Directly Responded to the } \\
\text { Question Asked in the Post or Comment. }\end{array}$ & 9 \\
\hline Online Dynamics & $\begin{array}{l}\text { Participants Describe Interactions Among Participants in } \\
\text { the Online Learning Community }\end{array}$ & 4 \\
\hline $\begin{array}{l}\text { Online Professional } \\
\text { Development }\end{array}$ & $\begin{array}{l}\text { Participant Describes Additional Online Learning They } \\
\text { Engage in }\end{array}$ & 8 \\
\hline $\begin{array}{l}\text { Parents Home } \\
\text { Family }\end{array}$ & $\begin{array}{l}\text { Discussion Related to Parents or Home to School } \\
\text { Connections }\end{array}$ & 24 \\
\hline $\begin{array}{l}\text { Personal } \\
\text { Experiences }\end{array}$ & Personal Experiences Related to Education & 13 \\
\hline Post Type-Article & & 11 \\
\hline $\begin{array}{l}\text { Post Type-Book } \\
\text { Recommendation }\end{array}$ & & 4 \\
\hline $\begin{array}{l}\text { Post Type- } \\
\text { Classroom Example }\end{array}$ & & 2 \\
\hline
\end{tabular}




\begin{tabular}{|c|c|c|}
\hline Name & Description & $\begin{array}{l}\text { Number of } \\
\text { Codes }\end{array}$ \\
\hline $\begin{array}{l}\text { Post Type- } \\
\text { Infographic }\end{array}$ & & 5 \\
\hline Post Type-Question & & 12 \\
\hline $\begin{array}{l}\text { Post Type- } \\
\text { Reflection }\end{array}$ & & 8 \\
\hline Post Type-Video & & 2 \\
\hline $\begin{array}{l}\text { Praise Agreement } \\
\text { Encouragement }\end{array}$ & $\begin{array}{l}\text { Participant Offers a Vague Agreement or Encouragement } \\
\text { or Thank You }\end{array}$ & 70 \\
\hline Prior Knowledge & $\begin{array}{l}\text { Discussion of Students' Prior Knowledge and Influence } \\
\text { on Their Learning }\end{array}$ & 1 \\
\hline Questioning & General Questions & 7 \\
\hline $\begin{array}{l}\text { Questions Not } \\
\text { Addressed }\end{array}$ & $\begin{array}{l}\text { Questions Posed to The Group with Little or No } \\
\text { Response }\end{array}$ & 14 \\
\hline $\begin{array}{l}\text { Minimal Answer } \\
\text { Question }\end{array}$ & $\begin{array}{l}\text { Only One or Two Participants Directly Responded to the } \\
\text { Question Asked in the Post or Comment. }\end{array}$ & 9 \\
\hline $\begin{array}{l}\text { Unanswered } \\
\text { Question }\end{array}$ & $\begin{array}{l}\text { Participants Did Not Directly Respond to the Question } \\
\text { Asked in the Post or Comment. }\end{array}$ & 5 \\
\hline Reading & Subject/Topic of Reading & 42 \\
\hline $\begin{array}{l}\text { Recognition of } \\
\text { Area for Growth }\end{array}$ & $\begin{array}{l}\text { Participants Describes/States an Area They Want to } \\
\text { Learn or Know More About, More Specific Than Desire } \\
\text { to Learn }\end{array}$ & 29 \\
\hline Recommendation & Specific Source/Idea is Suggested to Try & 28 \\
\hline $\begin{array}{l}\text { Recommendation } \\
\text { for Learning } \\
\text { Community }\end{array}$ & $\begin{array}{l}\text { Specific Suggestion for Improvement of the Online } \\
\text { Learning Space }\end{array}$ & 4 \\
\hline Reflection & $\begin{array}{l}\text { Thinking About How or Why We Do Something. } \\
\text { Thinking Back on Things we Have Already Done and } \\
\text { What we Have Learned or Are Still } \\
\text { Wondering/Questioning About an Area }\end{array}$ & 71 \\
\hline
\end{tabular}




\begin{tabular}{|c|c|c|}
\hline Name & Description & $\begin{array}{l}\text { Number of } \\
\text { Codes }\end{array}$ \\
\hline Safe Space & $\begin{array}{l}\text { Participants Describe Feeling Comfortable in The Online } \\
\text { Learning Group. May Also Fit in With Benefit of the } \\
\text { Online Community Code }\end{array}$ & 9 \\
\hline Sharing Resources & $\begin{array}{l}\text { Sharing Resources Used in Classrooms, May Not Be a } \\
\text { Specific Recommendation (i.e. I Love This You Should } \\
\text { Try It) But Instead More of a I Have Used This Before, } \\
\text { here are Some Ideas }\end{array}$ & 49 \\
\hline $\begin{array}{l}\text { Shifting } \\
\text { Practices/Thinking } \\
\text { from Online } \\
\text { Discussions }\end{array}$ & $\begin{array}{l}\text { Participant Notes a Direct Time They Changed or Re- } \\
\text { Thought About Their Own Practices or Thinking as a } \\
\text { Direct Result from The Online Community }\end{array}$ & 36 \\
\hline $\begin{array}{l}\text { Shifting } \\
\text { Practices/Thinking } \\
\text { from Own } \\
\text { Experiences }\end{array}$ & $\begin{array}{l}\text { Participants Notes a Learning/Shifting Time from Their } \\
\text { Own Experiences Not Necessary from the Learning } \\
\text { Community }\end{array}$ & 27 \\
\hline Social Justice & $\begin{array}{l}\text { Subject Topic, Discussion Related to Social Justice in } \\
\text { Classroom and Literature }\end{array}$ & 13 \\
\hline $\begin{array}{l}\text { Specific Learning } \\
\text { Example }\end{array}$ & $\begin{array}{l}\text { Participant Names a Time They Learned Something from } \\
\text { the Group Discussions During Interview or } \\
\text { Questionnaire }\end{array}$ & 39 \\
\hline STEM & Subject Topic Related to STEM Activities & 3 \\
\hline Student Teaching & $\begin{array}{l}\text { Participant Describes Their Student Teaching } \\
\text { Experience. May Also Be Related to Identity }\end{array}$ & 15 \\
\hline Support Others & $\begin{array}{l}\text { Participant Describes Time They Have Helped Other } \\
\text { Educators }\end{array}$ & 7 \\
\hline Teacher Agency & $\begin{array}{l}\text { Participant Describes a Time They Felt Confident or } \\
\text { Empowered or Maybe Even Took Action to Make } \\
\text { Changes }\end{array}$ & 14 \\
\hline Technology & Subject Topic Related to Technology Use & 12 \\
\hline
\end{tabular}

Table Continued 


\begin{tabular}{llr}
\hline Name & Description & $\begin{array}{c}\text { Number of } \\
\text { Codes }\end{array}$ \\
\hline Theory & $\begin{array}{l}\text { Discussion About Theories or How Theories Are } \\
\text { Influencing Our Teaching }\end{array}$ & 9 \\
This Is How I Do It & $\begin{array}{l}\text { Participant Describes Something They Have Always } \\
\text { Done in Their Classroom or Practices }\end{array}$ & 4 \\
Topics & Topics Addressed in The Discussions & \\
Unanswered & $\begin{array}{l}\text { Participants Did Not Directly Respond to the Question } \\
\text { Question }\end{array}$ & Asked in the Post or Comment. \\
Writing & Subject Topic of Writing in Classrooms & 8 \\
\hline
\end{tabular}




\section{APPENDIX F: INFORMED CONSENT}

\section{Dear Participant,}

I am a doctoral student under the direction of Dr. Deborah MacPhee in the College of Education at Illinois State University. I am conducting a research study to fulfill the requirements of my dissertation to explore the use of an online thirdspace for educators to collaborate and reflect critically on their teaching practices. I am requesting your participation, which will involve sustained participation in the online thirdspace via a Facebook secret group. The online thirdspace will take place from January 2019-April 2019. In addition, you will be asked to complete a pre- and post-study questionnaire and the option to participate in a poststudy interview. The online questionnaires should take no longer than 20 minutes to complete. The interviews will last approximately 30 minutes. The interview will be audio taped and I will be taking notes with your permission. The questions will revolve around how you describe your participation in the online thirdspace.

Your participation in this study is voluntary. The risks associated with this research are no greater than those encountered in everyday life. If you choose not to participate or to withdraw from the study at any time, there will be no ramifications of any kind. Your decision to participate or not to participate will not affect your employment in any way. The results of the research study may be published, but your name will not be used, pseudonyms will be used on the final report. I will take all precautions to maintain your confidentiality (your name will not be used, and the transcript from our interview and answers on the questionnaires will not be shared with anyone outside of my doctoral committee). All data will be kept in a secure location. Of course, you may choose to not answer any questions asked of you. The online thirdspace will take place via a Secret Group that cannot be found in a search on Facebook and only members participating in this study can see the page. You are ineligible to participate if you are currently within the European Economic Area.

The possible benefit of your participation may help other educators understand the possibilities of a thirdspace in teacher education. In addition, you may benefit from participation in this group as it will give you a chance to engage with other professional educators and examine your own teaching practices. This reflective space could lead to enhanced teaching for you.

If you have any questions concerning the research study, please contact me at (309) 241-0666 or mbelche@ilstu.edu or Dr. Deborah MacPhee at 309-438-3836 or dmacphe@ilstu.edu

I consent, begin the study

I do not consent, I do not wish to participate 
1. Email address

2. Full Name

3. Phone Number

4. Your Position

Classroom Teacher

$\square \quad$ Student Teacher

5. School Name:

6. Years of teaching experience (Classroom Teachers Only)
$1-2$
- 3-4
$\square \quad 5-6$
$\square \quad 7-8$
$\square \quad 9-10$
$\square \quad 11-15$
$\square \quad 16-20$
$\square \quad 21+$

7. Current Grade Level

$\begin{array}{ll}\square & \text { PreK } \\ \square & \text { K } \\ \square & 1 \\ \square & 2 \\ \square & 3 \\ \square & 4 \\ \square & 5 \\ \square & 6 \\ \square & 7 \\ \square & 8\end{array}$

8. Mentor Teacher's Name (Teacher Candidates Only) 